(To be submitted to Physics Reports)

A SURVEY OF THE FERMILAB RESEARCH PROGRAM

G. Giacomelli, * A. F. Greene, and J. R. Sanford January 1, 1975

*Also at University of Bologna, Bologna, Italy and INFN, Sezione di Bologna, Bologna, Italy 
TABLE OF CONTENTS

Section

1

Title

$\underline{\text { Page }}$

Introduction . . . . . . . . . . . . . . . 1

Total Cross Section Experiments. . . . . . . . 4

Elastic Scattering Experiments . . . . . . . 13

Charge Exchange Scattering and Other

Two-Body Reactions . . . . . . . . . . . . 20

Inclusive Reaction Experiments . . . . . . . . 25

Diffraction Dissociation Experiments . . . . . . 43

Multiparticle Experiments . . . . . . . . . . 47

7.1 General Multiparticle Physics. . . . . . . 47

7.2 Photon Final States . . . . . . . . . . 48

7.3 Large $-\mathrm{p}_{\mathrm{t}}$ Phenomena . . . . . . . . . . 48

7.4 Dilepton Production . . . . . . . . . . . 49

7.5 Miscellaneous . . . . . . . . . . 50

Hyperon and Neutral Kaon Experiments. . . . . . 53

Hadron Interactions in Bubble Chambers . . . . . 56

Electromagnetic Interactions Initiated

by Photons and Electromagnetic Radii . . . . . . 63

10.1 Photoproduction Experiments . . . . . . 63

10.2 Electromagnetic Radii . . . . . . . . 63

Electromagnetic Interactions Initiated by Muons . . . 67

Weak Interaction Experiments . . . . . . . . . 71

12.1 Total Cross Section Measurements . . . . . 73

12.2 Inclusive or Deep Inelastic Measurements. . . 73

12.3 Studies of Neutral Current Events . . . . . 74

Particle Searches . . . . . . . . . . . 78

13.1 Magnetic Monopoles . . . . . . . . . . 80

13.2 Quarks ... . . . . . . . . . . . 81

13.3 Intermediate Charged Vector Bosons . . . . 82

13.4 Intermediate Neutral Vector Bosons . . . . . 83

13.5 Heavy Leptons . . . . . . . . . . . . 84 
TABLE OF CONTENTS (Continued)

Section

Title

$\underline{\text { Page }}$

13.6 Charmed Particles . . . . . . . . . . . 85

13.7 Long-Lived Particles . . . . . . . . . . 88

13.8 Super-Heavy Elements. . . . . . . . . . 88

Emulsion Experiments . . . . . . . . . . . 101

15

Miscellaneous Experiments . . . . . . . . . 103

16

Acknowledgments . . . . . . . . . . . . 105

17

List of Experiments . . . . . . . . . . . . 106 


\title{
A SURVEY OF THE FERMILAB RESEARCH PROGRAM
}

G. Giacomelli, A. F. Greene, and J. R. Sanford

Fermi National Accelerator Laboratory

Batavia, Illinois 60510

\begin{abstract}
A survey is made of the experimental research program at the Fermi National Accelerator Laboratory covering the approved experimental proposals. These experiments are divided into physics topics and a comparison is made of the kinematic ranges of the measurements and the techniques used.
\end{abstract}




\section{INTRODUCTION}

This report represents a survey of the experimental research at the Fermi National Accelerator Laboratory. It is representative of the program as of January 1, 1975, which is two and one-half years after the accelerator began operation for high-energy physics. During this period the accelerator has operated principally at $300 \mathrm{GeV}$ with early running at 200 and lately

at $400 \mathrm{GeV}$. Most of the experiments discussed in this report may be classified as first generation. However, many experiments are now becoming rather complex and the entry into the second generation is definitely beginning. A brief look at the table of contents shows that the experiments cover a large portion of the field of high-energy particle physics, suggesting that the Fermilab program is rather comprehensive.

For this survey we have divided the approved Fermilab high-energy physics experiments into subtopics. Basically, we have separated the studies involving strong, electromagnetic, and weak interactions, and have inserted the approved Fermilab experiments into the categories which best describe the emphasis of their measurements. The category of strong interactions is further divided into total cross sections, elastic scattering, inclusive reactions, etc., because the number of experiments is so large. It should be noted, however, that in the section on total cross sections we have collected all of the experiments independent of the type of interaction. This seems appropriate since these measurements are very fundamental, and it is interesting to compare the experiments using hadrons, photons, and neutrinos. This framework for describing experiments is found to be 
generally useful in outlining the overall research program and in comparing new proposals with previously approved work.

For each physics subject the experiments are analyzed in terms of the ranges of kinematic variables. For example, total cross sections depend only on one variable which is the total center-of-mass energy or incident momentum. Neglecting polarization effects, elastic scattering depends on two variables which are the total center-of-mass energy and the scattering angle. Single particle inclusive reactions depend on three variables: the total center-of-mass energy, the angle, and the momentum of the observed final-state particle. More complex experiments are not easily classified and a more general comparison is made. For each subject we usually give a very brief description of the physics measurements, with the primary emphasis on tables of the approved experiments where the ranges of kinematic variables are listed, and on graphs where there is a pictorial description of the ranges of variables for the experiments.

Throughout the report experiments are referred to by number. That number is the one assigned to the proposal by Fermilab. Section 17 contains a list of these experiment numbers together with the institutions participating in the research, and where the experiments are treated in this report.

In each section we have included a few physics results if they are available. These results are of the simplest and most general type and are presented in the form of a data compilation. We could not attempt to be complete or enter into any detailed analysis since this would become a task outside the purpose of this report. 
There is an unevenness in this report when comparing one section with another. In some cases this is due to the availability or lack of physics results and in others due to the varying ease in describing the work. Since we expect to reissue this description in the future, an effort will be placed on strengthening some of the weaker sections. It will also be necessary to modify the tables and graphs as new experiments are approved and as results are available.

The information contained in this report has come from a large variety of sources. Principal among these are the experimental proposals to Fermilab, published papers, and unpublished reports. Throughout this paper, and particularly when referring to the list of approved experiments, one may question the status of the proposed measurements. A source of information for questions of this type is the Experimental Program Situation Report which is published quarterly in "NALREP," the Fermilab monthly newsletter. If the experiment is complete then perhaps there are publications associated with the work. At the time of this writing a general publications file is being developed. It is expected to be available for reference in later editions of this report.

A few caveats are in order. It is clear that the kinematic ranges stated in the tables cannot be completely exact. We apologize for this as well as for mistakes and omissions. We hope that readers will inform us of dis crepancies which they find. 


\section{TOTAL CROSS-SECTION EXPERIMENTS}

There are several ways of obtaining information on the total cross sections for the interaction of particles with various targets. The most accurate and most common technique for making the se measurements is the transmission method. This technique relies on a system of counters to identify and count the beam particles, a target where the beam particles are absorbed, and a series of cylindrical transmission counters. The ratios of the rates measured by these transmission counters with and without the target are used together with an extrapolation to zero solid angle to measure the total cross section.

Another method is to study the elastic differential cross sections at very small angles $\left[t \mid<0.01(\mathrm{GeV} / \mathrm{c})^{2}\right]$ and to obtain the total cross section through a fit to the differential cross section in the coulomb-nuclear interference region. Neglecting spin effects the differential cross section may be written as:

$$
\frac{\mathrm{d} \sigma}{\mathrm{d}|\mathrm{t}|} \simeq \underbrace{\mathrm{C}^{2}}_{\begin{array}{c}
\text { Coulomb } \\
\text { Term }
\end{array}}+\underbrace{\left(1+\rho^{2}\right) \frac{\sigma_{\text {tot }}^{2}}{16 \pi} \mathrm{e}^{\mathrm{bt}}}_{\begin{array}{c}
\text { Nuclear } \\
\text { Term }
\end{array}}-\underbrace{2(\rho+\alpha \phi) \frac{2 \alpha}{|\mathrm{t}|} \mathrm{G}(\mathrm{t})^{2} \frac{\sigma_{\text {tot }}}{4 \sqrt{\pi}} \mathrm{e}^{\mathrm{bt} / 2}}_{\begin{array}{c}
\text { Coulomb-Nuclear } \\
\text { Interference Term }
\end{array}} .
$$

$\mathrm{C}=\frac{2 \alpha}{|\mathrm{t}|} \mathrm{G}^{2}(\mathrm{t}) \mathrm{e}^{\mathrm{i} \alpha \phi}$ is the coulomb amplitude;

$G(t)=$ the proton form factor;

$\alpha \phi=$ the phase of the coulomb amplitude;

$\alpha=$ the fine structure constant; 
$\rho=$ the ratio of real-to-imaginary part of the forward elastic scattering amplitude;

$\sigma_{\text {tot }}=$ the desired total cross section; and

$b=$ the slope of the differential cross section.

The fits to Eq. (2.1) can in principle be used to obtain $\sigma_{\text {tot' }} \rho$, and $b$. In practice the fits are usually done by fixing $\sigma_{\text {tot }}$ and $b$ to values given by other measurements and thus to determine $p$.

From elastic scattering in the diffraction region $[0.01<|\mathrm{t}|<0.5$

$(\mathrm{GeV} / 2)^{2}$ ] it is possible to obtain the total cross section through an extrapolation to $t=0$ and the use of the optical theorem. However, in most cases this is used as a check of the normalization of the elastic cross sections rather than a determination of $\sigma_{\text {tot }}$

Another technique for measuring the total cross section is to count the number of interactions in a certain fiducial volume and to determine carefully the beam flux. This is a satisfactory method when the statistics are limited because of the type of detector being used or because the interactions are quite rare. This method is used in determining total cross sections from bubble-chamber exposures, whether they be of hadrons or of neutrinos. It is also used in electronic-neutrino experiments. The neutrino and antineutrino total cross-section measurements will be further discussed in Section 12 .

A different kind of transmission method is used for five experiments, specifically Experiments \#27A and \#305 with incident neutrons, Experiments \#82 and \#226 with incident $\mathrm{K}_{\mathrm{L}}{ }^{\circ}, \because$ and Experiment \# 8 with incident neutral hyperons. In this case a neutral particle detector, in the form of a forward multiparticle spectrometer, is set up in the neutral beam. The detector has a small efficiency for the wanted neutral particle but is highly 
selective in mass and momentum and is stable in time. It can thus be used as a "neutral particle monitor" and the total cross section may be determined from the relative number of counts with and without absorbers in the neutral beam.

Table 2.1 lists all of the approved Fermilab experiments that are expected to give substantial results on total cross sections independent of the form of the governing interaction force. (For a more complete listing of the diffractive elastic scattering experiments bearing on this subject see Section 3.) In each case the type of target particle to be used, the range of incident momentum, and the experimental approach are given. This information is shown in $\mathrm{Fig}$. 2.1 where the long-lived hadron measurements by various experiments are given together with the momentum range covered.

Figures 2.2 and 2.3 show compilations of the high energy total cross sections for the long-lived charged hadrons and for neutrinos producing charged muons. The energy dependence of the cross sections is strikingly different for the two cases: linear dependence on laboratory energy for neutrinos and only relatively small energy dependence for the hadrons. More detailed analysis shows that, with the exception of antiprotons, all high energy hadron-hadron cross sections are rising. At $100 \mathrm{GeV}$ the neutrino cross section is still more than $10^{11}$ times smaller than the hadron cross sections. 
Table 2.1. Summary of Total Cross-Section Measurements.

Note: The energy range quoted usually assumes the accelerator running at $300 \mathrm{GeV}$. The upper energy limit of some experiments will rise with the accelerator energy. The target particles are shown as: $p$ - proton $\left(\mathrm{H}_{2}\right)$, d - deuteron $\left(\mathrm{D}_{2}\right), \mathrm{A}$ - heavy nucleus.

Beam Particle
and

Exp. Number
Incident

Target Momentum

Particle $\quad(\mathrm{GeV} / \mathrm{c})$
Experimental Method

Protons

\# 36A and

\#186

\#69A

$\# 104$

$\mathrm{p}, \mathrm{d}, \mathrm{A}$

$23-280$

Neutrons

$$
\# 4
$$

\#27A and

\# 305

$\underline{\text { Pions }}$

\# 69A

\#104

Kaons and

Antiprotons

\#69A

$\# 104$ $p, d, A$

$23-280$

$p, d, A$

$30-280$

A

$40-280$

$\mathrm{p}, \mathrm{A}$

$50-200$

$\mathrm{p}, \mathrm{A}$

$50-180$

$p, d, A$

$23-240$ calculation from elastic scattering in the coulomb-nuclear interference region

calculation from elastic scattering in the coulomb-nuclear interference region

transmission measurements transmission measurements

transmission measurements using dissociation events

calculation from elastic scattering in the coulomb-nuclear interference region

transmission measurements calculation from elastic scattering in the coulomb-nuclear interference region

transmission measurements 
Table 2.1. (continued)

Beam Particle
and

Exp. Number

Neutral

Kaons

$\# 82$ and

\#226

Neutral

Hyperons

\# 8

Charged

Hyperons

$\# 97$

p $\quad 100-250$
Incident

Target Momentum

Particle $(\mathrm{GeV} / \mathrm{c})$
Experimental

Method transmission measurements using $\mathrm{K}^{\circ} \rightarrow \pi^{+} \pi^{-}$decay detector

transmission measurements

$\underline{\text { Photons }}$

\# 25A

Neutrinos

\#1A

$\# 21 \mathrm{~A}$

$\# 28 \mathrm{~A}$

\# 45A

$\# 53 \mathrm{~A}$ $\mathrm{p}, \mathrm{d}, \mathrm{A}$

$60-250$

(tagged

beam) extrapolation from elastic differential cross sections

interactions and hadron production

( $W B=$ Wide Band beam; NB = Narrow Band beam; $\mathrm{QT}=$ Quadrupole Triplet beam)

A

$10 \div<200$

(WB, NB,

\& QT)

A $\quad 30-<200$

( NB)

$\mathrm{p}, \mathrm{A}$

$\mathrm{p}$

$\mathrm{p}, \mathrm{A}$

$10-<150$

(WB)

$10-<150$

(WB)

$10-<150$ interactions in calorimeter with associated $\mu$ spectrometer; electronic experiment

interactions in calorimeter with associated $\mu$ spectrometer; electronic experiment

(WB) interactions in 15-ft bubble chamber with hydrogen and neon

interactions in 15-ft bubble chamber with hydrogen

interactions in 15-ft bubble chamber with hydrogen and neon 
Table 2.1. (continued)

Beam Particle and

Exp. Number

$\# 310$

\section{Antineutrinos}

Experimental

Method

interactions in calorimeter with associated $\mu$ spectrometer; electronic experiment
(WB, NB, \& QT)
\#21A
\# $31 \mathrm{~A}$
$\# 172$
\# 180
\# 310
A
$10-<200$ (WB, NB, \& QT)
A $\quad 30-<200$
(NB)
$\mathrm{p} \quad 10-<100$
(WB)
$\mathrm{p}, \mathrm{A}$
$\mathrm{p}, \mathrm{A}$
A
$10-<100$ (WB)
$10-<100$ (WB)
$10-<200$
(WB NB \& $Q T)$
\#1A
(1)
interactions in calorimeter with associated $\mu$ spectrometer; electronic experiment
interactions in calorimeter with associated $\mu$ spectrometer;
electronic experiment
interactions in 15-ft bubble chamber with hydrogen
interactions in 15-ft bubble chamber with hydrogen and neon
inter actions in $15-\mathrm{ft}$ bub
with hydrogen and neon

$\begin{array}{ll}10-<200 & \text { interactions in calorimeter with } \\ (\mathrm{WB}, \mathrm{NB}, & \text { associated } \mu \text { spectrometer; } \\ \& \mathrm{QT}) & \text { electronic experiment }\end{array}$


Beam Particle

(Target Particle Shown in Parenthesis; $p$-proton, $d$-deuteron, A-heavy nucleus)

Protons
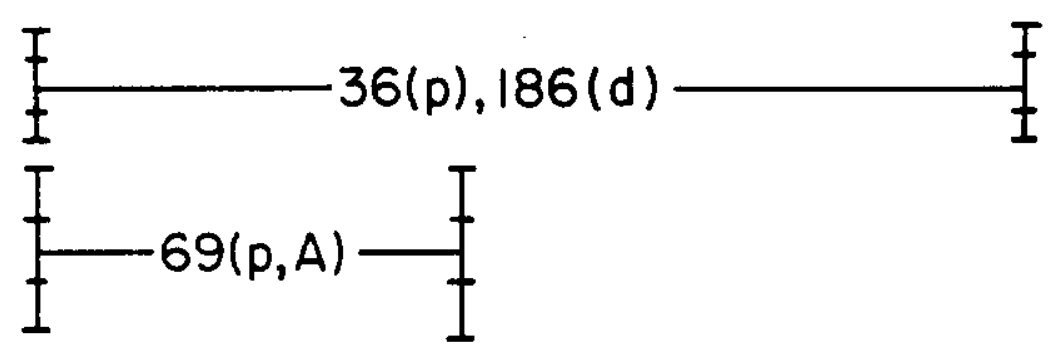

琶 $104(p, d, A) \longrightarrow$ 工王

Neutrons

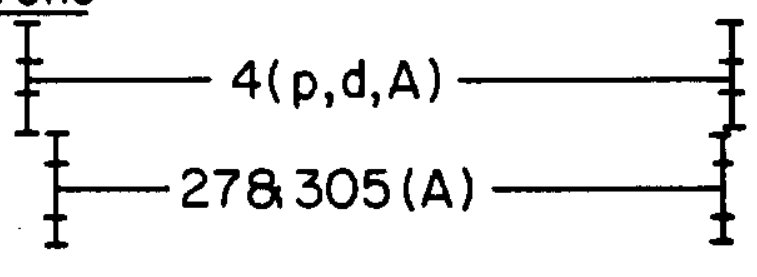

Pions $(+,-$,
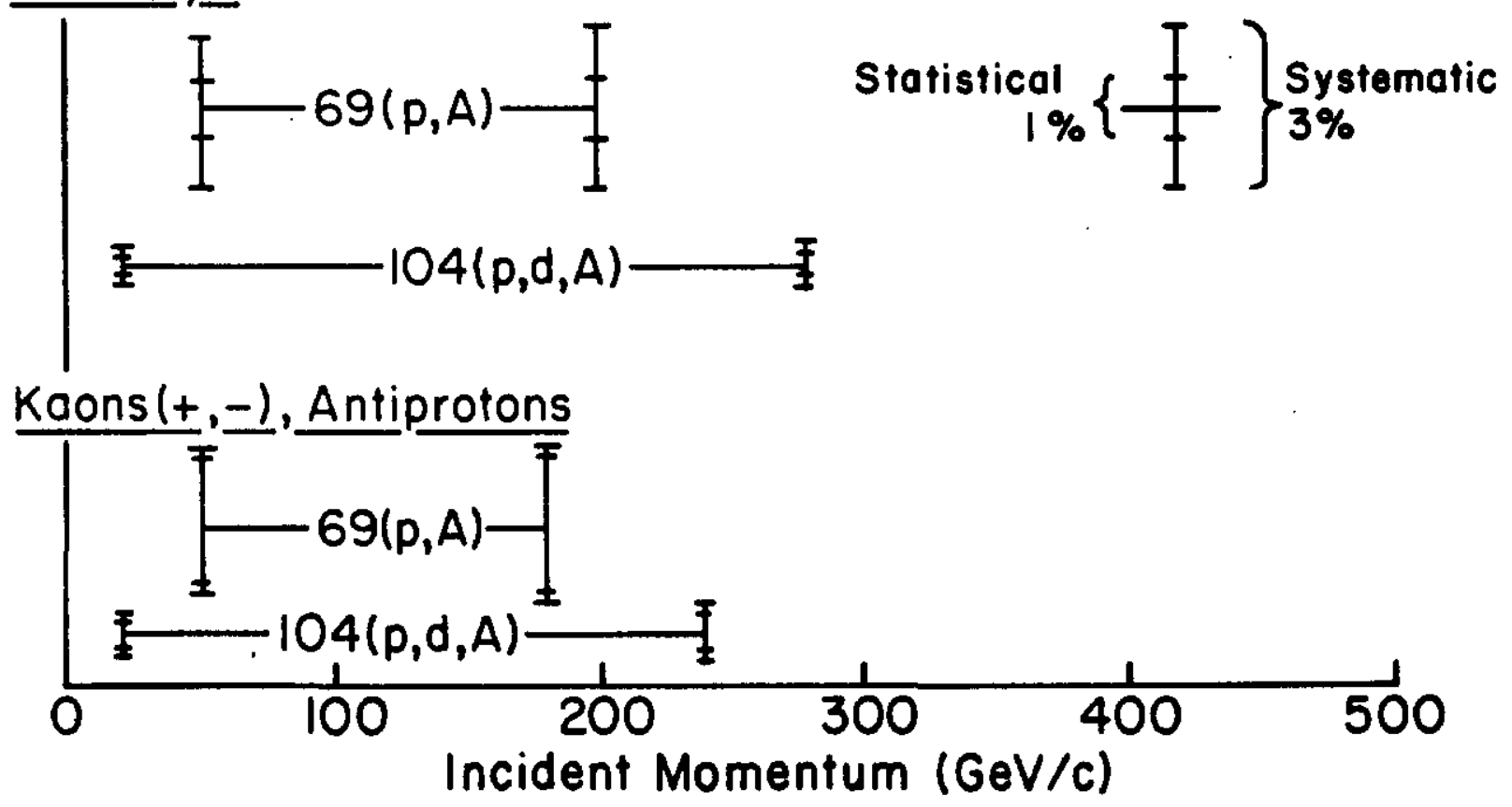

Error Estimates

Fig. 2.1 Total cross-section measurements of long-lived hadrons. 


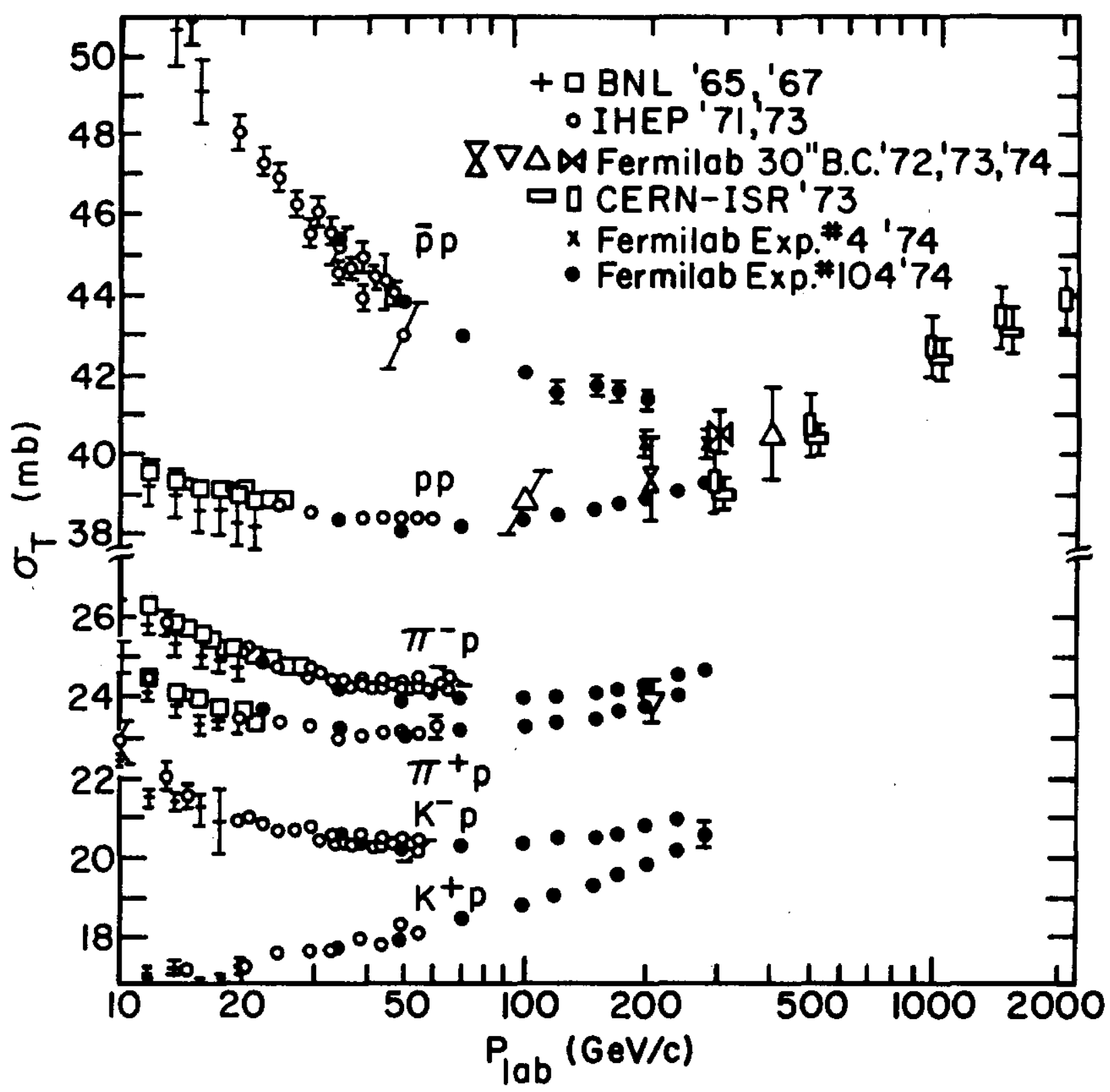

Fig. 2.2 Compilation of charged hadron total cross sections. 


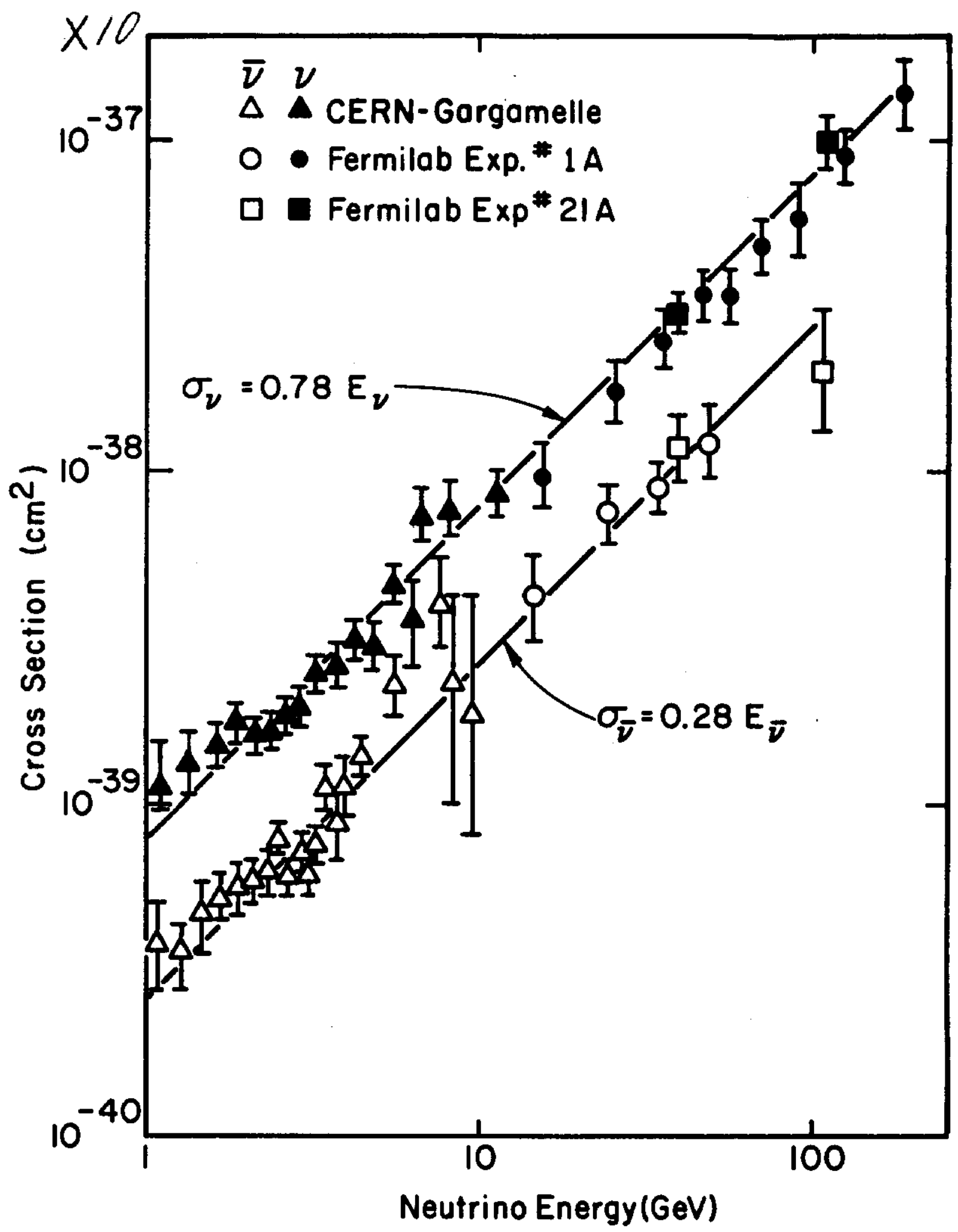

Fig. 2.3 Compilation of neutrino and antineutrino total cross sections where charged muons are produced. Points represent data available at the time of the XVII International Conference on High Energy Physics, London, July 1974. 


\section{ELASTIC SCATTERING EXPERIMENTS}

The first elastic scattering experiments at Fermilab were those using the internal proton beam and the hydrogen gas jet target. The experimental apparatus consisted of a series of small solid-state recoil detectors which allowed measurements for $|t| \leq 0.1(\mathrm{GeV} / \mathrm{c})^{2}$. Later generation experiments in the Internal Target Area will use a magnetic recoil spectrometer enabling measurements of larger angle scattering [up to $|t| \approx 3(\mathrm{GeV} / \mathrm{c})^{2}$ ].

The experiments in the external beam lines all use single or double arm spectrometers. Most measurements concern the diffraction region $\left[0.01<|\mathrm{t}|<0.5(\mathrm{GeV} / \mathrm{c})^{2}\right]$; in two other cases they involve very small or large angle scattering (Exp. \#69A and Exp. \#177A respectively), and in two cases they involve backward scattering (Exp. \#12 and Exp. \#290). Measure ments using beam particles other than protons are at present limited to approximately $250 \mathrm{GeV} / \mathrm{c}$ incident momentum. This is expected to change when new high energy secondary beams become available in the Proton Area.

Table 3.1 describes in an abbreviated fashion all of the presently approved elastic scattering measurements at Fermilab. The approximate beam momentum and $|t|$-range are given. The upper beam momentum or highest $|t|$-values may be subject to some adjustment when the beam fluxes and cross sections are better known. Two experiments will yield polari zation information on the scattering processes. Experiment \#61 employs a polarized proton target in a conventional secondary beam and Experiment \#313 examines the polarization of the recoil proton produced in scattering of the internal proton beam. Figures 3.1 and 3.2 describe in graphical form the kinematic regions covered by some of the experiments. 
Figure 3.3 is a compilation of $\pi^{-}-$p elastic scattering angular distributions from 5 to $200 \mathrm{GeV} / \mathrm{c}$. The distributions can be described by the form:

$$
\frac{\mathrm{d} \sigma}{\mathrm{dt}}=\mathrm{A} \mathrm{e}^{\mathrm{Bt}+\mathrm{Ct}{ }^{2}}
$$

where $C / B^{2}$, which describes the deviation from an exponential in $t$, is small. It can be seen that the $\pi^{-}$-p elastic scattering data have only a minor energy dependence; in particular, the local slope of a fixed $t$-value increases slowly with energy. This is indicative of a slow shrinkage of the diffraction pattern. It also appears that the higher order terms in $t$ become less important with increasing energy. 
Table 3.1. Summary of Hadron Elastic Scattering Measurements.

Note: The target particles are shown as: $p$-proton $\left(\mathrm{H}_{2}\right), d$-deuteron $\left(\mathrm{D}_{2}\right)$, A -heavy nucleus.

Beam

Particle and Exp.

Number

\section{Incident}

\section{Incident}

Protons

Particle

$\begin{array}{cc}\text { Momentum } & |\mathrm{t}| \text {-Range } \\ (\mathrm{GeV} / \mathrm{c}) & (\mathrm{GeV} / \mathrm{c})^{2}\end{array}$

Experimental Apparatus

\section{Protons}

\# 7

$\mathrm{p}$

$50-200 \quad 0.06-2$.

forward spectrometer and recoil arm

$\# 36 \mathrm{~A}$ and

$\mathrm{p}$

d

$50-400$

$0.001-0.09$

internal beam and recoil

\#186

$50-400$

$0.03-0.12$

detector

\#61

$\frac{\mathrm{p}}{(\text { polarized })}$

$50-150$

$0.15-1.5$

double arm spectrometer

\# 69A

$\mathrm{p}, \mathrm{A}$

$50-200$

$0.001-0.3$

forward spectrometer

$\# 96$

$p, d$

$50-175$

$0.02-0.8$

single arm spectrometer

\#177A

(tests)

$\mathrm{p}$

$300(200-400$

4. -20 .

double arm spectrometer later)

\#198

$\mathrm{p}$

$50-400$

$0.15-3$.

internal beam and recoil spectrometer

\#289

$\mathrm{He}^{4}$

$50-400$

$0.1-0.3$

internal beam and recoil detector

\#313

$\mathrm{p}$

$50-400$

$0.2-i .2$

internal beam and recoil spectrometer with polarimeter

\section{Neutrons}
$\# 12$
$\mathrm{p}$
$40-280$
$0.002<|u|<1$.
neutron counters and for - ward magnetic spectrom- eter
$\# 248$
$\mathrm{p}$
$40-280$
$0.1-3.5$
neutron and recoil spec- trometers
Pions
\# 7
$\mathrm{p}$
$50-200 \quad 0.06--2$.
forward spectrometer and recoil arm 
Table 3.1. (continued)

Beam

Particle and Exp.

Target $\begin{gathered}\text { Incident } \\ \text { Momentum }\end{gathered}$

Number

Particle $\quad(\mathrm{GeV} / \mathrm{c})$

$|\mathrm{t}|$-Range

$(\mathrm{GeV} / \mathrm{c})^{2}$ Experimental Apparatus

$\underline{\text { Pions }}$

$$
\text { \#61 }
$$

\#69A

$$
\# 96
$$

\#290

$$
\text { (polarized) }
$$

$50-150$

$\mathrm{p}, \mathrm{A}$

$50-200$

$\mathrm{p}, \mathrm{d}$

$50-175$

$10,50,80$
0.15-1.5 double arm spectrometer

$0.001-0.3$ forward spectrometer

0.02-0.8 single arm spectrometer

$0<|u|<0.8$ two magnetic spectrom eters

Kaons and

Antiprotons
$\# 7$
$p$
$50-\sim 200$
$0.06-1$
forward spectrometer and recoil arm
$\# 61$
\#69A
$\# 96$
$\mathrm{p}$ (polarized)
Neutral
Hyperons
\# 8
$p, d$
$100-250$
$0.1-0.6$
decay particle spectrom - eter and proton detector

Charged

Hyperons

$\# 97$

$\mathrm{p} \quad 100-250$

$0.1-0.6$

Cerenkov counter, decay particle spectrometer and proton detector 
Note: Target Particle Shown in Parenthesis; $p$-proton, $d$-deuteron, $A$-heavy nucleus

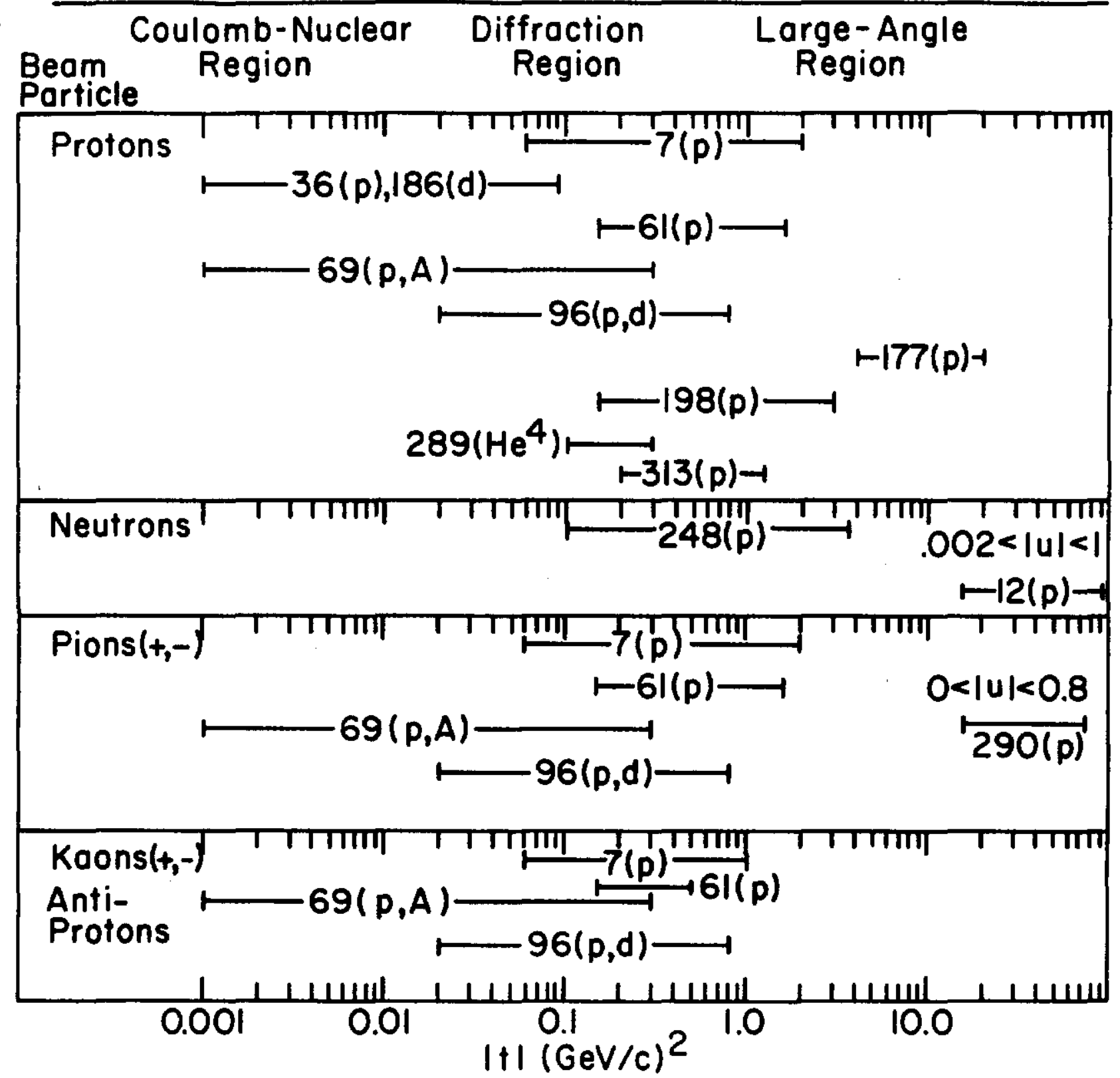

Fig. 3.1 Elastic scattering measurements of long-lived hadrons. 


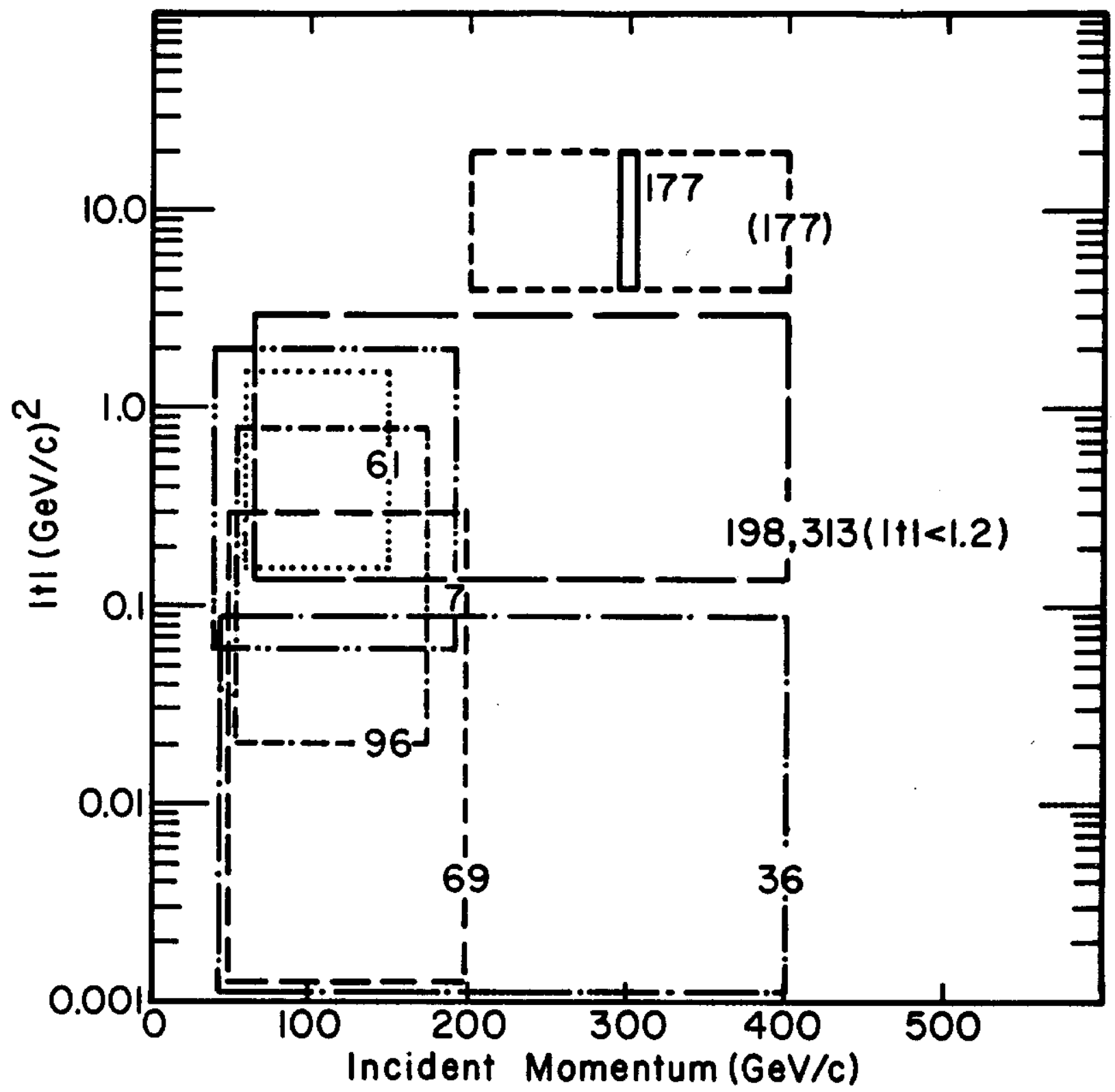

Fig. 3.2 Proton-proton elastic scattering measurements. 


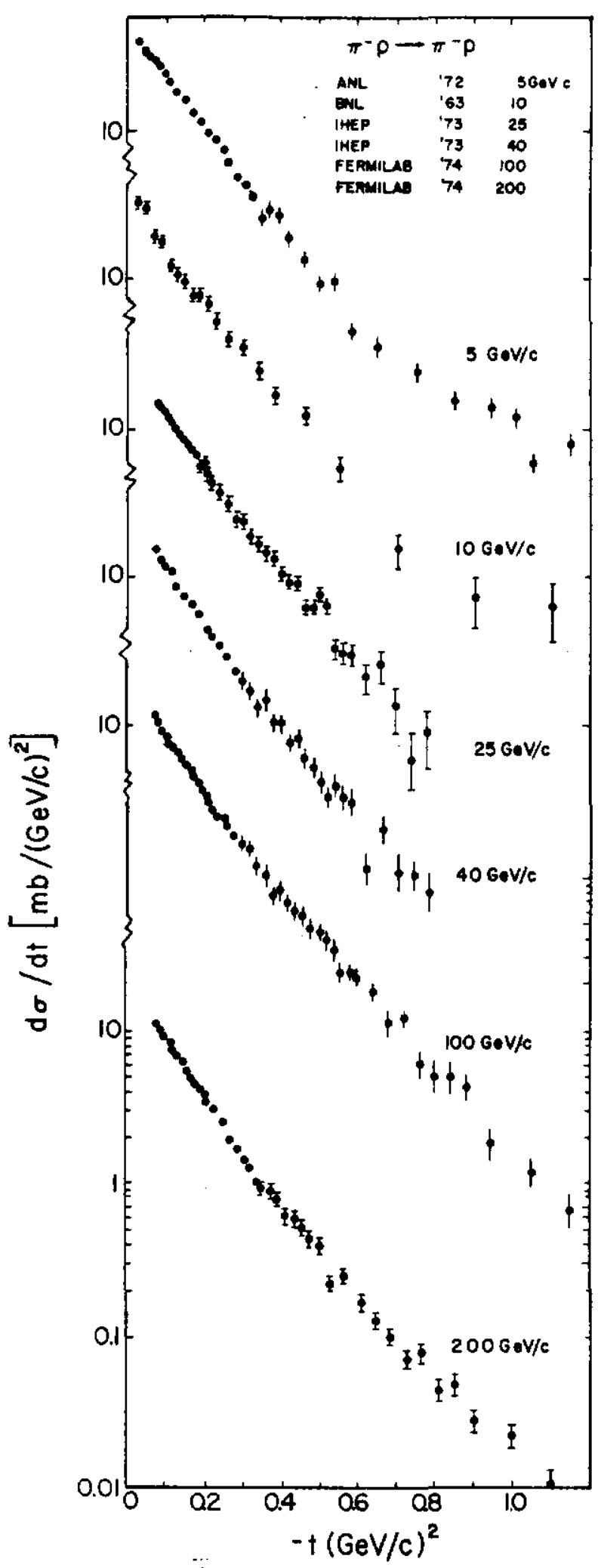

Fig. 3.3 Compilation of $\pi^{-}-p$ elastic scattering differential. cross sections. 


$$
\sigma_{\text {tot }}\left(\pi^{-} p\right)-\sigma_{\text {tot }}\left(\pi^{+} p\right)=\text { constant } x\left[\frac{\left(\frac{d \sigma}{d t}\right)_{\text {at }}^{\left(\pi_{t=0}^{-} p \rightarrow \pi^{0} n\right)}}{1+\tan ^{2} \frac{{ }^{\pi \alpha} p^{(t=0)}}{2}}\right]^{1 / 2} \text {. }
$$

Most of the parameters in this expression are self-evident; $\alpha_{p}(t=0)$ is the intercept of the effective $p$-trajectory at $t=0$.

A large variety of methods is used to measure the reactions described above. The $n-p$ charge exchange reaction is measured with a magnetic spectrometer to detect the forward-going proton, and with an array of counters to detect the recoil neutrons at large angles. At Fermilab the $\pi^{-}-p$ charge exchange reaction is measured with an elegant photon detector, composed of 140 narrow finger counters which locate the electromagnetic shower position to about $1 \mathrm{~mm}$ and integrate the total energy loss. Thus, the photon energy is measured to about $\pm 7 \%$ (full-width) for $100 \mathrm{GeV} / \mathrm{c}^{\circ} \pi^{\circ} \mathrm{s} . \pi-\mathrm{p}$ backward scattering will be measured with a double-arm magnetic spectrometer. Measurement of the associated production reactions will be possible using the Single Arm Spectrometer Facility to detect the forward-produced $\mathrm{K}^{+}$. $\mathrm{K}_{\mathrm{S}}^{\circ}$ regeneration is measured with a $\mathrm{V}^{\circ}$-spectrometer, where the pions from the decay $\mathrm{K}^{\circ} \rightarrow \pi^{+} \pi^{-}$are focused into parallel rays (see Section 8 for a further description of this experiment).

Table 4.1 lists the five approved experiments to study the se two-body reactions. In the table are given the Regge-trajectories expected to dominate each reaction. In the case of backward scattering, reactions (4.1) and (4.3) above, the common kinematic variable for describing them is $u$, the fourmomentum transfer from the incident beam particle to the outgoing proton. 
4. CHARGE EXCHANGE SCATTERING AND OTHER TWO-BODY REACTIONS

Five experiments have been approved to study specific two-body exclusive reactions. These reactions are:

$$
\begin{aligned}
& \mathrm{np} \rightarrow \mathrm{pn} \quad \mathrm{n}-\mathrm{p} \text { charge exchange or } \\
& n-p \text { backward scattering } \\
& \pi^{-} p \rightarrow \pi_{0}^{o} n \quad \pi^{-}-p \text { charge exchange } \\
& \rightarrow \eta^{0} \\
& \pi^{-} \mathrm{p} \rightarrow \mathrm{p}^{-}+\quad \pi-\mathrm{p} \text { backward scattering } \\
& \pi^{+} \mathrm{p} \rightarrow \mathrm{p} \pi^{+} \\
& \pi^{+} \mathrm{p} \rightarrow \mathrm{K}^{+} \Sigma^{+} \quad \text { associated production } \\
& \rightarrow \mathrm{K}^{+} \mathrm{Y}^{*+}(1385) \\
& \mathrm{K}_{\mathrm{L}}^{\mathrm{O}} \mathrm{p} \rightarrow \mathrm{K}_{\mathrm{S}}^{\mathrm{O}} \mathrm{p} \quad \mathrm{K}_{\mathrm{S}}^{\circ} \text { regeneration }
\end{aligned}
$$

The interest in these reactions stems from the fact that within the framework of Regge pole models they are described in a relatively simple form, involving the exchange of a small number of Regge trajectories. For example, the $\rho$-trajectory dominates the $\pi^{-} p \rightarrow \pi^{\circ} n$ reaction, the $\pi$-trajectory ( with $\rho-$ and $A_{2}$ - contributions) is expected to describe n-p charge exchange, w-exchange should dominate the $\mathrm{K}_{\mathrm{L}}{ }^{\mathrm{o}} \mathrm{p} \rightarrow \mathrm{K}_{\mathrm{S}}^{\mathrm{O}} \mathrm{p}$ reaction, $\mathrm{K}^{*}$-exchange for $\pi^{+} \mathrm{p} \rightarrow \mathrm{K}^{+} \Sigma^{+}$, and baryon exchange for $\pi-p$ backward scattering.

One of the features of these relatively simple reactions is that it is possible using the Regge pole model, isospin conservation, the optical theorem, and the like, to derive various relations. These formulas connect the reactions to one another, to elastic scattering, and to total cross section differences. For example, pion charge exchange can be used to provide a consistency check on the differences of pion total cross-section measurements using the following expression: 
The $u$-variable has a parallel meaning to the $t$-variable used in the other scattering reactions.

Figure 4.1 shows a compilation of the differential cross sections for $\pi^{-} \mathrm{p} \rightarrow \pi^{\circ} \mathrm{n}$ scattering from 5 to $101 \mathrm{GeV} / \mathrm{c}$. The dominant features are the slow shrinking of the forward peak, the strong energy dependence of the absolute value of the cross section, and the dips at $|t|=0$ and $\approx 0.6$, the latter appearing to be less prominant as the energy increases. 
Table 4.1. Summary of Two-Body Scattering Experiments.

\begin{tabular}{|c|c|c|c|c|}
\hline $\begin{array}{l}\begin{array}{c}\text { Reaction } \\
\text { and }\end{array} \\
\text { Exp. Number } \\
\end{array}$ & $\begin{array}{l}\text { Incident } \\
\text { Momentum } \\
(\mathrm{GeV} / \mathrm{c}) \\
\end{array}$ & $\begin{array}{c}|\mathrm{t}| \text { or }|\mathrm{u}| \\
\text { Range } \\
(\mathrm{GeV} / \mathrm{c})^{2} \\
\end{array}$ & $\begin{array}{c}\text { Dominant } \\
\text { Exchanged } \\
\text { Trajectories } \\
\end{array}$ & $\begin{array}{c}\text { Experimental } \\
\text { Apparatus }\end{array}$ \\
\hline $\begin{array}{l}n p \rightarrow p n \\
\# 12\end{array}$ & $40-280$ & $0.002<|\mathrm{u}|<1$ & $\pi$ & $\begin{array}{l}\text { magnetic spectrom- } \\
\text { eter and neutron } \\
\text { detectors }\end{array}$ \\
\hline $\mathrm{K}_{\mathrm{L}}{ }_{\# 82}^{\mathrm{o}} \rightarrow \mathrm{K}_{\mathrm{S}}^{\circ} \mathrm{p}$ & $30-120$ & $|t|<0.01$ & $\omega$ & 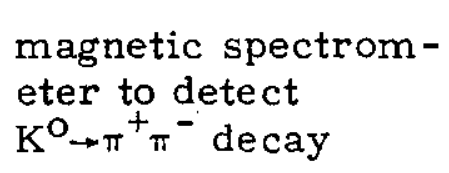 \\
\hline $\begin{aligned} \pi^{+} \mathrm{p} & \rightarrow \mathrm{K}^{+} \Sigma^{+} \\
& \rightarrow \mathrm{K}^{+} \mathrm{Y}^{*+}(1385) \\
& \# 99\end{aligned}$ & $20-150$ & $\mathrm{t}_{\min }<|\mathrm{t}|<0.6$ & $\begin{array}{l}\mathrm{K}^{*} \\
\mathrm{~K}^{*}\end{array}$ & $\begin{array}{l}\text { single arm magnetic } \\
\text { spectrometer }\end{array}$ \\
\hline $\begin{aligned} \pi^{-} p \rightarrow \pi^{\circ} n \\
\rightarrow \eta^{\circ} n \\
\# 111\end{aligned}$ & $20-200$ & $0<|t|<1.5$ & $\begin{array}{l}\rho \\
\mathrm{A}_{2}\end{array}$ & $\begin{array}{l}\text { photon shower } \\
\text { detector }\end{array}$ \\
\hline $\begin{array}{c}\pi^{-} \mathrm{p} \rightarrow \mathrm{p} \pi^{-} \\
\pi^{+} \mathrm{p} \rightarrow \mathrm{p} \pi^{+} \\
\# 290\end{array}$ & $10,50,80$ & $0<|u|<0.8$ & $\mathrm{~N}_{\alpha^{\prime}}{ }_{\Delta_{\delta}}^{\Delta_{\delta}}$ & $\begin{array}{l}\text { two magnetic } \\
\text { spectrometers }\end{array}$ \\
\hline
\end{tabular}




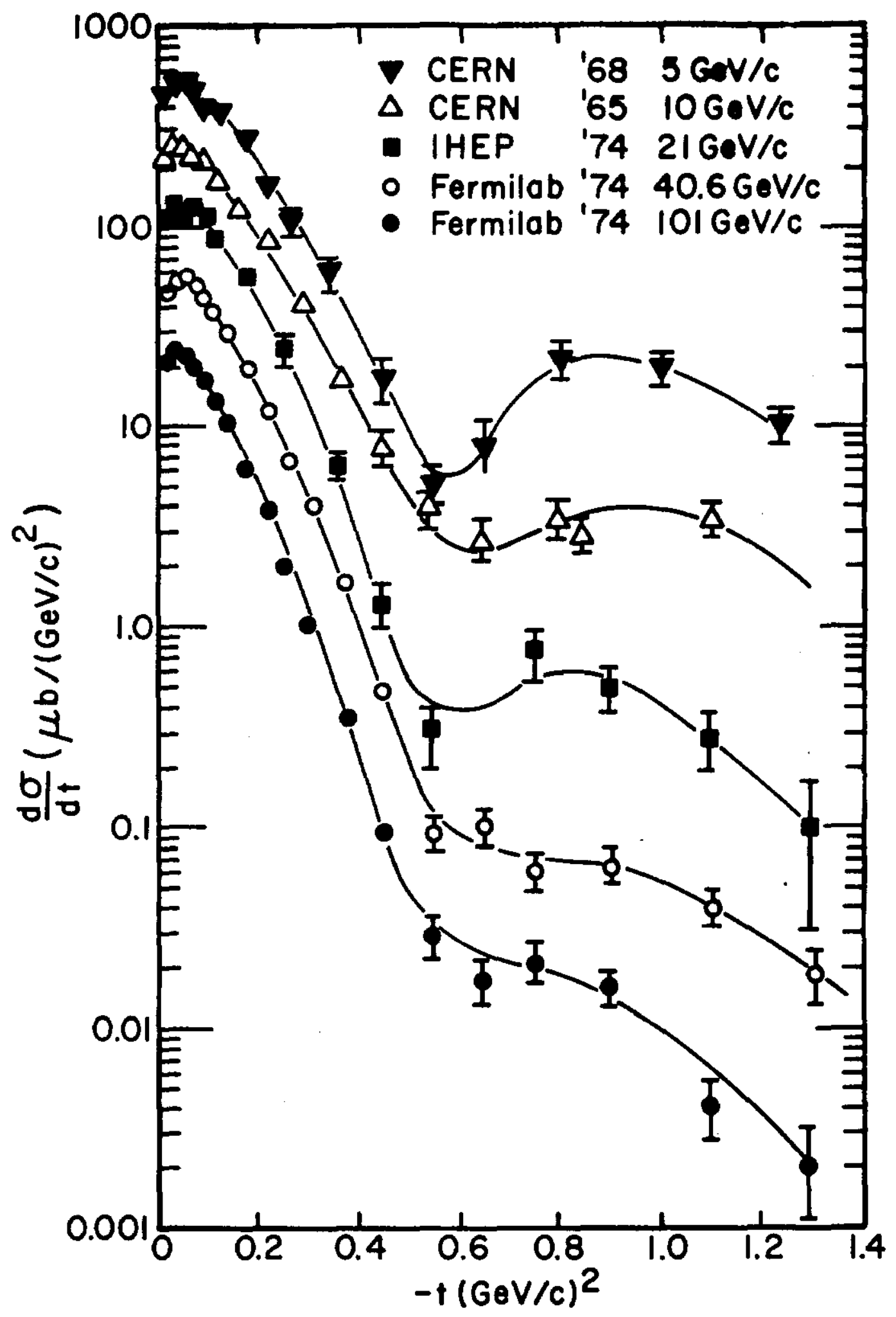

Fig. 4.1 Compilation of $\pi^{-} p \rightarrow \pi^{\circ}$ differential cross sections. 


\section{INCLUSIVE REACTION EXPERIMENTS}

An inclusive reaction of order one is defined as

$$
a+b \rightarrow c+X
$$

We shall refer to "a" as the incident particle, to "b" as the target particle, and to "c" as the produced particle which is identified and whose momentum and production angles are measured. The system $X$, also referred to as "anything," is unobserved.

Reaction (5.1) is usually observed with a single arm spectrometer. The spectrometer would have magnets and gas Cerenkov counters when particle " $\mathrm{c}$ " is charged. It has a calorimeter or shower detector when particle "c" is neutral. Also bubble chambers have been used to provide infor mation on inclusive processes; the information is unique for $K_{S}{ }^{o}$ and $\Lambda^{\circ}$ production (also see Section 9).

Reaction (5.1) is kinematically defined by three variables, for example the center-of-mass energy, the polar angle, $\theta$, and the momentum, $p$, of particle "c." The azimuthal angle, $\phi$, is ignorable because polarization effects are not examined with the exception of $\Lambda^{\circ}$ production in bubble chambers. There are many different choices for the three independent variables, for the cross sections, and for the scaling laws. Moreover, the conventional notation changes appreciably for inclusive reactions due to strong, electromagnetic, or weak interactions. In the last two cases, inclusive reactions are better known.as deep inelastic processes. Table 5.1 gives a list of definitions used in describing the three types of interactions. 
Another classification of inclusive reactions may be based on the transverse momentum value of the observed particle. One speaks of small$p_{t}$ and of large $-p_{t}$ phenomena. The latter have always been associated with interactions at small distances. It may also be worthwhile to recall that the average transverse momentum in processes due to strong interactions is small, about $350 \mathrm{MeV} / \mathrm{c}$, and slightly dependent on center-of-mass energy. On the contrary, the average transverse momentum squared in processes due to weak interactions grows linearly with the laboratory energy of the incoming particle.

We have separated the inclusive reactions according to the type of experiments. In this section we shall discuss strong interaction processes only. The electromagnetic interaction experiments will be described in Sections 10 and 11 and those for weak interactions are discussed in Section 12 .

Table 5.2 gives a list of the beam survey experiments which have been completed or will be performed in the different beam lines available at Fermilab. These are standard measurements that are made in each beam line during the initial stages of the first experiment in that line. The $\left(\mathrm{p}_{\ell}^{*}, \mathrm{p}_{\mathrm{t}}\right)$ domains covered by these surveys are shown in the Peyrou plot of Fig. 5.1.

A special class of inclusive reactions involves very small target recoils along with diffraction dissociation of the incoming beam particle. These reactions are extensively studied with the internal proton beam. We shall refer to them as reactions of the type

$$
p+p \rightarrow p+M M
$$

where $\mathrm{MM}=$ missing mass. The target (or recoil particle) could be a proton 
or a deuteron. We shall use the following kinematic variables: the four momentum transfer squared, $t$, and the missing mass, MM. Table 5.3 and Fig. 5.2 illustrate the ranges of values for the approved Fermilab experiments.

Table 5.4 lists the main features of the studied photon-producing reactions

$$
a+b \rightarrow \gamma+X
$$

where "a" can be either a proton or a pion and "b" is usually a nuclear tar get. In reality, these experiments examine the strong production of $\pi^{\circ}, \eta^{\circ}$, etc. Figure 5.3 illustrates the $\left(x, p_{t}\right)$ domains covered in the approved experiments with incident protons.

Table 5.5 lists the main features of the more general inclusive reactions for the production of charged particles by incident pions, kaons, protons, and antiprotons:

$$
\left(\begin{array}{l}
\pi^{ \pm} \\
K^{ \pm} \\
p^{ \pm}
\end{array}\right)+p \rightarrow\left(\begin{array}{l}
\pi^{ \pm} \\
K^{ \pm} \\
p^{ \pm}
\end{array}\right)+X
$$

The $\left(x, p_{t}\right)$ ranges covered by these experiments are illustrated in $F$ ig. 5.4 (for incident protons) and Fig. 5.5 (for incident $\pi, K, \bar{p}$ ).

There exists another group of experiments which can be included under single particle inclusive experiments, but can be considered separately. These involve direct single lepton production. Two experiments (\#70 and \#100A) used the proton beam in the Proton Area and Experiment \#184 relied on the variable energy available using the internal proton beam. Experiment \#335 will measure direct muon production in the forward direction (at 1.6 mrad). For this purpose it will use the first stage of a charged particle 
beam as a diffracted proton beam, and the second and third stages as a spectrometer. At large center-of-mass production angles the ratio, direct single lepton/pion, is $10^{-4}$ independent of $p_{t}$. Experiment \#335 should find out if this also holds true at small angles.

The apparatus of several of the single lepton experiments is now being expanded to include the possibility of detecting dileptons. These experiments are classified as multiparticle experiments and are included in Section 7. Table 5.6 summarizes the experiments on single lepton production. 
Table 5.1. Notation for Inclusive Measurements.

Weak or Electromagnetic Interactions

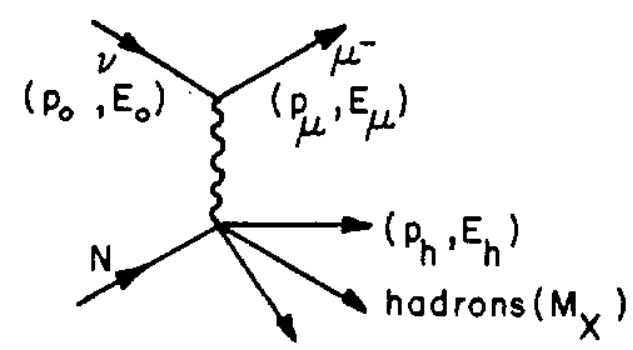

Strong Interactions

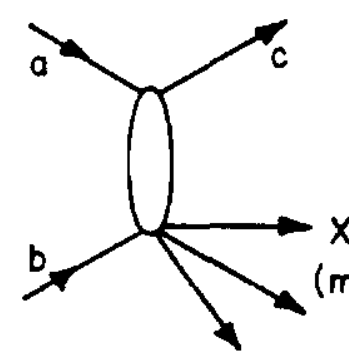

(missing moss, MM)

$\begin{aligned} p & =\text { momentum four-vector } \\ p, g^{*} & =\text { laboratory momentum and scattering angle }\end{aligned}$

$\mathrm{p}^{*}, \theta^{*}=$ center -of-mass (c.m.) momentum and scattering angle

$$
\begin{aligned}
& \mathrm{q}^{2}(=-\mathrm{t})=4 \mathrm{E}_{0} \mathrm{E}_{\mu} \sin ^{2} \frac{\theta}{2} \mu \\
& \approx\left(E_{h}+E_{\mu}\right) E_{\mu} \theta_{\mu}^{2} \\
& v=E_{h}=E_{0}-E_{\mu} \\
& x=\frac{q^{2}}{2 m_{N}^{\nu}} \approx \frac{\left(E_{h}+E_{\mu}\right)^{2} E_{\mu} \theta_{\mu}^{2}}{2 m_{N} E_{h}} \\
& \omega=\frac{1}{x} \\
& y=\frac{\nu}{E_{0}}=\frac{E_{h}}{E_{h}+E_{\mu}} \\
& v=x y=\frac{q^{2}}{2 m_{N} E_{0}} \\
& =\frac{2}{m_{N}} p_{\mu} \sin ^{2} \frac{\theta}{2}
\end{aligned}
$$

(involves muon information only) $\mathrm{u}=\mathrm{x}(1-\mathrm{y}) \approx \frac{\mathrm{E}_{\mathrm{h}}}{2 \mathrm{~m}_{\mathrm{N}}} \theta_{\mathrm{h}}^{2}$

(involves hadron information only)

$$
\mathrm{W}^{2}=\mathrm{M}_{\mathrm{X}}^{2}=\mathrm{m}_{\mathrm{N}}^{2}+2 \mathrm{~m}_{\mathrm{N}^{\nu}}{ }^{2}-\mathrm{q}^{2}
$$

$$
\begin{aligned}
s & =E_{c \cdot m}{ }^{2}=\left(p_{a}+p_{b}\right)^{2} \\
t & =\left(p_{a}-p_{c}\right)^{2} \\
p_{\perp} & =p_{t}=p \sin \theta=p^{*} \sin \theta^{*} \\
p_{\|} & =p_{\ell}^{*}=p^{*} \cos \theta^{*} \\
x_{\perp} & =\frac{p_{1}}{p_{\perp \max }} \approx \frac{2 p_{1}}{\sqrt{s}} \\
x_{\|} & =x_{\|}=\frac{p_{\|}}{p_{\| \max }} \approx \frac{2 p_{\|}}{\sqrt{s}} \\
x_{R} & =\sqrt{x_{\perp}^{2}+x_{\|}^{2}}
\end{aligned}
$$$$
\text { Rapidity }=y^{*}=\frac{1}{2} \ln \frac{E_{c}^{*}+p_{\|}}{E_{c}^{*}-p_{\| !}}
$$$$
\text { Pseudorapidity }=\eta^{*} \approx-\ln \tan \frac{\theta^{*}}{2}
$$

$$
\left(\mathrm{y}^{*} \approx \eta^{*} \text {, for } \mathrm{m}_{\mathrm{c}} \mathrm{small}\right)
$$

Lab rapidity $=y_{\text {lab }}=y_{\text {beam }}-y^{*}$

$$
\begin{aligned}
M M^{2} & =M_{X}^{2}=\left(p_{a}+p_{b}-p_{c}\right)^{2} \\
& \approx s(1-x)
\end{aligned}
$$

Invariant Cross Section,

$$
\begin{aligned}
f & =E \frac{d^{3} \sigma}{d^{3} p}=\frac{E}{p} \frac{d^{2} \sigma}{d \Omega d p} \\
& =f\left(s, p_{\perp}, p_{\|}\right)
\end{aligned}
$$


'lable 5.2. Summary of Beam Survey Experiments $(p+A \rightarrow c+X)$, Where $A$ is a Nuclear Target and $c$ is the Observed Particle.

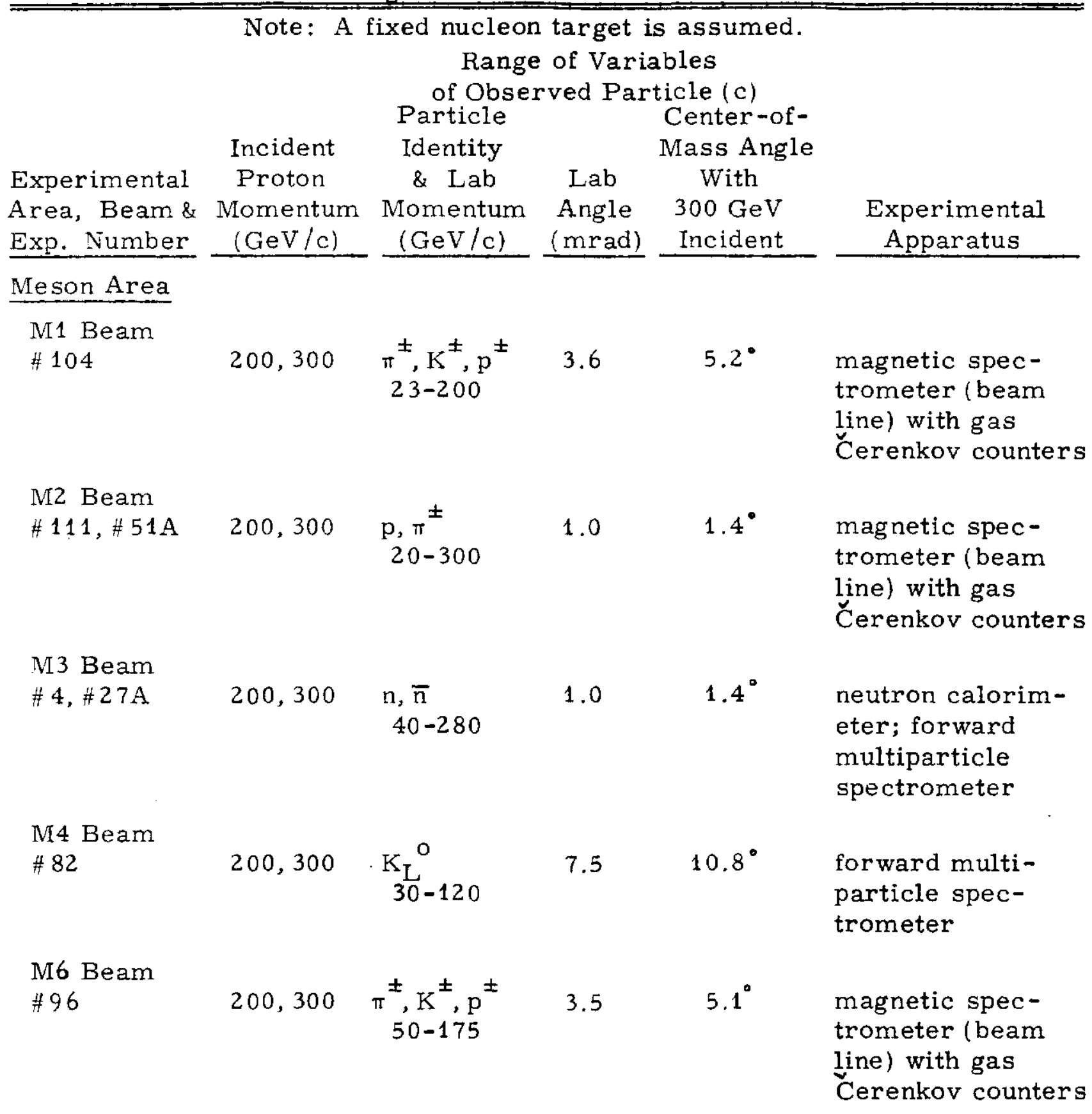

Neutrino Area

No Beam

15-ft B. C.

Users,

\#1A, \#21A
$300,400 \quad \pi^{ \pm}, \mathrm{K}^{ \pm}$
$10-200$

$0 \quad 0^{\circ}$

magnetic spectrometer ( N1 beam line) with gas Čerenkov counters and Cerenkov counters looking directly at production target 
Table 5.2. (continued)

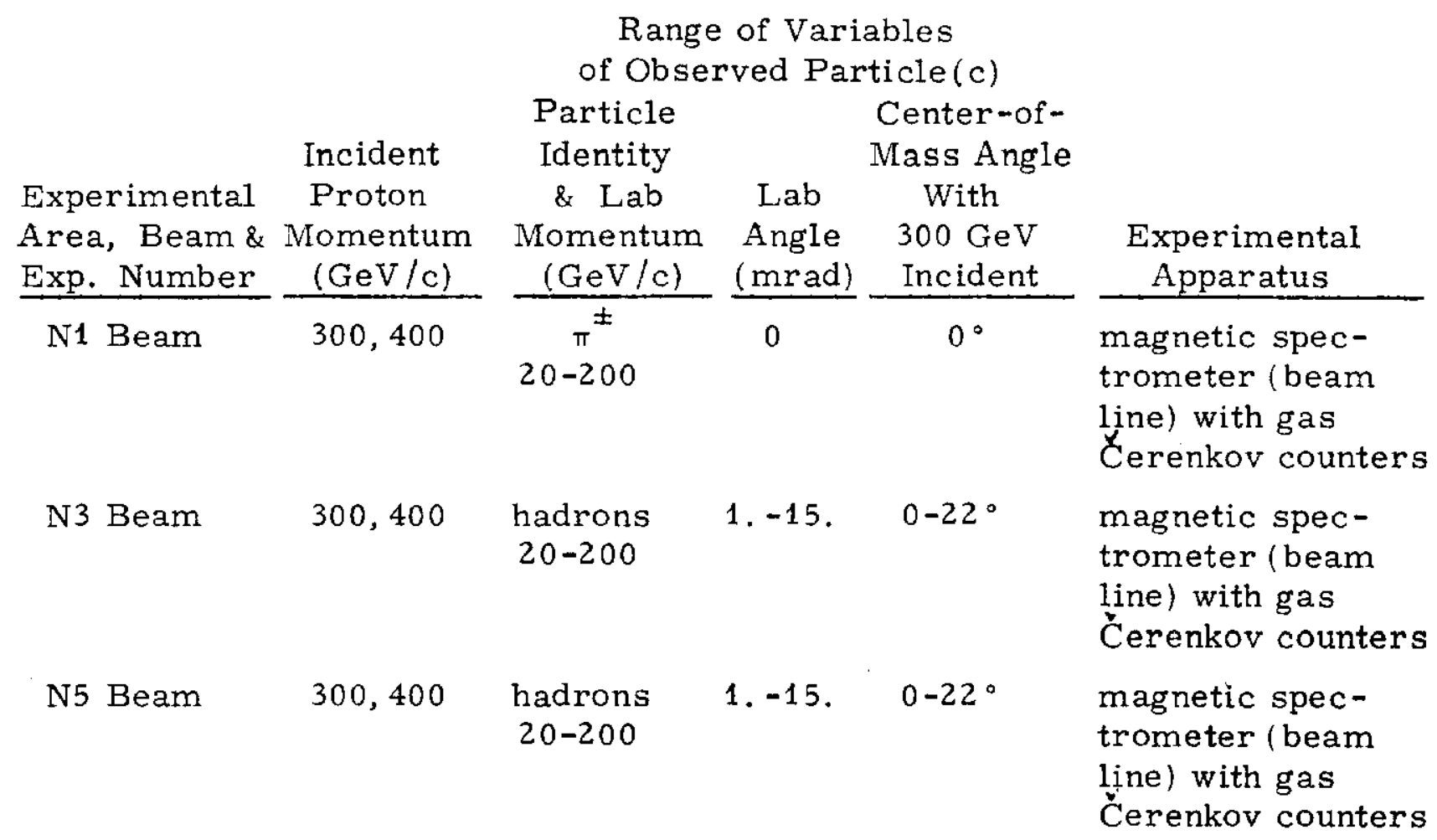

Proton Area

P-East

$\# 25 \mathrm{~A}$

$200,300,400$

$\begin{array}{ccc}Y & 0-1 . & 0-14^{\circ}\end{array}$

magnetic spectrometer (beam line) and lead glass counters

\#87A, \# 358

$200,300,400 \mathrm{n}: 40-280$

0

$0^{\circ}$

forward multi$\gamma: 10-250$ particle spec-

\#100A

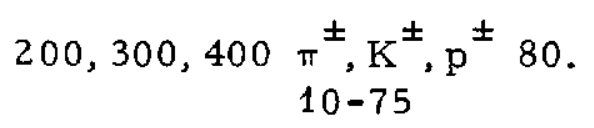
trometer

single arm mag netic spectrom eter with gas Cerenkov counters

P-Center \# 70

$$
\begin{aligned}
200,300,400 & \gamma, \pi^{\circ} \\
& 10-200
\end{aligned}
$$

50. $-100.65^{\circ}-104^{\circ}$

magnetic spectrometer and lead glass counters

P-West \#95A

$$
200,300,400 \frac{\gamma}{10-200}
$$

17. $-100.24^{\circ}-104^{\circ}$ magnetic spectrometer and lead glass counters 
Table 5.2. (continued)

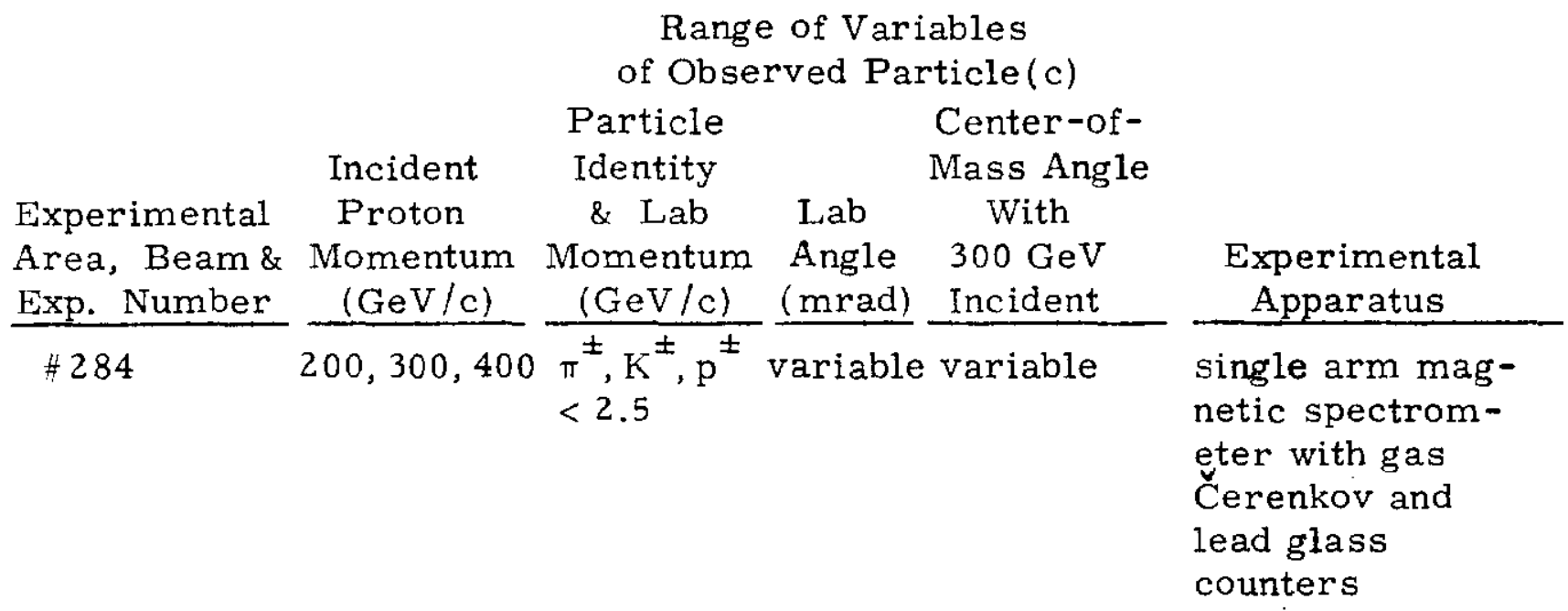

Note: General surveys of charged and neutral hyperon production will be done in the M2 Beam using diffracted protons by Experiments \# 8 and \#97. See Section 8. 


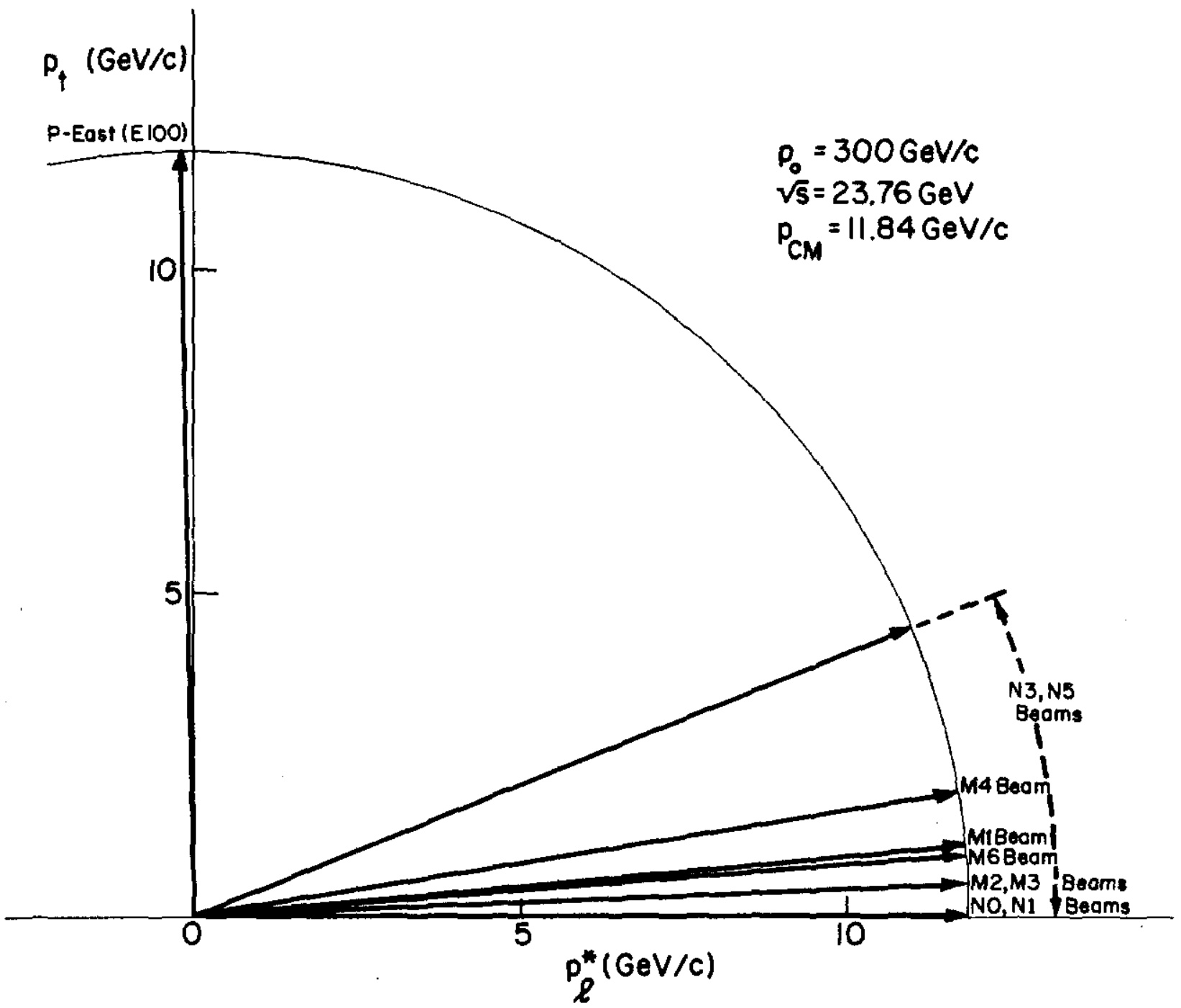

Fig. 5.1 Peyrou plot of some beam survey experiments. 
Table 5.3. Summary of Inclusive Reaction Studies of the Type $p p \rightarrow p+M M$, $p d \rightarrow d+M M$ Where the Recoil (p,d) Is Detected at Large Angles.

Notes: 1) An incident momentum of $300 \mathrm{GeV} / \mathrm{c}$ is assumed.

2) The grouping of experiments is an indication of a continuing experimental program.

Incident Missing Momentum $|t|$-Range Mass Range Experimental

$\frac{\text { Exp. Number }}{\# 14 \mathrm{~A}} \frac{\text { Target }}{\mathrm{C}^{\mathrm{a}} \mathrm{CH}_{2}^{\mathrm{b}}} \frac{(\mathrm{GeV} / \mathrm{c})}{200,300,400} \frac{(\mathrm{GeV} / \mathrm{c})^{2}}{0.02-0.2} \frac{(\mathrm{GeV})}{1 .-10}$
Apparatus external proton beam and solid state recoil detectors

\#221 $\mathrm{C}, \mathrm{CH}_{2} \quad 40-400 \quad 0.02-0.2 \quad 1 .-8 . \quad$ internal beam and solid state recoil detectors

\#321 p $40-400 \quad 0.01-0.23 \quad 1 .-14 . \quad$ internal beam and solid state recoil detectors

\begin{tabular}{|c|c|c|c|c|c|}
\hline$\# 36 \mathrm{~A}$ & $\mathrm{p}$ & $40-400$ & $.001-0.1$ & 1. -5 . & $\begin{array}{l}\text { internal beam and } \\
\text { solid state recoil } \\
\text { detectors }\end{array}$ \\
\hline$\# 186$ & $d$ & $40-400$ & $0.03-0.12$ & $1 .-12$ & $\begin{array}{l}\text { internal beam and } \\
\text { solid state recoil } \\
\text { detectors }\end{array}$ \\
\hline$\# 317$ & $p, d$ & $40-400$ & $0.01-0.1$ & 1. -8. & $\begin{array}{l}\text { inter nal beam and } \\
\text { solid state recoil } \\
\text { detectors }\end{array}$ \\
\hline$\# 67 \mathrm{~A}$ & $\mathrm{p}$ & $40-400$ & $0.1-0.6$ & $1.5-10$. & $\begin{array}{l}\text { internal beam and } \\
\text { scintillation } \\
\text { counters }\end{array}$ \\
\hline$\# 188$ & $p, d$ & $40-400$ & $0.1-0.6$ & $1.5-10$ & $\begin{array}{l}\text { internal beam and } \\
\text { scintillation } \\
\text { counters }\end{array}$ \\
\hline $\begin{array}{l}\quad \# 51 \mathrm{~A} \\
\text { (also with in- } \\
\text { cident } \pi^{\prime} s \text { ) }\end{array}$ & $\mathrm{p}$ & $50-250$ & $0.1-0.45$ & 2. -10 . & $\begin{array}{l}\text { secondary beam } \\
\text { with scintillation } \\
\text { counters and } \\
\text { spark chambers }\end{array}$ \\
\hline
\end{tabular}


Table 5.3. (continued)

\begin{tabular}{|c|c|c|c|c|c|}
\hline Exp. Number & Target & $\begin{array}{c}\text { Incident } \\
\text { Momentum } \\
(\mathrm{GeV} / \mathrm{c}) \\
\end{array}$ & $\begin{array}{l}|\mathrm{t}| \text {-Range } \\
(\mathrm{GeV} / \mathrm{c})^{2}\end{array}$ & $\begin{array}{c}\text { Missing } \\
\text { Mass Range } \\
(\mathrm{GeV}) \\
\end{array}$ & $\begin{array}{c}\text { Experimental } \\
\text { Apparatus } \\
\end{array}$ \\
\hline $\begin{array}{l}\quad \# 96 \\
\text { (also with in- } \\
\text { cident } \pi^{\prime} s, K^{\prime} s \text { ) }\end{array}$ & $\mathrm{p}, \mathrm{d}$ & $50-175$ & $0.02-0.8$ & 1. -8. & $\begin{array}{l}\text { secondary beam } \\
\text { with single arm } \\
\text { magnetic spec- } \\
\text { trometer }\end{array}$ \\
\hline
\end{tabular}

$$
\begin{aligned}
& \text { a } \mathrm{C}=\text { carbon } \\
& { }^{b} \mathrm{CH}_{2}=\text { polyethylene }
\end{aligned}
$$




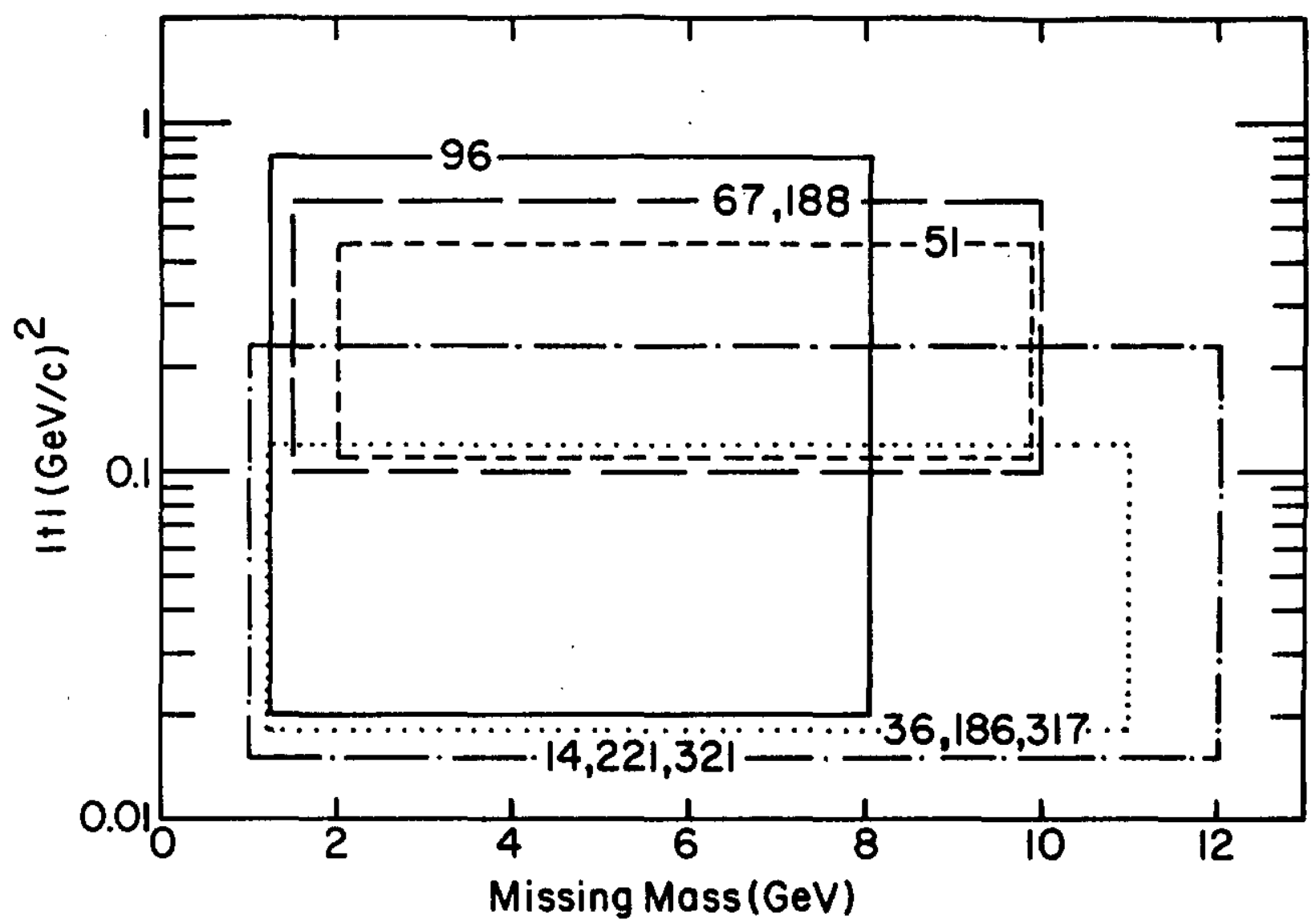

Fig. 5.2 Approximate ranges of inclusive reactions of the type $p p \rightarrow p+M M$, $p d \rightarrow d+M M$ where the recoil $(p, d)$ is detected at large angles. Incident momentum of $300 \mathrm{GeV} / \mathrm{c}$ is assumed. 
Table 5.4. Summary of Photon-Producing Reaction Studies.

\begin{tabular}{|c|c|c|c|c|}
\hline $\begin{array}{l}\text { Incident } \\
\text { Particle } \\
\text { and } \\
\text { Exp. } \\
\text { Number } \\
\end{array}$ & $\begin{array}{c}\text { Incident } \\
\text { Momentum } \\
(\mathrm{GeV} / \mathrm{c}) \\
\end{array}$ & $\begin{array}{c}\mathrm{p}_{\mathrm{t}} \text {-Range } \\
(\mathrm{GeV} / \mathrm{c}) \\
\end{array}$ & $\underline{x-R a n g e}$ & Experimental Apparatus \\
\hline \multicolumn{5}{|l|}{ Protons } \\
\hline$\# 63 \mathrm{~A}$ & $40-400$ & $0.1-3$ & $0.01-0.9$ & $\begin{array}{l}\text { internal beam and lead glass } \\
\text { counters }\end{array}$ \\
\hline$\# 70$ & $200,300,400$ & $1.8-8$ & $0-0.6$ & $\begin{array}{l}\text { external proton beam and lead } \\
\text { glass counters }\end{array}$ \\
\hline$\# 95 \mathrm{~A}$ & $100-400$ & $0.2-5$ & $0-0.7$ & $\begin{array}{l}\text { external proton beam and lead } \\
\text { glass counters }\end{array}$ \\
\hline$\# 120$ & $30-300$ & $0.001-0.04$ & $0-0.7$ & $\begin{array}{l}\text { internal beam and lead glass } \\
\text { counters }\end{array}$ \\
\hline$\# 268$ & 300 & $0.3-5$ & $-0.2-0.5$ & $\begin{array}{l}\text { secondary beam and photon } \\
\text { shower detector }\end{array}$ \\
\hline \multicolumn{5}{|l|}{ Pions } \\
\hline$\# 192$ & $100-300$ & - & - & $\begin{array}{l}\text { large aperture magnet with } \\
\mathrm{NaI}(\mathrm{T} \ell) \text { absorption counters }\end{array}$ \\
\hline$\# 268$ & 100,200 & $0.3-3$ & $-0.2-0.5$ & $\begin{array}{l}\text { secondary beam and photon } \\
\text { shower detector }\end{array}$ \\
\hline$\# 350$ & $100,150,200$ & $0.1-1.7$ & $0.8-1$ & $\begin{array}{l}\text { secondary beam and photon } \\
\text { shower detector }\end{array}$ \\
\hline
\end{tabular}




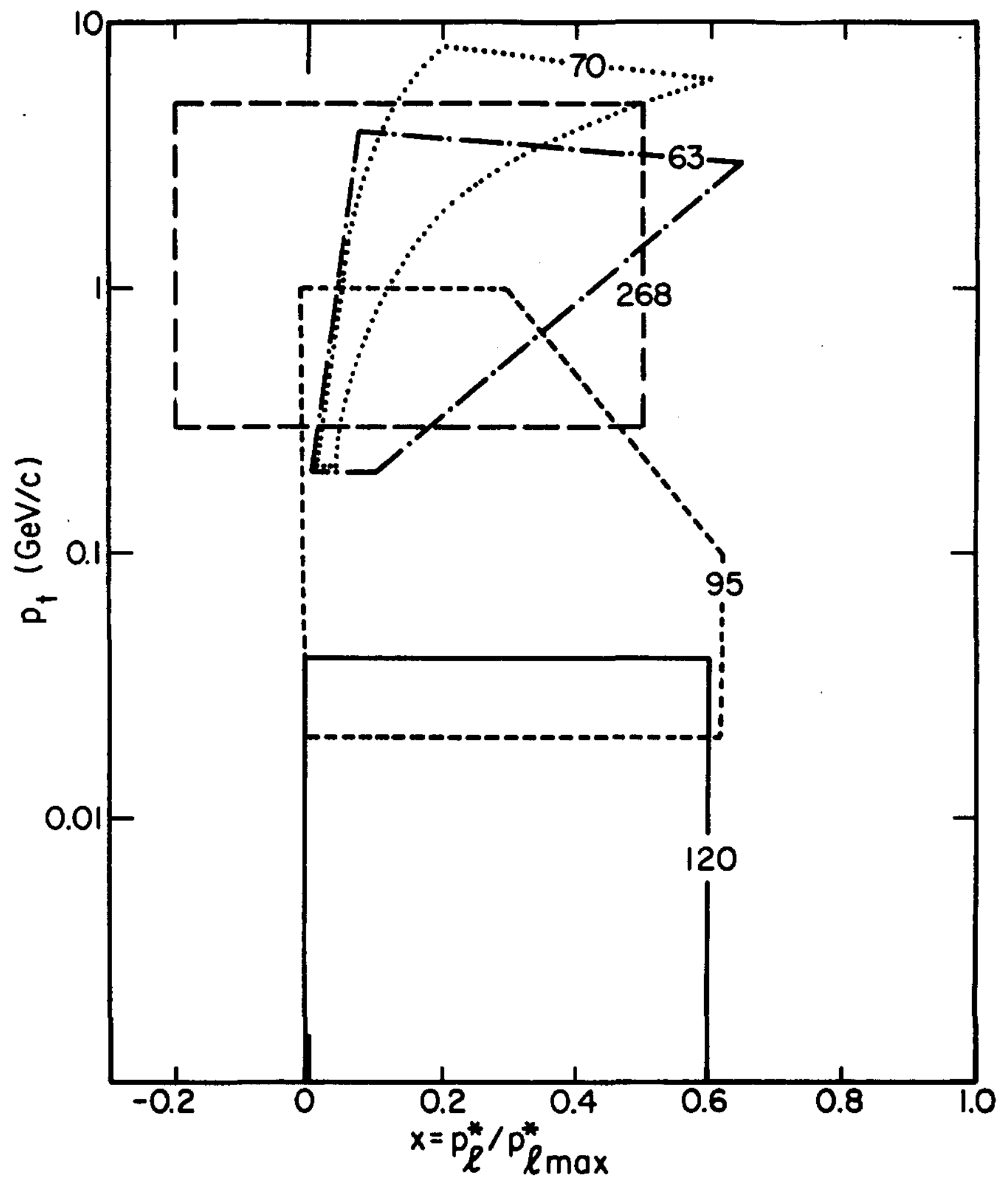

Fig. 5.3 Kinematic regions covered by the photon-producing reaction studies: $p+p(A) \rightarrow \gamma+X$. 
Table 5.5. Summary of General Inclusive Reaction Studies.

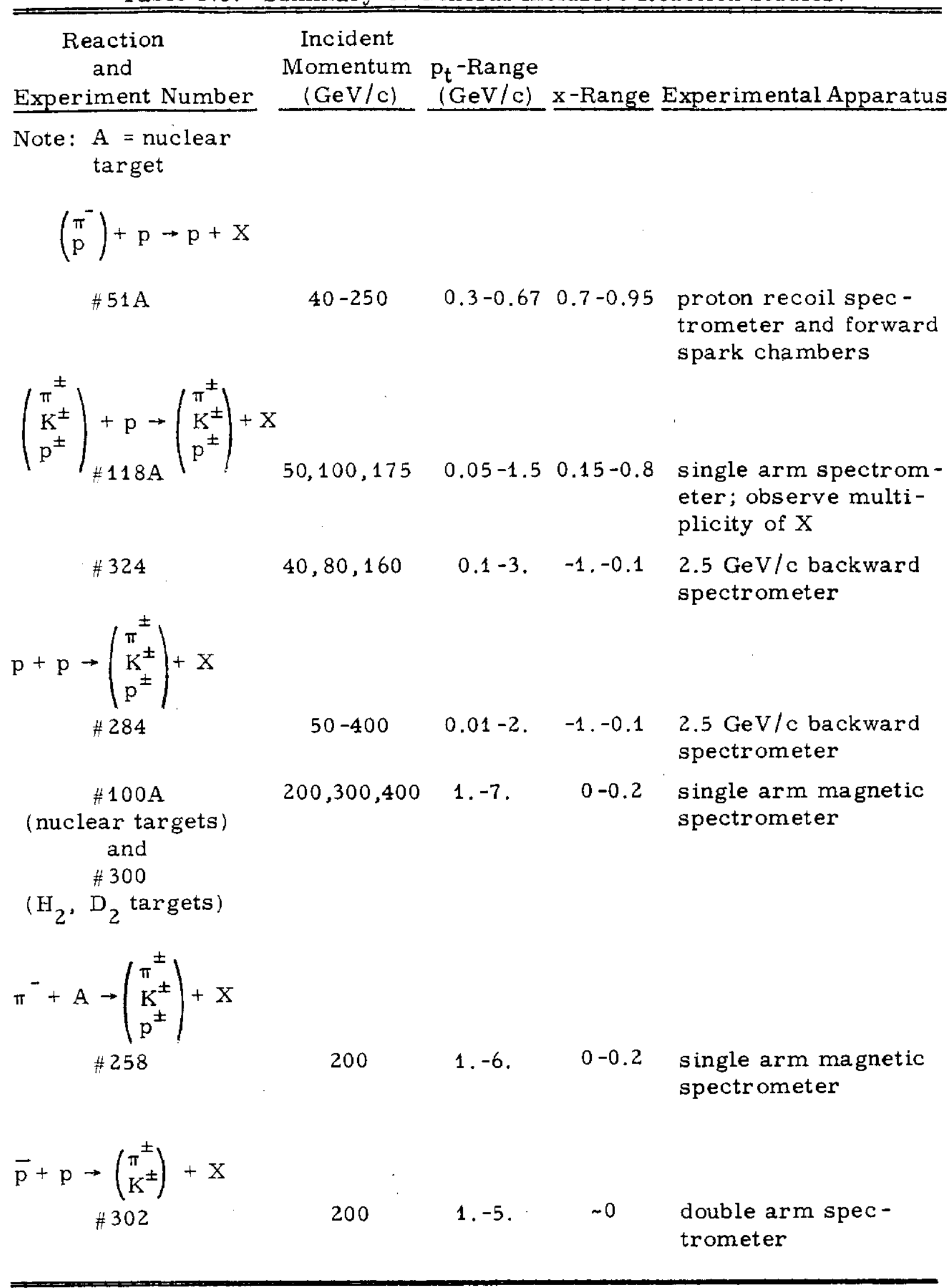




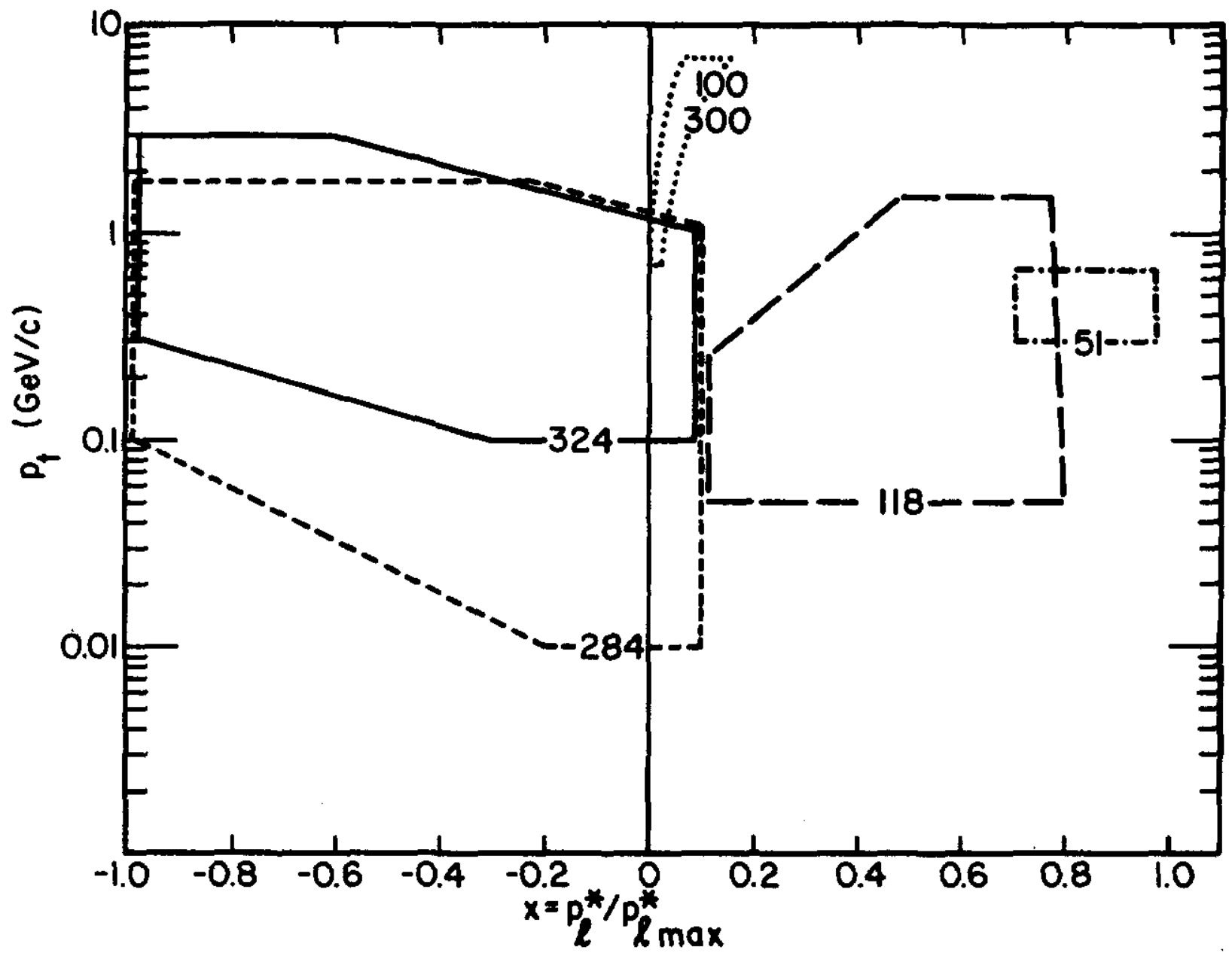

Fig. 5.4 Kinematic regions covered by general inclusive reactions initiated by protons :

$$
\begin{aligned}
\mathrm{p}+\mathrm{p}(\mathrm{A}) & \rightarrow \pi^{ \pm}+\mathrm{X} \\
& \rightarrow \mathrm{K}^{ \pm}+\mathrm{X} \\
& \rightarrow \mathrm{p}^{ \pm}+\mathrm{X} .
\end{aligned}
$$




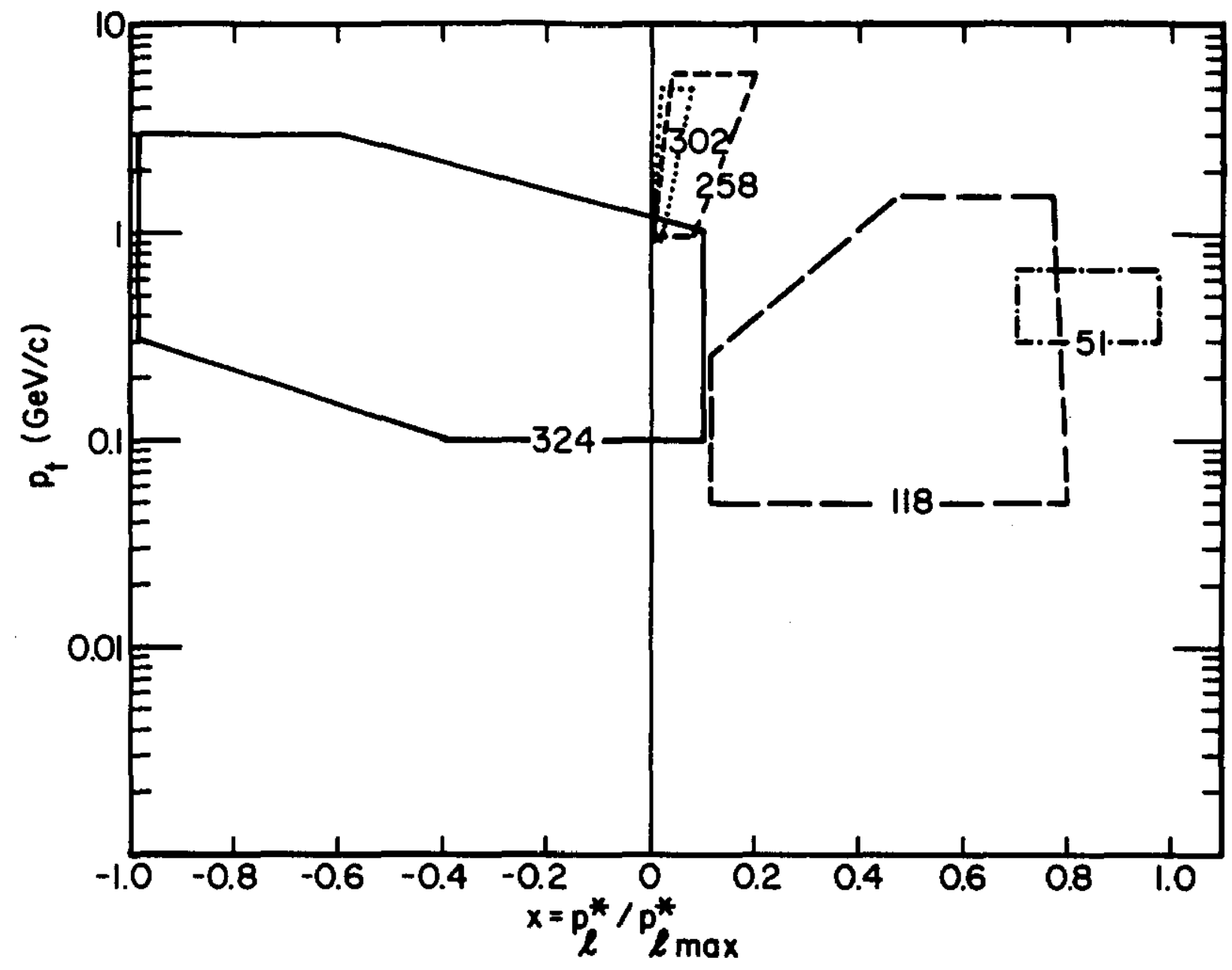

Fig. 5.5 Kinematic regions covered by general inclusive reactions initiated by $\pi, K, \bar{p}$ :

$$
\left(\begin{array}{c}
\pi^{ \pm} \\
\frac{K^{ \pm}}{p}
\end{array}\right)+p(A) \rightarrow\left(\begin{array}{c}
\pi^{ \pm} \\
K_{ \pm}^{ \pm} \\
p^{ \pm}
\end{array}\right)+X
$$


Table 5.6. Summary of Direct Single Lepton Production.

\begin{tabular}{|c|c|c|c|c|c|}
\hline $\begin{array}{l}\text { Reaction } \\
\text { and } \\
\text { Exp. Number } \\
\end{array}$ & $\begin{array}{l}\text { Incident } \\
\text { Momentum } \\
(\mathrm{GeV} / \mathrm{c}) \\
\end{array}$ & $\begin{array}{l}\text { Lab } \\
\text { Angle } \\
\text { (mrad) }\end{array}$ & $\begin{array}{c}\text { Center - } \\
\text { of-Mass } \\
\text { Angle } \\
\end{array}$ & $\begin{array}{l}\mathrm{p}_{\mathrm{t}} \text {-Range } \\
(\mathrm{GeV} / \mathrm{c})\end{array}$ & $\begin{array}{c}\text { Experimental } \\
\text { Apparatus }\end{array}$ \\
\hline \multicolumn{6}{|l|}{$\begin{array}{l}\text { Note: } A= \\
\text { nuclear target }\end{array}$} \\
\hline $\begin{array}{c}\mathrm{pA} \rightarrow\left(\begin{array}{l}\mathrm{e}^{ \pm} \\
\mu\end{array}\right)+\mathrm{X} \\
\# 70\end{array}$ & $200,300,400$ & $50-100$ & $270^{\circ}-90^{\circ}$ & 2. -5 . & $\begin{array}{l}\text { single arm magnetic } \\
\text { spectrometer }\end{array}$ \\
\hline \multicolumn{6}{|l|}{$p A \rightarrow \mu^{ \pm}+X$} \\
\hline$\# 100 \mathrm{~A}$ & $200,300,400$ & 80 & $-90^{\circ}$ & $1.5-5.5$ & $\begin{array}{l}\text { single arm magnetic } \\
\text { spectrometer }\end{array}$ \\
\hline$\# 184$ & $30-300$ & 80 & $-90^{\circ}$ & $0.85-2.5$ & $\begin{array}{l}\text { internal beam and } \\
\text { single arm magnetic } \\
\text { spectrometer }\end{array}$ \\
\hline$\# 335$ & 300 & 1.6 & $1.3^{\circ}$ & $0.14-0.35$ & $\begin{array}{l}\text { single arm magnetic } \\
\text { spectrometer } \\
\text { (charged particle } \\
\text { beam line) }\end{array}$ \\
\hline
\end{tabular}




\section{DIFFRACTION DISSOCIATION EXPERIMENTS}

Under the general category of diffraction dissociation we shall classify a number of reactions characterized by: i) small momentum transfers, ii) no quantum numbers exchanged, and iii) essentially no energy dependence of the cross section. These reactions are thought to proceed via Pomeron (P) exchange and may be further classified as beam or target fragmentation reactions, as illustrated in Fig. 6.1.

Generally, in the laboratory frame of reference, the beam fragmentation reaction can be described as a nearly elastic process where the target particle recoils at about $90^{\circ}$ in the lab and a sort of jet of 2 or 3 particles goes forward at very small angles. Target fragmentation is a nearly elastic reaction where the scattered beam particle retains most if its momentum and is scattered at only a very small angle. Diffractive events lead to the production of a relatively small number of particles whose characteristic rapidity distribution is sketched in Fig. 6.1. The center-of-mass rapidity is defined as $\mathrm{y}^{*}=\frac{1}{2} \ln \left(\mathrm{E}^{*}+\mathrm{p}_{\|} / \mathrm{E}^{*}-\mathrm{p}_{\|}\right)$( see Table 5.1).

So far at Fermilab there are two principal efforts directed at beam particle dissociation. One of these, involving neutron dissociation, is accomplished with a "V" spectrometer used to detect the reaction $n A \rightarrow(\pi-p) A$ where the $\mathrm{A}$ in Experiment \#27A represents nuclear targets from carbon to lead. Experiment \#305, by the same participants, includes also the use of a high pressure gas target with hydrogen, deuterium, and helium gases. These experiments have also looked at the coulomb dissociation process where the exchanged particle is a photon rather than a Pomeron. This 
process is observable at very small angles [for $|t|<0.004(\mathrm{GeV} / \mathrm{c})^{2}$ ] and is known to be dependent on $Z^{2}$.

The other approved beam dissociation experiment at Fermilab (Experiment \#86A) involves fragmentation of pions using a streamer chamber filled with helium gas. The helium serves as the target and also as the detector of the interaction when it recoils coherently. The streamer chamber allows a study of the forward particles produced in the dissociation process. The use of helium also has another feature. Because of the quantum numbers of the helium nucleus, the only particle exchanges which can contribute are the Pomeron and its negative signature counterpart ( $P$ and $P^{\prime}$ respectively) and the $\omega$. This then enables a simpler understanding of the reaction.

Experiment \#96 and \#118A will study target fragmentation reactions induced by different types of particles $\left(\pi^{ \pm}, K^{ \pm}, p^{ \pm}\right)$. One should thus be able to see if the process is independent of the projectile particles. Experiment \#118A will have charged particle detectors surrounding the production target to allow a more detailed look at the multiplicity of target fragments.

Table 6.1 serves to explain more specifically the details of these approved experiments. It should be noted that some of the missing mass experiments listed in Table 5.3 may also be classified as diffraction dissociation experiments in which there is fragmentation of the target particle. 
Table 6.1. Summary of Diffraction Dissociation Experiments.

\begin{tabular}{|c|c|c|c|c|}
\hline $\begin{array}{l}\text { Reaction } \\
\text { and Exp. Number }\end{array}$ & $\begin{array}{c}\text { Incident } \\
\text { Momentum } \\
(\mathrm{GeV} / \mathrm{c}) \\
\end{array}$ & $\begin{array}{l}|\mathrm{t}| \text {-Range } \\
(\mathrm{GeV} / \mathrm{c})^{2} \\
\end{array}$ & $\begin{array}{c}\text { Missing } \\
\text { Mass Range } \\
(\mathrm{GeV}) \\
\end{array}$ & $\begin{array}{c}\text { Experimental } \\
\text { Apparatus }\end{array}$ \\
\hline \multicolumn{5}{|l|}{$\begin{array}{l}\text { Note: } A=\text { nuclear } \\
\text { target }\end{array}$} \\
\hline \multicolumn{5}{|l|}{$\begin{array}{c}\text { Beam Particle } \\
\text { Dissociation } \\
\end{array}$} \\
\hline \multicolumn{5}{|l|}{$\mathrm{n}+\mathrm{A} \rightarrow\left(\pi^{-} \mathrm{p}\right)+\mathrm{A}$} \\
\hline $\begin{array}{l}\# 27 \mathrm{~A} \\
\text { and }\end{array}$ & $40-280$ & $\lesssim 0.3$ & $1.1-3$ & $\begin{array}{l}\text { forward multi- } \\
\text { particle spectrom- } \\
\text { eter }\end{array}$ \\
\hline \multicolumn{5}{|l|}{$\begin{array}{c}\# 305 \\
\left(A=p, d, H e^{4} \text { also }\right)\end{array}$} \\
\hline \multicolumn{5}{|l|}{$\pi+\mathrm{He}^{4} \rightarrow \pi^{\prime} \mathrm{s}+\mathrm{He}^{4}$} \\
\hline$\# 86 \mathrm{~A}$ & $100-200$ & $0.01-0.09$ & $1.1-5$ & $\begin{array}{l}\text { helium-filled } \\
\text { streamer chamber }\end{array}$ \\
\hline
\end{tabular}

Target Particle

Dissociation

$\left(\begin{array}{l}\pi^{ \pm} \\ K^{ \pm} \\ p^{ \pm}\end{array}\right)+p \rightarrow\left(\begin{array}{l}\pi^{ \pm} \\ K^{ \pm} \\ p^{ \pm}\end{array}\right)+X$

\#96

$50-175 \quad 0.02-0.8$

1. -8 .

single arm spectrometer

\#118A

$50,100,175$

$0.15-1.5$

1. -10 .

single arm spectrometer; observation of multiplicity of $\mathrm{X}$ 

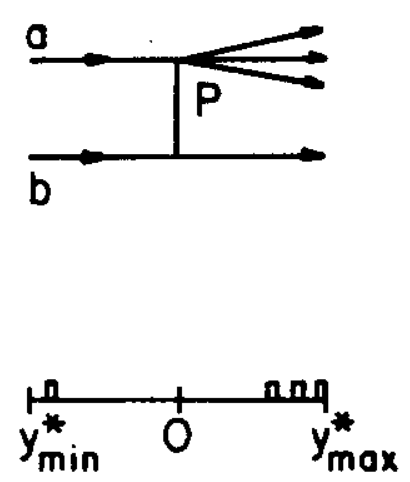

(a)
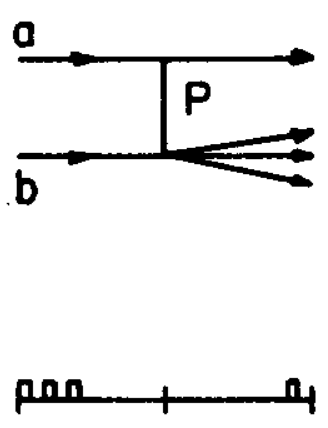

(b)
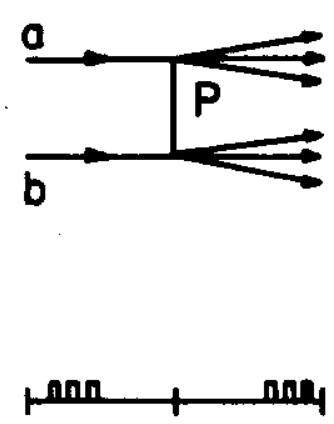

(c)

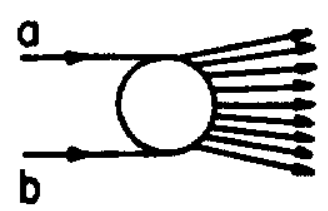

100enpaner

(d)

Fig. 6.1 Pictorial descriptions of production processes with characteristic rapidity distributions. $P$ indicates Pomeron exchange.

(a) Fragmentation of the beam particle, a.

(b) Fragmentation of the target, b.

(c) Double fragmentation of $a$ and $b$.

(d) Central collision production reaction. 


\section{MULTIPARTICLE EXPERIMENTS}

The group of experiments labeled somewhat arbitrarily as multi particle experiments covers a collection of various physics interests including both neutral and charged particle final states. The principal feature is the motivation to observe and study all final-state particles with a goal of separating and analyzing specific channels. We have separated this work into five categories. The diffraction dissociation experiments discussed in Section 6 might also be included here, but for the purpose of this analys is they are discussed separately. We shall mention a few of the features of the experiments in each of the five categories and then describe them further in Table 7.1.

\subsection{General Multiparticle Physics}

The multiparticle spectrometer associated with Experiment \#110A is a general purpose instrument. This specific experiment has a wide range of physics objectives, such as the study of the $s$-and t-dependences of the cross sections for peripheral processes, searches for new resonant states, measurement of $\pi-\pi$ and $K-\pi$ elastic and inelastic scattering, and a study of the properties of high multiplicity events. Experiment \#260, a study of large- $p_{t}$ phenomena, will utilize this facility with the addition of calorimeters. It is included under those experiments discussed below.

It is expected that eventually another general purpose multiparticle spectrometer may be available for studies of hadron interactions. This is the spectrometer incorporating the Chicago cyclotron magnet now used for exploring muon interactions (Experiment \#98). At present only one 
experiment with an incident hadron beam has been approved for that apparatus (Experiment \#331). This potential limited use does not yet permit its inclusion here.

\subsection{Photon Final States}

Some of the experiments designed to study reactions with multi-photon final states have as a possible objective the association of the photons with the annihilation of a monopole-antimonopole pair. This is one of the specific goals of Experiments \#22, \#192, and \#230. (Also see Section 13.1 and Table 13.1.) Another possibility is that high energy interactions might produce massive lepton pairs and massive photon pairs. Such is the physics interest of Experiments \#95A and \#192.

\subsection{Large $-\mathrm{p}_{\mathrm{t}}$ Phenomena}

The group of experiments designed to study large $-p_{t}$ phenomena are also referred to as "searches for hadron jets." The interest in this type of multiparticle physics has come from the experimental observation that inclusive cross sections do not decrease with increasing $p_{t}$ as rapidly above $p_{t} \approx 1.5 \mathrm{GeV} / \mathrm{c}$ as they do below. Explanations of this are varied but range from production of new particles to possible observation of parton-parton collisions. In some sense, these experiments are extensions of the ideas of the normal inclusive experiments described in Section 5 with emphasis on a specific kinematic region and interest in production of particles other than the leading one. 


\subsection{Dilepton Production}

As mentioned in Section 5, many of the experiments studying dilepton production are extensions of the work begun in examining single lepton production. The relatively large ratio of direct muon production to pion production $\left(\sim 10^{-4}\right)$, and its relatively constant value over a wide range of kinematic variables, is not understood. It is thought that it could arise from decays of vector mesons or more exotic particles such as the intermediate vector bosons, charmed particles, etc. (Section 13 should also be consulted as a cross reference.)

The recent discoveries, first at Brookhaven and SLAC and then at Frascati and DESY, of a number of neutral, narrow dilepton resonances $\left(\mathrm{e}^{+} \mathrm{e}^{-}, \mu^{+} \mu^{-}\right)$has produced new impetus in this area of research. Thus, the list of experiments of this type will most certainly grow in the next few months. It may be worthwhile to recall that at high energy the effective mass of a dilepton system is given by

$$
\mathrm{M}_{\ell^{+} \ell^{-}} \approx 4 \mathrm{p}_{\ell^{+}} \mathrm{p}_{\ell^{-}} \sin ^{2}\left(\theta_{\ell^{+} \ell^{-}}\right) / 2
$$

where $\theta_{\ell^{+} \ell^{-}}$is the angle between the two leptons and $p_{\ell^{+}}, p_{\ell^{-}}$are the momenta of the positively and negatively charged leptons respectively. In some experiments the angle, $\theta_{\ell^{+} \ell^{-}}$, is fixed by the position of the spectrometer arms and the effective mass distribution is measured as a function of the momenta of the outgoing leptons. In other experiments both leptons go through a single spectrometer at forward angles. 


\subsection{Miscellaneous}

The basic objectives of the experiments labeled miscellaneous appear adjacent to each entry. One of these includes a study of particle multiplicity from pions hitting nuclear targets (Experiment \#178), which is primarily a study of the early evolution of hadronic states. Another experiment (\#302) involves a test of charge conjugation using the reactions $\overrightarrow{p p} \rightarrow \pi^{ \pm}+X$, and Experiment $\# 357$ is a charmed particle search hoping to detect the reaction $p p \rightarrow C \bar{C}+X, C \rightarrow K \pi$ (where $C$ is a charmed particle). 
Table 7.1. Summary of Multiparticle Experiments.

Physics Emphasis and
Exp. Number Particle (GeT/c)

\section{In:irlent}

General Multi-

particle Physics

$\# 110 \mathrm{~A}$

$\pi$

$50-200$

300

$$
\text { \#22 }
$$

$\mathrm{p}$

300

\#95A

\#192

\#230

Large $-\mathrm{p}_{\mathrm{t}}$

$\underline{\text { Phenomena }}$

\begin{tabular}{|c|c|c|}
\hline$\# 236 \mathrm{~A}$ & $\pi, K, p$ & $20-280$ \\
\hline$\# 246$ & $\pi$ & 300 \\
\hline$\# 260$ & $\pi, p$ & $\sim 200$ \\
\hline
\end{tabular}

Dilepton

Production

$\# 87 \mathrm{~A}$
$\# 192$

\#288

$\# 305$ $\mathrm{p}$

$\mathrm{n}$

$40-280$ n $\quad 40-280$
Experimental

Apparatus general multiparticle spectrometer

sweeping magnets with lead converter and proportional wire chambers

100-400 lead glass counters

100-300 large aperture magnet with $\mathrm{NaI}(\mathrm{T} \ell$ ) absorption counters lead converter and wide-gap spark chambers

magnetic spectrometer with photon and hadron calorimeter

symmetric pair of calorimeters on either side of the beam

general multiparticle spectrometer with photon and hadron calorimeters

10-250 forward magnetic spectrometer 100-300 large aperture magnet with $\mathrm{NaI}(\mathrm{T} l)$ absorption counters double arm magnetic spectrometer 
Table 7.1. (continued)

Physics Emphasis and

Exp. Number

\#325

\# 331

\# 337

\# 358

\# 365

\# 366

Miscellaneous $\pi$

$\overline{\mathrm{p}}$

$\mathrm{p}$
Incident Beam Momentum Particle $(\mathrm{GeV} / \mathrm{c})$

p $\quad 100-400$

$\pi^{-}, \mathrm{p}$

$\mathrm{p}$

$\mathrm{n}$

$\pi^{-}$

$\mathrm{n}$

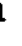

$40-280$

\section{Experimental}

Apparatus

single arm magnetic spectrometer with muon arm

50-300 large multiparticle spectrometer

two muon range telescopes

forward magnetic spectrometer

forward muon spectrometer

two particle mass focusing spectrometer

\# 302

\#357

300

100-175 multiplicity determination using Cerenkov pulse height

200 test of charge conjugation invariance using a double arm spectrometer

charmed particle search using two arm magnetic spectrometer with Cerenkov counters 


\section{HYPERON AND NEUTRAL KAON EXPERIMENTS}

The main aims of the two approved hyperon experiments are: i) the study of hyperon production (the survey part of the experiment); ii) the study of hyperon elastic scattering and of their total cross sections; iii) eventually, the study of some of their decay modes. One of the experiments (\#8) involves neutral hyperons, while the other (\#97) involves charged hyperons. The two experiments are located in the Meson Area, at the end of the M2 beam which will be used as a diffracted proton beam to transport fluxes of up to $10^{10}$ protons per pulse to the hyperon production target. This is immediately followed by a $30 \mathrm{kG}$ sweeping magnet with an insert used as a beam dump. The channel of the insert is straight for the neutral hyperon experiment and curved for charged hyperons. Charged hyperons are identified with gas differential Čerenkov counters, while neutral hyperons are identified in a $\mathrm{V}^{\mathrm{O}}$-spectrometer via their decay into charged particles. It should be noted that the neutral hyperon beam could also be used for $\mathrm{K}_{\mathrm{S}}{ }^{\mathrm{O}}$ physics.

The $\mathrm{K}_{\mathrm{L}}{ }^{\circ}$ physics at Fermilab is presently done in the M4 beam of the Meson Area. Because of the relatively large production angle $(7.5 \mathrm{mrad})$ the neutral kaon portion of the beam is enhanced somewhat to a level of about one kaon to six neutrons; furthermore, the length of the beam $(1,600$ feet) insures that no $\mathrm{K}_{\mathrm{S}}{ }^{\circ}$ are present. So far only two experiments have been approved for that beam line, both using apparatus consisting of a $\mathrm{V}^{\mathrm{O}}$ spectrometer with wire spark chambers and a magnet. The main aim of the two experiments is the study of $\mathrm{K}_{\mathrm{S}}{ }^{\circ}$ regeneration in vacuum, carbon, polyethylene, by electrons, etc. Ancillary measurements will yield information on $\sigma_{\text {tot }}\left(K_{L}{ }^{\circ} \mathrm{A}\right)$ and on the differential cross section for $K_{L}{ }^{o} p \rightarrow K_{L}{ }^{o}$. 
Table 8.1 describes briefly the approved hyperon and neutral kaon experiments. 
Table 8.1. Summary of Hyperon and Neutral Kaon Experiments.

\begin{tabular}{|c|c|}
\hline $\begin{array}{l}\text { Particle Type } \\
\text { and } \\
\text { Exp. Number }\end{array}$ & Major Physics Emphasis \\
\hline $\begin{array}{c}\text { Neutral Hyperons } \\
\quad \# 8\end{array}$ & $\begin{array}{l}\text { survey of neutral hyperon production and } \\
\text { decay; measurement of } \Lambda-N \text { total and } \\
\text { diffraction elastic scattering cross sections }\end{array}$ \\
\hline $\begin{array}{c}\text { Charged Hyperons } \\
\# 97\end{array}$ & $\begin{array}{l}\text { survey of charged hyperon production and } \\
\text { decay; measurement of small angle hyperon } \\
\text { elastic scattering }\end{array}$ \\
\hline $\begin{array}{c}\text { Neutral Kaons } \\
\# 82\end{array}$ & $\begin{array}{l}\text { measurement of } \mathrm{K}_{\mathrm{S}}^{\mathrm{O}} \text { regeneration in vacuum, } \\
\text { carbon, and } \mathrm{CH}_{2} \text {; ancillary measurements of } \\
\sigma_{\text {tot }}\left(\mathrm{K}_{\mathrm{L}}{ }^{\mathrm{O}} \mathrm{A}\right), \mathrm{d \sigma} / \mathrm{dt}\left(\mathrm{K}_{\mathrm{L}}{ }^{\mathrm{O}} \mathrm{p} \rightarrow \mathrm{K}_{\mathrm{S}}^{\mathrm{O}} \mathrm{p}\right)\end{array}$ \\
\hline $\begin{array}{c}\text { Neutral Kaons } \\
\# 226\end{array}$ & 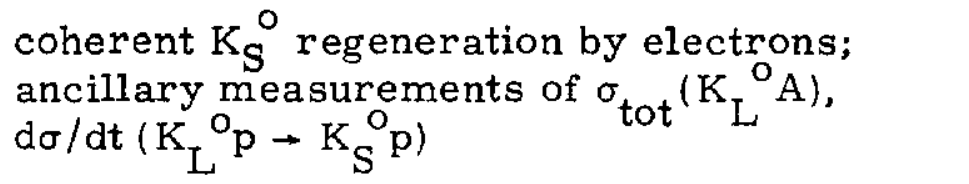 \\
\hline
\end{tabular}




\section{HADRON INTERACTIONS IN BUBBLE CHAMBERS}

Two bubble chambers are in operation at the Laboratory. One is the 30-in. chamber with associated hybrid systems. The other is the recently completed $15-\mathrm{ft}$ chamber.

The first physics studies were done in the 30-in. bubble chamber filled with hydrogen and exposed to $200-\mathrm{GeV}$ protons. Approximately 0.2 million pictures were taken with several incident beams during the first year of operation (June, 1972 - June, 1973) and about one million additional pictures were taken during the second year (June, 1973 - June, 1974). Much of this increase in picture-taking was due to improvements in the accelerator operation and to the acquired ability to send up to four fast beam pulses to the bubble chamber during each 7-sec accelerator cycle.

The hadron beams to the bubble chambers are capable of operating at energies up to $400 \mathrm{GeV} / \mathrm{c}$. A beam tagging system is in operation in the $30-\mathrm{in}$. beam line and a similar one is being built for the 15-ft line. This system provides for identification of each beam particle sent to the bubble chamber. The information available from the computer includes the incident particle's position, direction, and momentum as derived from a set of upstream proportional wire chambers. Particle identification is performed with a differential Čerenkov counter. The computer also records whether the beam particle has triggered the downstream hybrid spectrometer system or penetrated a thick muon identifier beyond.

Some methods have been introduced for enriching the fraction of wanted particles in the bubble-chamber beams. For example, in the two $200 \mathrm{GeV} / \mathrm{c}$ 
$\pi^{+}$exposures in the $30-$ in. chamber a water filter in the beam was utilized to enhance the $\pi^{+}$(and $\mathrm{K}^{+}$) content with respect to the protons. This is done using the fact that the $\mathrm{pN}$ total cross section is much larger than the $\pi^{+} \mathrm{N}$ (and $\mathrm{K}^{+} \mathrm{N}$ ). Other methods, including retargeting of secondary particles or using decay products, are being studied for enhancing the fluxes of $\bar{p}$ and $\mathrm{K}^{-}$ for future experiments. These techniques, if successful, are expected to be available for use in the beam lines to both bubble chambers.

Presently there are available for the 30-in. bubble chamber two distinctly different hybrid systems, one involving proportional wire chambers and the other using optical wide-gap spark chambers. These systems are presently maintained and operated by the groups that constructed them (Experiments \#2B and \#154), although they are frequently utilized by other experiments through special arrangements. Both hybrid systems utilize the bubble chamber fringe field and the relatively long lever arm to gain additional momentum and directional accuracy. The bare bubble chamber has a momentum resolution of $\pm 10 \%$ for secondary particles of $15 \mathrm{GeV} / \mathrm{c}$, which means that in a typical $100 \mathrm{GeV} / \mathrm{c}$ exposure one can momentum analyze only the particles produced in the backward hemisphere. The addition of the hybrid system brings in an improvement of about a factor of seven, allowing momentum measurements of leading particles near $200 \mathrm{GeV} / \mathrm{c}$ with errors of about $\pm 10 \%$. The hybrid systems also use lead converters between the last two sets of chambers, allowing the detection of forward-going gamma rays and thus permitting study of reactions involving $\pi^{\circ}$ !s. 
Early bubble-chamber experiments were capable of yielding quickly the main features of strong interactions in the new high-energy domain opened up by the Fermilab accelerator. This information concerned total cross sections, differential elastic scattering, charged multiplicity, moments of the multiplicity distribution, and some inclusive cross sections. Many of these early results are now superseded by higher statistics data from counter experiments. Nevertheless, the bubble chamber plays a major role in some specific studies, among which one may single out the following:

(i) Study of the average charge multiplicity and of the higher moments of the multiplicity distribution for different incident particles at different momenta.

(ii) Study of some specific subjects connected with the multiplicities of charged particles, like Koba-Nielsen-Olesen (KNO) scaling usually expressed as:

$$
\frac{\langle\mathrm{n}\rangle \sigma_{\mathrm{n}}}{\sigma_{\text {inel }}}=\mathrm{f} \frac{\mathrm{n}}{\langle\mathrm{n}\rangle} .
$$

That is, the quantity $<n>\sigma_{n} / \sigma_{\text {inel }}$ is a function only of $n /<n>$ and is thus independent of energy. ( $\mathrm{n}$ is the number of charged particles from an inelastic reaction, and $\sigma_{n}$ and $\sigma_{\text {inel }}$ are the total n-particle and inelastic cross sections respectively.)

(iii) Study of the inclusive production of short-lived neutral and charged particles, like $\mathrm{K}^{\circ}, \Lambda^{\circ}, \bar{\Lambda}^{\circ}$, etc.

(iv) Study of some exclusive channels such as $\pi^{-} \mathrm{p} \rightarrow \pi^{-} \mathrm{p}^{-} \pi^{+}$.

(v) Study of some diffractive phenomena. 
(vi) Study of various types of correlations. These range from charge-charge correlations to $\mathrm{p}_{\mathrm{t}}$ - and rapidity-correlations for inclusive and semi-inclusive processes.

(vii) Study of factorization properties when changing the incident beam particle.

(viii) Study of resonance production $\left[\Delta(1236), \rho, A_{1}, A_{2}\right]$.

Tables 9.1 and 9.2 summarize the approved exposures for the 30 -in. and 15-ft chambers respectively. The 15-ft hadron program is a newly emerging one. The engineering run (Experiment \#234) has been completed and only a few additional experiments have been approved. The primary 15-ft activity for the near future will be the neutrino program for which it was specifically built (see Table 12.2).

Figure 9.1 is representative of some of the early results from the 30 -in. bubble-chamber research. It suggests a functional form for the charged prong ratio, $\mathrm{n} /<\mathrm{n}>$ when plotted against $<\mathrm{n}>\sigma_{\mathrm{n}} / \sigma_{\text {inel }}$. This function is independent of energy as shown by the data from pp collisions at different energies, suggesting KNO scaling. 
Table 9.1. Summary of 30-In. Bubble-Chamber Experiments.

Note: Typical exposures are for 50,000-100,000 pictures. One of the two hybrid systems is used during most of the exposures.

Incident

Particle and

Momentum

Hydrogen Fill

Deuterium Fill

Hydrogen and

Ne on Fill

$(\mathrm{GeV} / \mathrm{c})$ Experiment Number Experiment Number Experiment Number

\section{Protons}

$100 \quad \# 252 \quad$ \#194

$200 \quad \# 2 \mathrm{~B}, \# 141 \mathrm{~A}$ \#280

$300 \quad \# 2 \mathrm{~B}, \# 37 \mathrm{~A}$

\#161

400

\#138

\#196

500

\# 207

$\pi^{+}$(with

protons)

$60 \quad$ \#228

100

\# 2B, \#121A

150

\#299

200

\# 217

\#295

300

\# 277

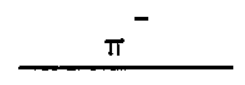

100

\# 2B, \#125

150

\#154, \#299

200

\#2B, \#137

$\# 218$

\#163A

300

\#143A, \#281

400

\#215

\#338

$\overline{\mathrm{p}}$

40

\# 344

100

\#311

\# 345 
Table 9.2. Summary of 15-Ft Bubble-Chamber Hadron Experiments.

Note: Typical exposures are for $25,000-50,000$ pictures.

Incident Particle and Momentum $(\mathrm{GeV} / \mathrm{c})$

Protons

300

$\underline{\pi^{+} \text {(with protons) }}$

150

$\pi$

100

200

250
Hydrogen Fill

Experiment Number

\#343

\#341

\#83A

234
Hydrogen and

Neon Fill

Experiment Number 


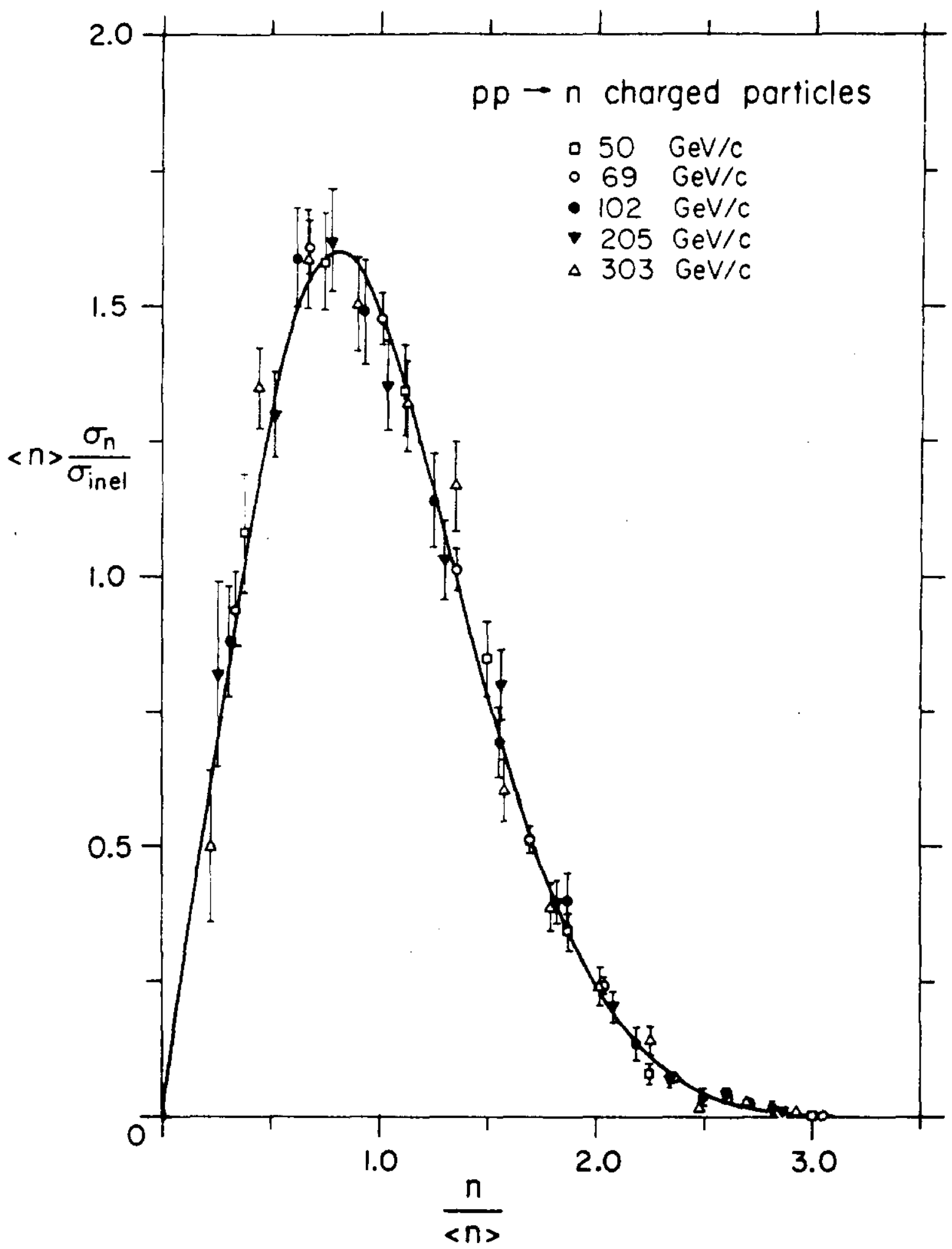

Fig. 9.1 Bubble chamber data on $p-p$ interactions suggesting KobaNielsen-Olesen (KNO) scaling behavior. The curve is an empirical fit to the data. The points at 50 and $69 \mathrm{GeV} / \mathrm{c}$ are from data obtained with the Mirabelle chamber at Serpukhov, while the other data were obtained using the 30 -inch bubble chamber. From Physical Review Letters 29, 1624 (1972). 


\section{ELECTROMAGNETIC INTERACTIONS INITIATED BY PHOTONS AND ELECTROMAGNETIC RADII}

\subsection{Photoproduction Experiments}

The approved photoproduction experiments use either a tagged or a broad band untagged photon beam. The first is a multistage beam $\left(\pi^{\circ} \rightarrow \gamma \rightarrow e \rightarrow \gamma\right)$ while the second is a simpler beam obtained directly from the $\gamma$-decays of $\pi^{\circ}$ 's followed by filtering out the neutrons.

A measurement of the total cross section for the photoproduction of hadrons (Experiment \#25A) will use the tagged photon beam. It is a classical type of total cross section measurement for neutral particles where one measures:

(i) the incoming fluxes of photons of known energy, and

(ii) the number of interactions leading to hadrons.

Two other experiments that will use the tagged photon beam will study elastic and inelastic Compton scattering and $\phi$ photoproduction in a two-body reaction (Experiments \#152B and \#263 respectively).

Using the broad band photon beam, Experiment \#87A measures the general features of photoproduction phenomena at high energies and forward angles and also some specific items like the direct production of lepton pairs (see Section 7). Their work will also include a systematic search for $J^{P}=1^{-}$ boson resonances, which should be directly coupled to the photon.

These experiments are summarized in Table 10.1.

\subsection{Electromagnetic Radii}

The electromagnetic radius of a particle, "a, " may be determined from a measurement of its elastic scattering with electrons: 


$$
a+e^{-} \rightarrow a+e^{-}
$$

In such a case the measured cross section deviates from the electromagnetic cross section due to point scattering:

$$
\left(\frac{\mathrm{d} \sigma}{d q^{2}}\right)_{\text {measured }}=\left(\frac{\mathrm{d} \sigma}{d q^{2}}\right)_{\substack{\text { point } \\ \text { charge }}} \times \mathrm{F}_{\mathrm{a}}{ }^{2},
$$

where for small $q^{2}(=-t)$,

$$
\mathrm{F}_{\mathrm{a}}^{2} \approx\left[1+\frac{1}{6} \mathrm{q}^{2}<\mathrm{r}_{\mathrm{a}}^{2}>\right]^{-2}
$$

The objective of this type of experiment is the determination of the effective radius of particle "a, " $<\mathrm{r}_{\mathrm{a}}{ }^{2}>$.

In Experiment \#216 measurements will be made of $\pi^{-}-e^{-}$and $\mathrm{K}^{-}-\mathrm{e}^{-}$ elastic scattering. It is planned to determine the effective pion radius to a precision of a few per cent and the effective kaon radius to $\pm 20 \%$. The incident beam energy is expected to be $100 \mathrm{GeV}$ and measurements will be confined to $\mathrm{q}^{2}(=-\mathrm{t})<0.086(\mathrm{GeV} / \mathrm{c})^{2}$ using a hydrogen target.

A more difficult measurement is that to determine the electromagnetic radius of the $\mathrm{K}^{\circ}$. For this one studies the reaction:

$$
\mathrm{K}_{\mathrm{L}}^{\mathrm{o}}+\mathrm{e}^{-} \rightarrow \mathrm{K}_{\mathrm{S}}^{\circ}+\mathrm{e}^{-}
$$

Such a study is planned in Experiment \#226 involving measurement of coherent regeneration of $\mathrm{K}_{\mathrm{S}}{ }^{\mathrm{O}}$ by electrons using a spectrometer to detect the decay $\mathrm{K}^{\mathrm{O}} \rightarrow \pi^{+} \pi^{-}$(also see Section 8 ).

Table 10.2 is a summary of the experiments to measure electromagnetic radii. 


$$
-65-
$$

Table 10.1. Summary of Photoproduction Experiments.

\begin{tabular}{|c|c|c|c|c|}
\hline $\begin{array}{l}\text { Type of Beam } \\
\text { and } \\
\text { Exp. Number }\end{array}$ & Reaction & $\begin{array}{l}\text { Incident } \\
\text { Photon } \\
\text { Energy } \\
(\mathrm{GeV}) \\
\end{array}$ & $\begin{array}{l}|\mathrm{t}| \text {-Range } \\
(\mathrm{GeV} / \mathrm{c})^{2} \\
\end{array}$ & $\begin{array}{c}\text { Experimental } \\
\text { Apparatus }\end{array}$ \\
\hline Tagged y & $\begin{array}{l}\text { Note: A=heavy } \\
\text { nucleus }\end{array}$ & & & \\
\hline$\# 25 \mathrm{~A}$ & $\begin{array}{l}\sigma_{\text {tot }}: \\
\gamma p \rightarrow \text { hadrons } \\
\gamma d \rightarrow \text { hadrons } \\
\gamma A \rightarrow \text { hadrons }\end{array}$ & $60-250$ & - & $\begin{array}{l}\text { hadron counters } \\
\text { and lead glass } \\
\text { shower detectors }\end{array}$ \\
\hline$\# 152 B$ & $\begin{aligned} \gamma p & \rightarrow \gamma p \\
& \rightarrow \gamma \text { thadrons }\end{aligned}$ & $20-250$ & - & $\begin{array}{l}\text { forward shower } \\
\text { spectrometer } \\
\text { and recoil } \\
\text { detectors at } \\
\text { large angles }\end{array}$ \\
\hline$\# 263$ & $\mathrm{\gamma p}^{\rightarrow} \underset{\phi \rightarrow \mathrm{K}^{+} \mathrm{K}^{-}}{\phi}$ & $20-195$ & $0-2$. & $\begin{array}{l}\text { forward magnetic } \\
\text { spectrometer }\end{array}$ \\
\hline \multicolumn{5}{|l|}{ Untagged $Y$} \\
\hline$\# 87 \mathrm{~A}$ & $\begin{array}{l}\gamma \mathrm{A} \rightarrow \text { bosons }+X \\
\left(\text { bosons with } \mathrm{J}^{\mathrm{P}}=1^{-} \text {) }\right. \\
\gamma \mathrm{A} \rightarrow \ell^{+} \ell^{-} \mathrm{X} \\
(\ell=\text { lepton) }\end{array}$ & $10-250$ & - & $\begin{array}{l}\text { forward magnetic } \\
\text { spectrometer }\end{array}$ \\
\hline
\end{tabular}


Table 10.2. Summary of Experiments on Electromagnetic Radii.

\begin{tabular}{|c|c|c|c|}
\hline $\begin{array}{c}\text { Reaction } \\
\text { and } \\
\text { Exp. Number }\end{array}$ & $\begin{array}{c}\text { Incident } \\
\text { Momentum } \\
(\mathrm{GeV} / \mathrm{c}) \\
\end{array}$ & $\begin{array}{l}|t|-\text { Range } \\
(\mathrm{GeV} / \mathrm{c})\end{array}$ & $\begin{array}{l}\text { Experimental } \\
\text { Apparatus }\end{array}$ \\
\hline $\begin{array}{l}\pi^{-} \mathrm{e}^{-} \rightarrow \pi^{-} \mathrm{e}^{-} \\
\mathrm{K}^{-} \mathrm{e}^{-} \rightarrow \mathrm{K}^{-} \mathrm{e}^{-} \\
\# 216 \text { (tests) }\end{array}$ & 100 & $<0.086$ & $\begin{array}{l}\text { forward magnetic } \\
\text { spectrometer }\end{array}$ \\
\hline $\begin{array}{c}\mathrm{K}_{\mathrm{L}}^{\mathrm{o}} \mathrm{e}^{-} \rightarrow \mathrm{K}_{\mathrm{S}}^{\mathrm{o}} \mathrm{e}^{-} \\
\# 226\end{array}$ & $30-120$ & $<0.01$ & $\begin{array}{l}\text { magnetic spectrometer to } \\
\text { detect } \mathrm{K}^{\mathrm{O}} \rightarrow \pi^{+} \pi^{-} \text {decay }\end{array}$ \\
\hline
\end{tabular}




\section{FLECTROMAGNETIC INTERACTIONS INITLATED BY MUONS}

The present effort in muon experiments at Fermilab is concentrated on the study of inclusive reactions at large transverse momenta (deep inelastic scattering) and in exploratory measurements of the produced hadrons.

Using the notation of Table 5.1, the double differential cross section for lepton-hadron deep inelastic scattering may be written as:

$$
\frac{d^{2} \sigma}{d \Omega d E^{\prime}}=\frac{4 \alpha^{2} E^{\prime 2}}{q^{4}}\left(2 W_{1} \sin ^{2} \frac{\theta}{2}+W_{2} \cos ^{2} \frac{\theta}{2}\right)
$$

Generally, the $W_{1}$ and $W_{2}$ structure functions depend on $q^{2}$ and $v$. However, in the one photon exchange approximation, scale invariance requires that as $v$ and $\mathrm{q}^{2}$ become large enough (the Bjorken limit), $\mathrm{W}_{1}$ and $\mathrm{W}_{2}$ depend only upon a single dimensionless variable, $\omega=2 \mathrm{~m}_{\mathrm{p}}{ }^{\nu} / \mathrm{q}^{2} \cdot \mathrm{W}_{1}$ is proportional to the cross section for virtual photons with transverse polarization, while $\mathrm{W}_{2}$ is proportional to the sum of the cross sections for both transverse and longitudinal polarizations. A separation of $W_{1}$ and $W_{2}$ is equivalent to a separation of the se two cross sections. Measurements at small $\mathrm{q}^{2}$ allow an evaluation of $\sigma_{\text {tot }}(\gamma p)$ for real photons by performing an appropriate extrapo1ation.

Experiment \#26 studies the classical deep inelastic (inclusive) reaction

$$
\mu^{+}+\mathrm{Fe} \rightarrow \mu^{+}+\mathrm{X}
$$

at as high a $\mathrm{q}^{2}$ as possible. For this purpose they use a long heavy target followed by an iron magnet. Besides comparing their results to the predictions of Eq. (11.1) using the structure functions determined in $\mathrm{e}-\mathrm{d}$ deep 
inelastic experiments at SLAC, they compare directly their own data at different energies. These data are obtained with a configuration of "geometrical scaling" of their apparatus, such that one can compare directly the experimental distributions and ascertain any violations of scale invariance. Experiment \# 98 has a 1.2-m liquid hydrogen (and deuterium) target, a large forward magnetic spectrometer (using the magnet of the former University of Chicago cyclotron), a forward $\gamma$-ray detector, and a muon identifier. The equipment, triggered by muons which have lost energy in the scattering process, yields data on many exclusive processes at small $\mathrm{q}^{2}$ values, including $\mu \mathrm{e} \rightarrow \mu \mathrm{e}$ scattering, as well as data on inclusive and semiinclusive processes. One of the main features of this apparatus is that it is possible also to make a partial study of the final state hadrons.

The ranges of variables (incident energy, $E_{0}$, energy loss, $v$, and four momentum transfer squared, $q^{2}$ ) covered by the two experiments are summarized in Table 11.1 and illustrated in Fig. 11.1 together with neutrino experiments. 
Table 11.1. Summary of Muon Experiments.

\begin{tabular}{|c|c|c|c|}
\hline $\begin{array}{c}\text { Reaction and } \\
\text { Experiment Number }\end{array}$ & $\begin{array}{l}\text { Incident } \\
\text { Energy } \\
(\mathrm{GeV}) \\
\end{array}$ & $\begin{array}{l}\text { Ranges of } \\
\text { Variables }\end{array}$ & $\begin{array}{c}\text { Experimental } \\
\text { Apparatus }\end{array}$ \\
\hline$\mu^{+}+\underset{\# 26}{\rightarrow \mu^{+}}+x$ & 56,150 & $\begin{array}{c}1<\mathrm{q}^{2}<80(\mathrm{GeV} / \mathrm{c})^{2} \\
v<150 \mathrm{GeV}\end{array}$ & $\begin{array}{l}\text { heavy nuclear target } \\
\text { and } \mu \text {-spectrometer }\end{array}$ \\
\hline $\begin{array}{c}\mu^{+} p \rightarrow \mu^{+}+(\text {observed } X) \\
\mu^{+} d \rightarrow \mu^{+}+(\text {observed } X) \\
\# 98\end{array}$ & 100,150 & $\begin{array}{c}0.5<\mathrm{q}^{2}<30(\mathrm{GeV} / \mathrm{c})^{2} \\
20<v<80 \mathrm{GeV}\end{array}$ & $\begin{array}{l}\mathrm{H}_{2}\left(\mathrm{D}_{2}\right) \text { target; final } \\
\text { state particles } \\
\text { measured using } \\
\text { large aperture spec- } \\
\text { trometer }\end{array}$ \\
\hline
\end{tabular}




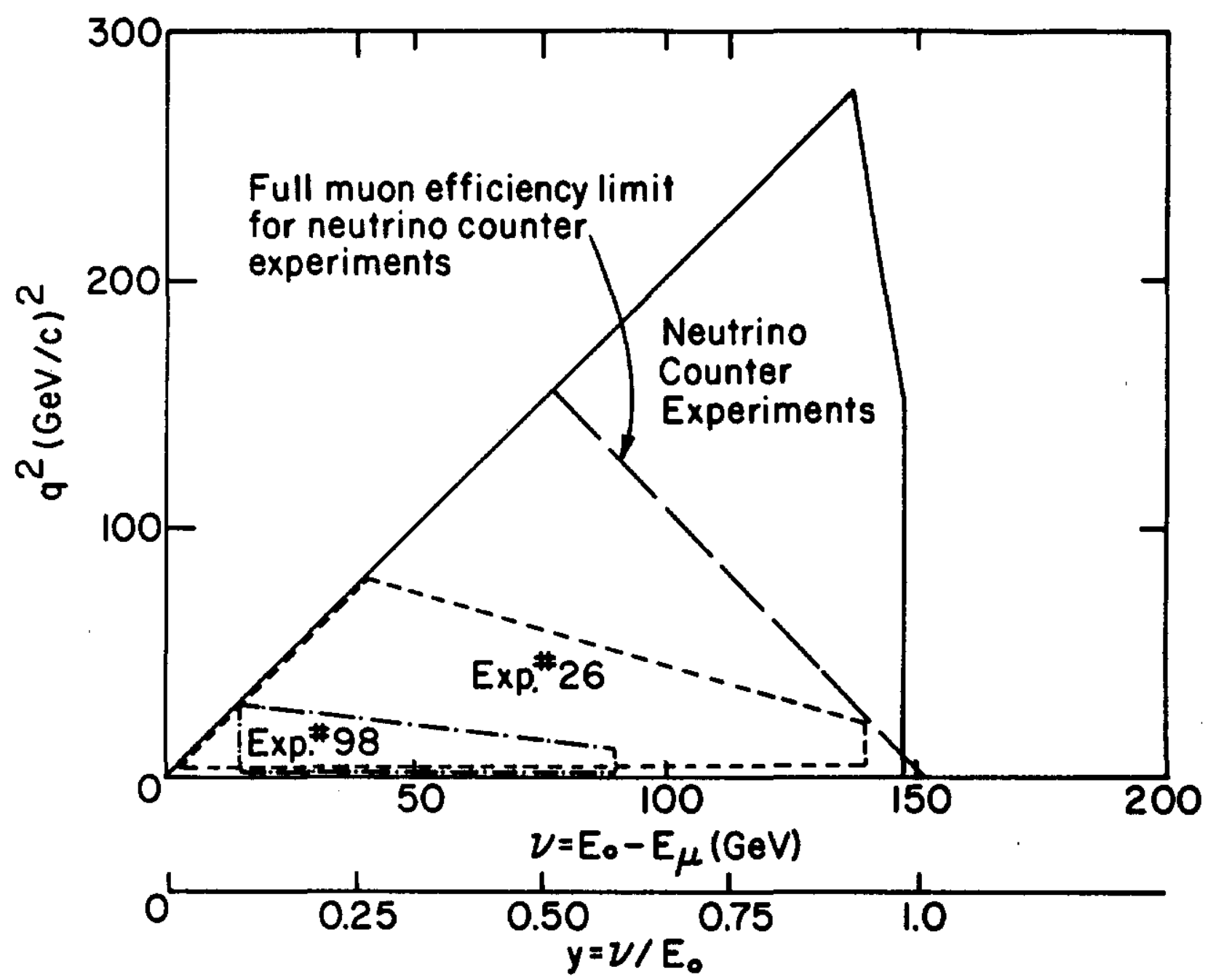

Fig. 11.1 Ranges of $\mathrm{q}^{2}, \nu$ for inclusive lepton-hadron interactions. 


\section{WEAK INTERACTION EXPERIMENTS}

This section will be confined to neutrino physics, although some information on weak interactions will likely come also from studies of the decays of hyperons and kaons (see Section 8).

The Fermilab facilities are extremely well suited to studies of neutrino interactions. The principal advantages are the high energy of the accelerator (up to $400 \mathrm{GeV}$ ) and the high beam intensities (over $10^{13}$ protons/pulse). The intensity is an obvious factor when dealing with rare interactions but the high energy is also a great help since the neutrino total cross section varies linearly with energy up to the highest energies measured so far $(\sim 150 \mathrm{GeV})$.

The basic neutrino experimental facilities consist of two large electronic detectors with hadron calorimeters and muon magnetic spectrometers. The calorimeter normally serves as a target and as a detector of the energy of the produced hadrons. It is usually capable of making energy measure ments with a resolution of approximately 15-30\% (half-width). The muon spectrometer is used to identify the secondary muon in charged current interactions and to measure its momentum to an accuracy of approximately $\pm 15-20 \%$. Hence, the neutrino energy, $E_{0}=E_{\mu}+E_{\text {hadrons }}$ is usually known to approximately $\pm 20-30 \%$. A recent feature has been the observation of neutral current events without secondary muons. In this case one is forced to rely more heavily on the hadron calorimeter information, and it is also very useful to determine the neutrino energy from its source, for example using dichromatic focusing where there is momentum selection of secondary pions and kaons before decay into neutrinos. These electronic experiments are 
described in Table 12.1. The ranges of kinematic variables are illustrated in Fig. 11.2 together with muon experiments. Note that high $\mathrm{q}^{2}$-values are easier to obtain with neutrino experiments since there is no $1 / q^{4}$ factor from the photon propagator in the expression for the differential cross section (comparing Eq. (11.1) with a similar expression for neutrino production].

The 15-ft bubble chamber was recently brought into operation, and it is expected that this will become a primary tool for the study of neutrino interactions. Experiments have already been approved for hydrogen and for neon/ hydrogen fills of the chamber, and there are future possibilities for using deuterium and track-sensitive targets. The bubble chamber is supplemented by an external muon identifier made of metallic absorbers and proportional wire chambers. The presently approved 15 -ft bubble chamber experiments are shown in Table 12.2.

The present neutrino beams in use are the wide band and dichromatic beams. Others are also available using the bare target or a quadrupole focusing triplet. For descriptions of these beams see the "Design Description of the External Experimental Areas at the Fermi National Accelerator Laboratory, "July, 1974, by T. E. Toohig.

We shall concentrate on three aspects of neutrino physics, which for the present moment are interesting because of the newness of the observations. Further aspects connected with new particle searches, specifically $W^{ \pm}, W^{\circ}$, heavy leptons, dilepton, and trilepton final states, will be dis cussed in Section 13. 


\subsection{Total Cross Section Measurements}

Table 2.1 describes the experiments capable of contributing to these measurements. Present experiments are limited to accuracies of about $\pm 20 \%$, primarily due to systematic uncertainties. It is hoped that future experiments will be able to perform measurements at the \pm 5 to $\pm 10 \%$ level. The major features of the results are: i) the linearity of the total cross section with neutrino energy, and ii) the ratio of the antineutrino to neutrino total cross sections of about 1/3. See Fig. 2.3 for a compilation of recent results.

\subsection{Inclusive or Deep Inelastic Measurements}

From a series of assumptions about the form of the weak interaction, namely i) the scaling hypothesis for hadron coupling, ii) that nucleons consist predominantly of spin $-1 / 2$ fermion constituents, and iii) there exists maximal V-A interference, one obtains the following expressions for the differential cross sections:

$$
\begin{aligned}
& \left(\frac{\mathrm{d}^{2} \sigma}{\mathrm{dxdy}}\right)_{\nu N} \approx \frac{\mathrm{G}^{2} \mathrm{~m}_{N^{2}} \mathrm{E}_{\nu}}{\pi} \mathrm{F}_{2}(\mathrm{x}) \\
& \left(\frac{\mathrm{d}^{2} \sigma}{\mathrm{dxdy}}\right)_{\overline{\nu N}} \approx \frac{\mathrm{G}^{2} \mathrm{~m}_{N^{2}} \mathrm{E}_{\nu}}{\pi}(1-y)^{2} \mathrm{~F}_{2}(\mathrm{x}) .
\end{aligned}
$$

Most of the variables are defined in Table 5.1. Other variables are $G$, the coupling constant at the hadron vertex, and $\mathrm{F}_{2}(\mathrm{x})$, one of the structure functions describing the hadron vertex. $F_{2}(x)$ can be taken from measurements of e-d scattering. 


\subsection{Studies of Neutral Current Events}

Until recently when one referred to neutrino or antineutrino inter actions it was thought that $\mathrm{a}_{\mu}{ }^{-}$or $\mu^{+}$always accompanied the reaction. Now it has been observed that in about $15 \%$ and $30 \%$ of the events (for $v$ and $\bar{v}$ respectively), interactions occur where a charged lepton is not seen, but instead the $v$ or $\bar{v}$ keeps its identity. The existence of these events places further demands on the detection systems and complications on the analysis. For example, the determination of total cross sections will likely now be done in two pieces, one for charged current cross sections and the other for neutral currents. Much more effort will now be required in a careful determination of the secondary hadron energy and in knowing the energy of the incident $v$ or $\bar{v}$. 
Table 12.1. Summary of Electronic Neutrino Experiments.

\begin{tabular}{|c|c|c|c|c|c|}
\hline $\begin{array}{c}\text { Exp. Number } \\
\text { and } \\
\text { Stage of } \\
\text { Development }\end{array}$ & \multirow[t]{2}{*}{$\begin{array}{l}\text { Type of } \\
\text { Focusing } \\
\text { System } \\
\text { and } \\
\text { Beam Spill } \\
\end{array}$} & $\begin{array}{l}\text { Desc } \\
\text { Effective } \\
\text { Calorimeter } \\
\text { Size } \\
\text { (Metric Tons) } \\
\end{array}$ & $\begin{array}{l}\text { Calorimeter } \\
\text { Description }\end{array}$ & \multirow[t]{2}{*}{$\begin{array}{c}\text { Muon } \\
\text { Spectrometer } \\
\text { Description } \\
\end{array}$} & \multirow[t]{2}{*}{$\begin{array}{c}\text { Major } \\
\text { Physics } \\
\text { Emphasis } \\
\end{array}$} \\
\hline & & & $\begin{array}{l}\text { Note: } S C=\text { Spark } \\
\text { Chambers }\end{array}$ & & \\
\hline \multicolumn{6}{|l|}{ Wonder Building } \\
\hline $\begin{array}{l}\text { \#21A - Phase I } \\
\text { (Before } 1 / 74 \text { ) }\end{array}$ & $\begin{array}{c}\text { Narrow } \\
\text { Band } \\
\text { (slow spill) }\end{array}$ & $\sim 140$ tons & $\begin{array}{l}80 \text { liquid } \\
\text { scint. counters } \\
5-\mathrm{ft} \text { square } \\
4-\text { in. steel } \\
\text { SC: every } 4 \text { th }\end{array}$ & $\begin{array}{l}\text { magnet: } \\
5-\mathrm{ft} \text { diam. } \\
8-\mathrm{ft} \text { of iron } \\
16 \mathrm{kG} \\
\mathrm{SC}: \\
5-\mathrm{ft} \text { square }\end{array}$ & $\begin{array}{l}\text { general features of } \nu \\
(\bar{v}) \text { interactions with } \\
\text { emphasis on total } \\
\text { cross sections }\end{array}$ \\
\hline $\begin{array}{l}\# 21 A \text { - Phase II } \\
(1 / 74 \text { - Present })\end{array}$ & $\begin{array}{l}\text { Narrow } \\
\text { Band } \\
\text { (slow spill) }\end{array}$ & -120 tons & $\begin{array}{l}70 \text { liquid } \\
\text { scint. counters } \\
5-\mathrm{ft} \text { square } \\
4-\text { in. steel } \\
\text { SC: every } 2 \text { nd }\end{array}$ & $\begin{array}{l}\text { same but } \\
\text { SC: } \\
5 \mathrm{ft} \times 10 \mathrm{ft} \\
\text { and } \\
10 \mathrm{ft} \times 10 \mathrm{ft}\end{array}$ & $\begin{array}{l}\text { general features of } v \\
(\bar{v}) \text { interactions with } \\
\text { emphasis on total } \\
\text { cross sections }\end{array}$ \\
\hline$\# 254$ & $\begin{array}{l}\text { Narrow } \\
\text { Band } \\
\text { ( slow spill) }\end{array}$ & \multicolumn{3}{|c|}{$\begin{array}{l}\text { Same as present version } \\
\text { of apparatus for Exp. \#21A. }\end{array}$} & $\begin{array}{l}\text { search for a second } \\
\text { muon neutrino by } \\
\text { measuring the ratio of } \\
\text { total cross sections for } \\
\pi \text { and } K \text { produced } \\
\text { neutrinos }\end{array}$ \\
\hline$\# 262$ & $\begin{array}{c}\text { Narrow } \\
\text { Band } \\
\text { (fast spill) }\end{array}$ & \multicolumn{3}{|c|}{$\begin{array}{l}\text { Same as present version } \\
\text { of apparatus for Exp. \#21A. }\end{array}$} & $\begin{array}{l}\text { investigation of neutral } \\
\text { current events }\end{array}$ \\
\hline$\# 320$ & $\begin{array}{c}\text { Narrow } \\
\text { Band } \\
\text { (fast spill) }\end{array}$ & \multicolumn{3}{|c|}{$\begin{array}{l}\text { Same as present version } \\
\text { of apparatus for Exp. \#21A. }\end{array}$} & $\begin{array}{l}\text { study of neutral } \\
\text { current events }\end{array}$ \\
\hline \multicolumn{6}{|l|}{ New Laboratory E } \\
\hline$\# 356$ & $\begin{array}{l}\text { New Narrow } \\
\text { Band } \\
\text { (fast spill) }\end{array}$ & $\sim 140$ tons & $\begin{array}{l}80 \text { liquid } \\
\text { scint. counters } \\
5 \text {-ft square } \\
4-\text { in. steel } \\
\text { SC: every } 2 \text { nd }\end{array}$ & $\begin{array}{l}\text { two magnets, } \\
\text { each: } \\
11.5-\mathrm{ft} \text { diam. } \\
8 \mathrm{ft} \text { of iron } \\
19 \mathrm{kG} \\
\text { large SC }\end{array}$ & $\begin{array}{l}\text { studies of deep } \\
\text { inelastic distribution } \\
\text { for } v(\bar{v}) \text { interactions }\end{array}$ \\
\hline \multicolumn{6}{|l|}{ Laboratory C } \\
\hline $\begin{array}{l}\text { \#1A - Phase I } \\
(\text { Before } 9 / 73)\end{array}$ & $\begin{array}{c}\text { Bare } \\
\text { Target } \\
\text { (fast spill) }\end{array}$ & $\begin{array}{l}-20 \text { tons } \\
\text { for full } \\
\text { events } \\
\text { (60 tons } \\
\text { max.) }\end{array}$ & $\begin{array}{l}16 \text { liquid } \\
\text { scint. mod. } \\
10-\mathrm{ft} \text { square } \\
18 \text {-in. thick } \\
\text { SC: every } 4 \text { th }\end{array}$ & $\begin{array}{l}\text { magnet: } \\
12-\mathrm{ft} \text { diam. } \\
16 \mathrm{ft} \text { of iron } \\
17 \mathrm{kG} \\
\text { SC: } \\
8-\mathrm{ft} \text { square }\end{array}$ & $\begin{array}{l}\text { general features of } v \\
(\bar{v}) \text { interactions }\end{array}$ \\
\hline
\end{tabular}


Table 12.1. (continued)

\begin{tabular}{|c|c|c|c|c|c|}
\hline $\begin{array}{c}\text { Exp. Number } \\
\text { and } \\
\text { Stage of } \\
\text { Development }\end{array}$ & $\begin{array}{l}\text { Type of } \\
\text { Focusing } \\
\text { System } \\
\text { and } \\
\text { Beam Spill } \\
\end{array}$ & $\begin{array}{l}\text { Desc } \\
\text { Effective } \\
\text { Calorimeter } \\
\text { Size } \\
\text { (Metric Tons) }\end{array}$ & $\begin{array}{l}\text { Calorimeter } \\
\text { Description }\end{array}$ & $\begin{array}{l}\text { Muon } \\
\text { Mustus } \\
\text { Spectrometer } \\
\text { Description } \\
\end{array}$ & $\begin{array}{c}\text { Major } \\
\text { Physics } \\
\text { Emphasis }\end{array}$ \\
\hline & & & $\begin{array}{l}\text { Note: SC }=\text { Spart } \\
\text { Chambers }\end{array}$ & & \\
\hline $\begin{array}{l}\text { \#1A-Phase II } \\
(9 / 73-10 / 74)\end{array}$ & $\begin{array}{c}\text { Broad and } \\
\text { Narrow } \\
\text { Band, } \\
\text { Quad } \\
\text { Triplet } \\
\text { (fast spill) }\end{array}$ & $\begin{array}{l}-20 \text { tons } \\
\text { for full } \\
\text { events } \\
(60 \text { tons } \\
\text { max.) }\end{array}$ & $\begin{array}{c}\text { same but } \\
\text { extra } \mu \\
\text { identifier } \\
\text { (14 in. of } \\
\text { steel) }\end{array}$ & $\begin{array}{l}\text { same but } \\
\text { SC: } \\
10-\mathrm{ft} \text { square }\end{array}$ & $\begin{array}{l}\text { investigation of neutral } \\
\text { current events; genera } \\
\text { features of } v(\bar{v}) \text { inter- } \\
\text { actions }\end{array}$ \\
\hline $\begin{array}{c}\text { \#1A - Phase III } \\
(10 / 74 \text { - Present })\end{array}$ & $\begin{array}{c}\text { Broad and } \\
\text { Narrow } \\
\text { Band, } \\
\text { Quad } \\
\text { Triplet } \\
\text { (fast spill) }\end{array}$ & $\begin{array}{l}-20 \text { tons } \\
\text { for full } \\
\text { events } \\
(\sim 80 \text { tons } \\
\text { for dimuon } \\
\text { search })\end{array}$ & $\begin{array}{l}15 \text { liquid } \\
\text { scint. mod. } \\
10-\text { ft square } \\
18-\text { in. thick } \\
\text { SC: every } 4 \text { th } \\
\mu \text { identifier/ } \\
\text { target } \\
\text { (28 in. of } \\
\text { steel) }\end{array}$ & $\begin{array}{l}\text { magnet: } \\
12-\mathrm{ft} \text { diam. } \\
16 \mathrm{ft} \text { of iron } \\
17 \mathrm{kG} \\
\mathrm{SC} \text { : } \\
10-\mathrm{ft} \text { square }\end{array}$ & $\begin{array}{l}\text { search for dimuon } \\
\text { events; general feature } \\
\text { of } v(\bar{v}) \text { interactions }\end{array}$ \\
\hline \multicolumn{6}{|l|}{$\begin{array}{l}\text { Extended } \\
\text { Laboratory C }\end{array}$} \\
\hline$\# 310$ & $\begin{array}{c}\text { Broad and } \\
\text { Narrow } \\
\text { Band, } \\
\text { Quad } \\
\text { Triplet } \\
\text { (fast spill) }\end{array}$ & $160-350$ tons & $\begin{array}{l}16 \text { liquid } \\
\text { scint. mod. } \\
10-\mathrm{ft} \text { square } \\
18-\text { in. thick } \\
\text { SC: every } 2 \text { nd } \\
\text { Lead plates: } \\
\text { every } 2 \text { nd } \\
+ \\
\text { iron plate } \\
\text { calorimeter } \\
\text { absorber }\end{array}$ & $\begin{array}{l}\text { magnet: } \\
12-\mathrm{ft} \text { diam. } \\
16 \mathrm{ft} \text { of iron } \\
17 \mathrm{kG} \\
+ \\
24-\mathrm{ft} \text { diam. } \\
6 \mathrm{ft} \text { of iron } \\
-15 \mathrm{kG} \\
\text { with drift } \\
\text { chambers }\end{array}$ & $\begin{array}{l}\text { general features of } v \\
(\bar{v}) \text { interactions }\end{array}$ \\
\hline
\end{tabular}


Table 12.2. Summary of Neutrino Experiments Using the 15-Ft Bubble Chamber.

Notes: 1) All presently approved experiments use the wide band beam with fast spill.

2) It is likely that the external muon identifier (EMI) will be available for many experiments.

3) For calculation of the numbers of events two horns and $1 \times 10^{13}$ incident protons per pulse at $300 \mathrm{GeV} / \mathrm{c}$ are assumed.

\begin{tabular}{|c|c|c|c|}
\hline $\begin{array}{l}\begin{array}{c}\text { Incident Particle } \\
\text { and }\end{array} \\
\text { Experiment Number } \\
\end{array}$ & $\begin{array}{l}\text { Chamber Fill } \\
\text { and } \\
\text { Approx. Tonnage } \\
\text { (Metric Tons) } \\
\end{array}$ & $\begin{array}{c}\text { Number of } \\
\text { Pictures } \\
\text { and Approx. } \\
\text { Number of Events }\end{array}$ & $\begin{array}{l}\text { Major } \\
\text { Physics } \\
\text { Emphasis } \\
\end{array}$ \\
\hline \multicolumn{4}{|l|}{ Neutrinos } \\
\hline$\# 45 \mathrm{~A}$ & $\begin{array}{l}\mathrm{H}_{2} \\
1.4 \text { tons }\end{array}$ & $\begin{array}{l}300 \mathrm{~K} \text { pictures } \\
\sim 12,000 \text { events }\end{array}$ & $\begin{array}{l}\text { general features } \\
\text { of } v \text { interactions }\end{array}$ \\
\hline$\# 28 \mathrm{~A}$ & $\begin{array}{l}\mathrm{H}_{2} \text { and } \mathrm{Ne} \\
-8 \text { tons }\end{array}$ & $\begin{array}{r}50 \mathrm{~K} \text { pictures } \\
-12,000 \text { events }\end{array}$ & $\begin{array}{l}\text { general features } \\
\text { of } v \text { interactions }\end{array}$ \\
\hline & & $\begin{array}{c}50 \mathrm{~K} \text { pictures } \\
\text { (spec. targeting) }\end{array}$ & $\begin{array}{l}\text { search for } v \text { pro- } \\
\text { duction through } \\
\text { decay of particles } \\
\text { other than } \pi, K\end{array}$ \\
\hline$\# 53 \mathrm{~A}$ & $\begin{array}{l}\mathrm{H}_{2} \text { and } \mathrm{Ne} \\
\sim 20 \text { tons }\end{array}$ & $\begin{array}{l}100 \mathrm{~K} \text { pictures } \\
\sim 60,000 \text { events }\end{array}$ & $\begin{array}{l}\text { general features } \\
\text { of } v \text { interactions } \\
\text { with a request for } \\
\text { use of plates }\end{array}$ \\
\hline$\# 155$ & $\begin{array}{c}\mathrm{H}_{2} \\
1.4 \text { tons }\end{array}$ & $\begin{array}{l}50 \mathrm{~K} \text { pictures } \\
\sim 2,000 \text { events }\end{array}$ & $\begin{array}{l}\text { test of external } \\
\text { muon identifier }\end{array}$ \\
\hline
\end{tabular}

Antineutrinos

$\begin{array}{cccc}\text { \#31A } & \mathrm{H}_{2} & 200 \mathrm{~K} \text { pictures } & \text { general features } \\ \text { \#172 } & 1.4 \text { tons } & \sim 2,000 \text { events } & \text { of } \bar{v} \text { interactions } \\ & \mathrm{H}_{2} \text { and Ne } & 50 \mathrm{~K} \text { pictures } & \text { general features } \\ \text { fill undecided } & - & \text { of } \bar{v} \text { interactions } \\ & \mathrm{H}_{2} \text { and Ne } & 50 \mathrm{~K} \text { pictures } & \text { general features } \\ & \text { fill undecided } & - & \text { of } \bar{v} \text { interactions }\end{array}$




\section{PARTICLE SEARCHES}

In this section we shall describe the work at Fermilab to search for new particles. One of the obvious features of the Fermilab accelerator is that it opens up a new mass range for particle production, particularly for those produced with small cross sections or for production by pion or other secondary particle beams. This description will concentrate on, if we may quote Bjorken, "well established undiscovered particles." Examples are magnetic monopoles, quarks, the charged intermediate vector bosons ( $W^{ \pm}$), the neutral vector bosons $\left(\mathrm{W}^{\circ}\right.$ or $\mathrm{Z}^{\circ}$ or $\left.\Phi^{\circ}\right)$, heavy leptons, charmed particles, long-lived particles, and super-heavy elements. The recent discovery of narrow resonances in the $e^{+} e^{-}$and $\mu^{+} \mu^{-}$final states has given new impetus to particle searches. Several approved experiments are extending their measurements and there are many new proposals. Since this has all been happening so quickly we have added this information within the context of what had already been prepared on this subject.

Some experiments are designed specifically as searches for new objects. These are easy to classify. However, there are other more general experiments (such as those studying neutrino physics) which might uncover new phenomena or new particles. These experiments are classified according to the types of particles that they may be able to observe. Of course, these capabilities will change as there is an understanding of these phenomena and a further development of theoretical models.

In most parts of this section the description is accompanied by a table which normally gives the following information: 
(i) the production reactions of the particle (and its identified decay products if it is unstable),

(ii) the mass limit,

(iii) the upper limit for the total production cross section to be set by the experiment if the particle is not observed, and

(iv) the type of detection method used.

When considering the mass limit it is useful to refer to the center-of-mass energies possible at the momenta of the various particle beams.

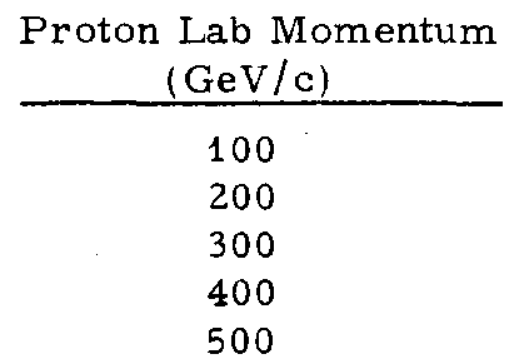

\begin{tabular}{c}
$\begin{array}{c}\text { Center-of-Mass Energy } \\
\text { (GeV) }\end{array}$ \\
\hline 13.8 \\
19.4 \\
23.8 \\
27.4 \\
30.7
\end{tabular}

If the particle being looked for is a boson, it can be produced singly and the mass limit can in principle be almost equal to the center-of-mass energy. ( The simplest production reaction is of the type $\mathrm{pp} \rightarrow \mathrm{BNN}$ where $\mathrm{B}$ is the new particle and $\mathrm{N}$ is a nucleon.) If the particle is a fermion it must be produced in pairs and the mass limit is at most one-half of this energy. (The simplest production reaction is then of the type $p p \rightarrow F \bar{F} N N$ where $F$ and $\bar{F}$ are the new particles.) In practice one must be considerably above the threshold energy in order to have an appreciable production cross section. In determining the upper limit for the total production cross section there are some problems connected with the fact that the experiments can measure the differential production cross section only for specific angles and momenta. Hence, the total cross section, determined by integration, is model dependent. 


\subsection{Magnetic Monopoles}

The detection techniques are based on the following expected properties of a monopole:

(i) The magnetic monopole should have a large magnetic charge,

$$
\mathrm{g}=\mathrm{ng}_{\mathrm{D}^{\prime}}
$$

with $\mathrm{n}=1,2,3, \ldots$. and $\mathrm{g}_{\mathrm{D}}=137 \mathrm{e} / 2$. This implies that relativistic monopoles have large ionization losses equal to $4,700 \mathrm{n}^{2}$ times that of minimum ionizing particles. Such losses can be readily detected.

(ii) The magnetic monopoles are produced in pairs and annihilate immediately into many photons. These might be the cause of the so-called Schein events with multiple photons found in cosmic rays.

The first method above allows two further possibilities: a direct type of measurement when one looks at the magnetic monopoles as soon as they are produced, or indirect measurements, when it is assumed that the monopoles have stopped and are trapped in materials and observed later. The monopole candidates in two Fermilab experiments are studied indirectly and are either extracted and accelerated in solenoids or they should produce a perturbation in the current of a superconducting solenoid. Three other experiments are searches connected with multi- $\gamma$ production. Experiment \#202 is a search for tachyon monopoles in the cosmic ray flux; it is not associated with the accelerator operation, but only with the large magnetic field of the 15 -ft bubble chamber. The experiments that are expected to produce results from searches for monopoles are described in Table 13.1. 


\subsection{Quarks}

The detection techniques for quarks are based on their ionization: relativistic quarks with charge $\pm 1 \mathrm{e} / 3$ ionize at a level of $1 / 9$ that of normal particles; quarks of charge $\pm 2 \mathrm{e} / 3$ ionize at the level of $4 / 9$ normal; $\pm 4 \mathrm{e} / 3$ particles (di-quarks) ionize at the level of $16 / 9$ normal, etc. All of the standard approved quark searches rely on these ionization properties through measurement of energy loss in a counter telescope. In addition, one can actually use a specific feature of fractional charges by remembering that a charge $1 \mathrm{e} / 3$ particle of $100 \mathrm{GeV} / \mathrm{c}$ momentum needs a beam line set at 300 $\mathrm{GeV} / \mathrm{c}$ in order to be transported. Thus, one can run a beam line at a nominal momentum higher than that of the accelerator, avoiding all charge 1 e particles. This technique is often referred to as the "super-momentum method."

In Experiment \#276 it is planned to search for integrally charged quarks of the type proposed by Han and Nambu in a scheme of hadron structure different from that normally referred to (and involving fractional charge). It is assumed that these particles would attach themselves to target nuclei, thus forming an atom with one electron less than the original nucleus. The identification of the particles might then be possible through studying the chemical properties of the target.

The approved quark search experiments are described in Table 13.2. A compilation of the upper limits for $-1 \mathrm{e} / 3$ quark production at several accelerators is shown in Fig. 13.1. The limits are at approximately the 
two-standard deviation level and have been computed assuming isotropic production in the center-of-mass frame (solid lines) and forward peaking as in normal hadron production (dashed lines).

13.3 Intermediate Charged Vector Bosons $\left(W^{ \pm}\right)$

The experiments with intended searches for the charged intermediate vector bosons $\left(\mathrm{W}^{ \pm}\right)$may be classified as follows:

(i) Production Initiated by Neutrinos

The experiments look for differences in what one would expect from normal neutrino (or antineutrino) interactions. An example would be dimuon events such as:

$$
\begin{aligned}
& \nu_{\mu} \mathrm{A} \rightarrow \mu^{-} \mathrm{W}^{+} \mathrm{A}, \mathrm{W}^{+} \rightarrow \mu^{+} \nu_{\mu} \\
& \bar{\nu}_{\mu} \mathrm{A} \rightarrow \mu^{+} \mathrm{W}^{-} \mathrm{A}, \mathrm{W}^{-} \rightarrow \mu^{-} \nu_{\mu} .
\end{aligned}
$$

The signature in reaction (13.2) would be a low energy $\mu^{-}$in the forward direction and a high energy $\mu^{+}$at large angles with transverse momentum $\leq \mathrm{m}_{\mathrm{W}} / 2$. A more indirect method would be to look for deviations from the predictions of four-fermion interactions. For example, a $W^{ \pm}$could manifest itself in a deviation of the neutrino total cross section from a linear dependence on $\mathrm{E}_{\nu}$; in the reaction $\nu_{\mu} \mathrm{A} \rightarrow \mu^{-}+$hadrons, the existence of a $\mathrm{W}^{ \pm}$would be signaled by an excess of events in the $\left(q^{2}, v\right)$ plot at low $q^{2}(x)$ and large $v(y)$. (See Table 5.1 for definitions of these terms and Fig. 11.1 for the kinematic region covered by the neutrino experiments. ) 
(ii) Production Initiated by Protons and Photons

The reactions to be studied involve single lepton production and are generally the same experiments described in Table 5,6. The reactions looked for are of the type:

$$
\mathrm{pA} \rightarrow \mathrm{W}^{ \pm}+\mathrm{X}, \mathrm{W}^{ \pm} \rightarrow \mu^{ \pm} v_{\mu} \text {, or } \mathrm{W}^{ \pm} \rightarrow \mathrm{e}^{ \pm} v_{\mu},
$$

or a similar reaction with incident photons. Consequently, one looks for a peak in the transverse momentum distribution of $\mu^{ \pm}$or $e^{ \pm}$directly produced at large angles. In practice these experiments have rather limited sensitivity. Table 13.3 summarizes the experiments capable of looking for $W^{ \pm}$ particles as we have discussed.

\subsection{Intermediate Neutral Vector Bosons $\left(W^{\circ}\right.$ or $Z^{\circ}$ or $\left.\Phi^{\circ}\right)$}

The neutral vector bosons, as in the case of the intermediate charged bosons $\left(W^{ \pm}\right)$, may be looked for in reactions initiated by neutrinos and by protons. Examples of possible production reactions are:

$$
\begin{aligned}
& v_{\mu^{A}} \rightarrow \mathrm{W}^{\circ}+\mathrm{X}, \mathrm{W}^{\mathrm{O}} \rightarrow \mu^{+} \mu^{-}, \mathrm{e}^{+} \mathrm{e}^{-} \\
& \text {and } \\
& \mathrm{pA} \rightarrow \mathrm{W}^{\mathrm{O}}+\mathrm{X}, \mathrm{W}^{\mathrm{O}} \rightarrow \mu^{+} \mu^{-}, \mathrm{e}^{+} \mathrm{e}^{-} .
\end{aligned}
$$

Experiments must be capable of detecting two charged leptons in order to undertake such a search. The experiments of this type with incident protons are listed in Table 7.1. Most of the neutrino counter experiments have, or will have, the capability of detecting two charged muons (see Table 12.1). The 15 -ft bubble chamber work will be useful in a search for the $\mathrm{W}^{\circ}$ particularly using the external muon identifier or with a hydrogen and neon mixture. Those experiments are listed in Table 12.2. 
One possible (but unlikely) explanation of the recently observed narrow peaks in the dilepton mass spectrum at $3.1,3.7$, and $4.1 \mathrm{GeV}$ is that they are intermediate neutral vector bosons.

\subsection{Heavy Leptons}

There are theoretical models which predict the existence of many types of heavy leptons. Examples are the following:

(i) Sequential leptons. These would be members of the known lepton family with accompanying neutrino,

$$
\left(\mathrm{e}^{-}, v_{\mathrm{e}}\right),\left(\mu^{-}, v_{\mu}\right),\left(\lambda^{-}, v_{\lambda}\right), \ldots .
$$

where $\lambda$ indicates the new member. New quantum numbers would accompany the new particles.

(ii) Excited leptons. These would be excited states of the presently known leptons which could decay electromagnetically as follows:

$$
e^{*} \rightarrow \text { ey or } e \pi, \mu^{*} \rightarrow \mu \gamma \text { or } \mu \pi \text {. }
$$

These decays preserve their electron or muon identity.

(iii) Gauge leptons. These particles are required by various gauge theories which attempt to unify weak and electromagnetic interactions. These theories predict lepton families as follows:

$$
\left(e^{-}, \nu_{e}, E^{o}, E^{+}\right),
$$

where $\mathrm{E}^{\circ}$ and $\mathrm{E}^{+}$are the new leptons, and

$$
\begin{aligned}
& \mathrm{E}^{\mathrm{o}} \rightarrow \mathrm{e}^{+} \mathrm{e}^{-} \nu_{\mathrm{e}} \text { or } \mathrm{E}^{\mathrm{o}} \rightarrow \mathrm{e}^{+}{ }_{\mu}^{-} \bar{\nu}_{\mu} \text { or } \mathrm{E}^{\mathrm{o}} \rightarrow \mathrm{e}^{+}+(\text {hadrons })^{-}
\end{aligned}
$$

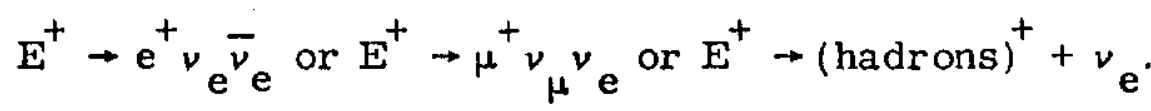


The $\left(\mu^{-}, v_{\mu}, \mathrm{M}^{\mathrm{O}}, \mathrm{M}^{+}\right)$family would have similar decays.

(iv) Heavy quasistable leptons. These particles would have a larger mass than the muon, decaying weakly to the known leptons.

Table 13.4 describes in a bit more detail some of the experiments which will look for heavy leptons. Some of these experiments are the same as those which will look for vector bosons. The production and decay reactions shown are only examples. One can easily use some imagination to suggest several ways in which heavy leptons might be observed.

\subsection{Charmed Particles}

Because of the recent interest in this subject (as evidenced by the large number of recent proposals), we shall elaborate on the searches for charmed particles, including the $\mathrm{e}^{+} \mathrm{e}^{-}, \mu^{+} \mu^{-}$uncharmed states.

In considering charmed particles we recall that the basic quark triplet $(u, d, s)$ could be extended to a quartet $(u, d, s, c)$. The four quarks would have electric charges $+2 e / 3,-1 e / 3,-1 e / 3$, and $+2 e / 3$ respectively; the $u, d, s$ quarks have "charm number" equal to zero while the c-quark does not. In this model the quark structure of uncharmed bosons is for example, $\pi^{+}=\overline{\mathrm{du}}, \mathrm{K}^{+}=\overline{\mathrm{su}}$, and for charmed bosons, $\mathrm{D}^{+}=\overline{\mathrm{d}} \mathrm{c}, \mathrm{F}^{+}=\overline{\mathrm{sc}}$. From reviews of predictions of properties of charmed particles (see for example "Search for Charm, "by M. K. Gaillard, B. W. Lee, and J. L. Rosner, FERMILAB Pub-74/68-THY and Addenda) one can assume the following:

(i) Charmed meson masses are about 2-3 GeV while charmed baryons should be considerably heavier (5-8 GeV). 
(ii) The production cross section of charmed mesons should not be much smaller than $1 / 10$ that of the strange particle cross section.

(iii) The lifetime of charmed particles is of the order of $10^{-13} \mathrm{sec}$.

(iv) Strong and electromagnetic interactions conserve "charm" quantum number, so that charmed particles (C) are produced in pairs,

$$
\mathrm{pN} \rightarrow \mathrm{C}^{+}+\mathrm{C}^{-}+\mathrm{X}
$$

(v) Weak interactions do not conserve charm quantum number, so that one may look at single charmed particle production,

$$
v_{\mu} \mathrm{N} \rightarrow \mathrm{C}^{ \pm}+\mathrm{X}
$$

(vi) There are sizable branching ratios for $\mathrm{C}^{+} \rightarrow \mu^{+}$(or $\left.\mathrm{e}^{+}\right)+v$, $\mathrm{C}^{+} \rightarrow \mu^{+}\left(\right.$or $\left.\mathrm{e}^{+}\right)+$hadrons and for $\mathrm{C} \rightarrow \mathrm{K} \pi$.

A feature of assumption (iii) $\left(\tau \sim 10^{-13} \mathrm{sec}\right)$ is that the simultaneous observation of the production and decay vertices of a charmed particle is possible only in nuclear emulsions. Table 13.5 lists experiments which might yield information related to the existence of charm. Some specific groups of these experiments will be described below.

Production of Charmed Particles in Hadron-Nucleon Collisions

(i) With emulsions. In principle in any of the emulsion exposures performed at Fermilab it would be possible to see charmed particles by looking at tracks which decay a short distance after the production vertex. In practice, the limits which can be obtained may not be very meaningful if the production cross section is smaller than what is assumed in (i) above. 
(See Section 14 for a discussion of the emulsion experiments.)

(ii) In the direct production of $\mu \mu$, ee, and $\mu$ e pairs,

$$
\begin{array}{r}
\mathrm{hN} \rightarrow \mathrm{C}^{+}+\mathrm{C}^{-}+\mathrm{X} \text { (h indicates hadron) } \\
\mathrm{C}^{+} \rightarrow \mu^{+}+\mathrm{X} \text { or } \mathrm{e}^{+}+\mathrm{X} \\
\mathrm{C}^{-} \rightarrow \mu^{-}+\mathrm{X} \text { or } \mathrm{e}^{-}+\mathrm{X} .
\end{array}
$$

All the dilepton experiments may give some information on such processes, but a signal may not be easily identified as charmed particle production and decay.

(iii) The standard resonance physics experiments. If charmed bosons decay into $\mathrm{K}^{\circ} \pi^{+}, \mathrm{K}^{+} \pi^{\circ}$, and $\mathrm{K}^{ \pm} \pi^{+}$states with $\tau \sim 10^{-13}$ sec, then they would appear as very narrow $K \pi$ bumps in standard resonance physics experiments with counters or bubble chambers (see Sections 7 and 9). The main problems for these experiments are mass resolution and background.

\section{Production of Charmed Particles in Neutrino-Nucleon Collisions}

Experiments capable of contributing here could be neutrino counter and 15 -foot bubble-chamber experiments (as those described in Section 12) and possibly an emulsion stack exposed to a neutrino beam (Experiment \#247).

\section{Production of cc̄ States $(\psi, \mathrm{J})$}

The quark states consisting of $\bar{c} \bar{c}$ are a possible interpretation of the resonances at $3.1,3.7$, and $4.1 \mathrm{GeV}$ recently observed in the dilepton experiments at Brookhaven, SLAC, Frascati, and DESY. A number of Fermilab experiments will likely yield information on these particles. They can be located in Table 13.5 through the ee and $\mu \mu$ final states. 


\subsection{Long-Lived Particles}

There are a number of experiments at Fermilab employing time -of flight and other techniques to look for long-lived heavy particles produced in proton interactions. These are described in Table 13.6.

\subsection{Super-Heavy Elements}

In a theory recently proposed by Lee and Wick, it is suggested that there exists a new state of high density, high mass nuclear matter with high baryon number. While this theory is only one example, there are several experiments intending to search for heavy nuclear states. These are described briefly in Table 13.7. 
Table 13.1. Summary of Magnetic Monopole Searches.

Note: The magnetic charge, $g=n g_{D}$, where $g_{D}=137 \mathrm{e} / 2$.

\begin{tabular}{|c|c|c|c|c|c|}
\hline \multirow{3}{*}{$\begin{array}{l}\text { Prod. Reaction } \\
\text { and }\end{array}$} & \multirow{3}{*}{$\begin{array}{c}\text { Incident } \\
\text { Momentum } \\
(\mathrm{GeV} / \mathrm{c})\end{array}$} & \multicolumn{3}{|c|}{ Limits } & \multirow[b]{3}{*}{$\begin{array}{c}\text { Experimental } \\
\text { Technique }\end{array}$} \\
\hline & & & & & \\
\hline & & $\begin{array}{c}\text { Magnetic } \\
\text { Charge }\end{array}$ & $\begin{array}{l}\text { Mass } \\
(\mathrm{GeV})\end{array}$ & $\begin{array}{c}\text { Cross Section } \\
\left(\mathrm{cm}^{2}\right)\end{array}$ & \\
\hline
\end{tabular}

Note: $A=$ nuclear target

$\mathrm{M}, \overline{\mathrm{M}}=$ monopole, antimonopole

$\mathrm{pA} \rightarrow \mathrm{M}+\overline{\mathrm{M}}+\mathrm{X}$ \#3

300,400

$0.01<\mathrm{n}<10$

15.

$10^{-42}$

\#76

300,400

$0.03<\mathrm{n}<34$

15.

$10^{-42}$

300

200

$30-280$

$50-200$

$-$

10.

$$
\begin{aligned}
& \gamma \mathrm{A} \rightarrow \text { hadrons } \\
& \text { \#25A } \\
& \mathrm{pA} \rightarrow \text { Multi }-\gamma \\
& \text { \#22 } \\
& \text { Multi }
\end{aligned}
$$

.


Table 13.2. Summary of Quark Searches.

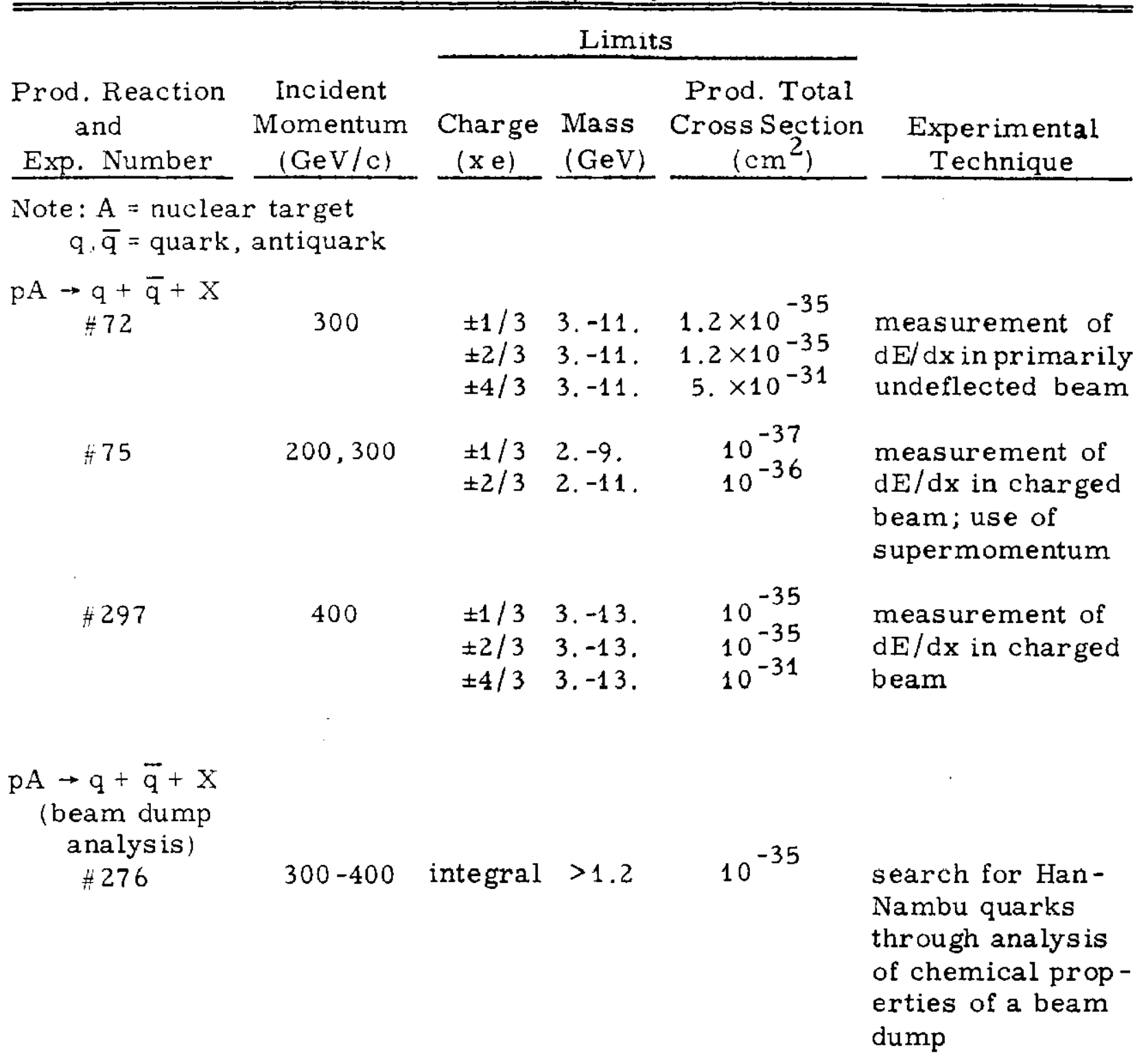




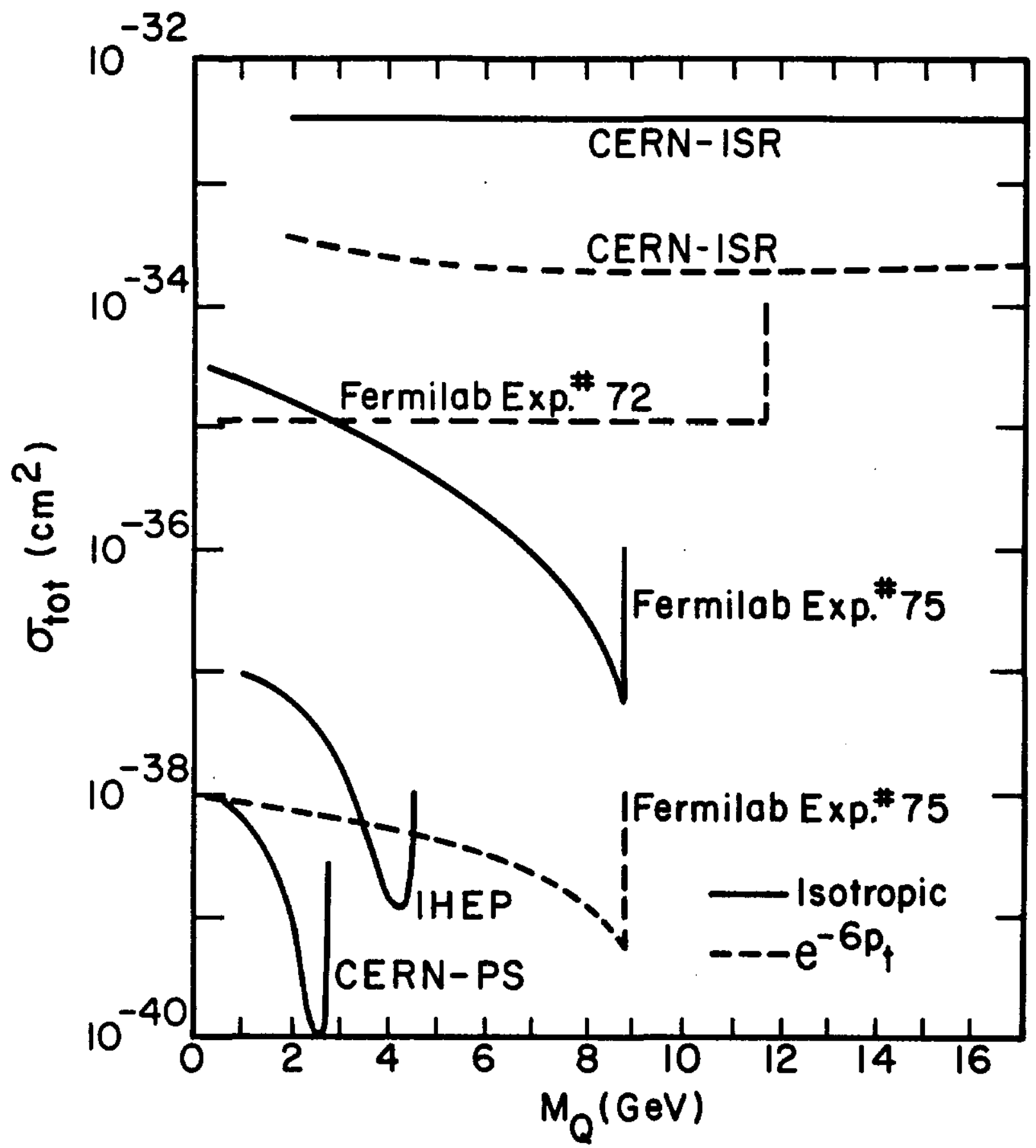

Fig. 13.1 Upper limits for the production of $-1 \mathrm{e} / 3$ quarks in $\mathrm{pN}$ collisions at CERN-PS, Serpukhov (IHEP), Fermilab, and the CERN-ISR. Solid lines were drawn assuming isotropic quark production in the center -of-mass frame; dashed lines were drawn assuming an exponential dependence on $\mathrm{p}_{t}$. 
Table 13.3. Summary of Searches for the Intermediate Vector Bosons $\left(W^{ \pm}\right)$.

Prod. Reaction and

Exp. Number
Incident Momentum

$(\mathrm{GeV} / \mathrm{c})$

\section{Limits}

Prod. Total

Mass Cross Section

$\underline{(\mathrm{GeV})}$
Experimental

Technique/ Apparatus

Note: $A=$ nuclear target

$\nu$ (or $\bar{\nu}$ ) Induced Reactions

(WB - wide band beam; NB - narrow band beam; QT - quadrupole triplet beam)

$$
\begin{aligned}
& \nu_{\mu} \mathrm{A} \rightarrow \underset{\mathrm{W}^{+} \rightarrow \mu^{+}{ }_{\nu}^{+}}{\mathrm{W}^{-}+\mathrm{X}} \\
& \text { \#1A and } \\
& \text { \# } 310 \\
& 10-<200 \quad 15 . \\
& \text { (WB, NB, } \\
& \text { and } \mathrm{QT} \text { ) } \\
& \text { \#21A and } \\
& 30-<200 \\
& 15 . \\
& \text { (NB) } \\
& \text { \#356 } \\
& 10-<200 \quad 15 . \\
& \text { (WB, NB, } \\
& \text { and } Q T \text { ) } \\
& \# 21 \mathrm{~A} \\
& 30-<200 \\
& 15 . \\
& \text { (NB) } \\
& \sigma_{\mathrm{T}}(v \mathrm{~N}) \\
& \text { \#1A and } \\
& \text { \# } 310
\end{aligned}
$$

$21 \mathrm{~A}$

In $15-\mathrm{ft}$ bubble chamber:

$$
\begin{aligned}
\nu_{\mu} \mathrm{A} \rightarrow \mathrm{W}^{+} & +\mu_{+}^{-}+\mathrm{X} \\
\mathrm{W}^{+} & \rightarrow \mu_{+}^{+} \\
& \rightarrow \mathrm{e}^{+} \nu \\
& \rightarrow \text { hadrons }
\end{aligned}
$$

For neutrinos:
\#28A, \# 45A, \# 53A $10-<150$
10.
study of specific
(WB) reactions in $15-\mathrm{ft}$ bubble chamber 
Table 13.3. (continued)

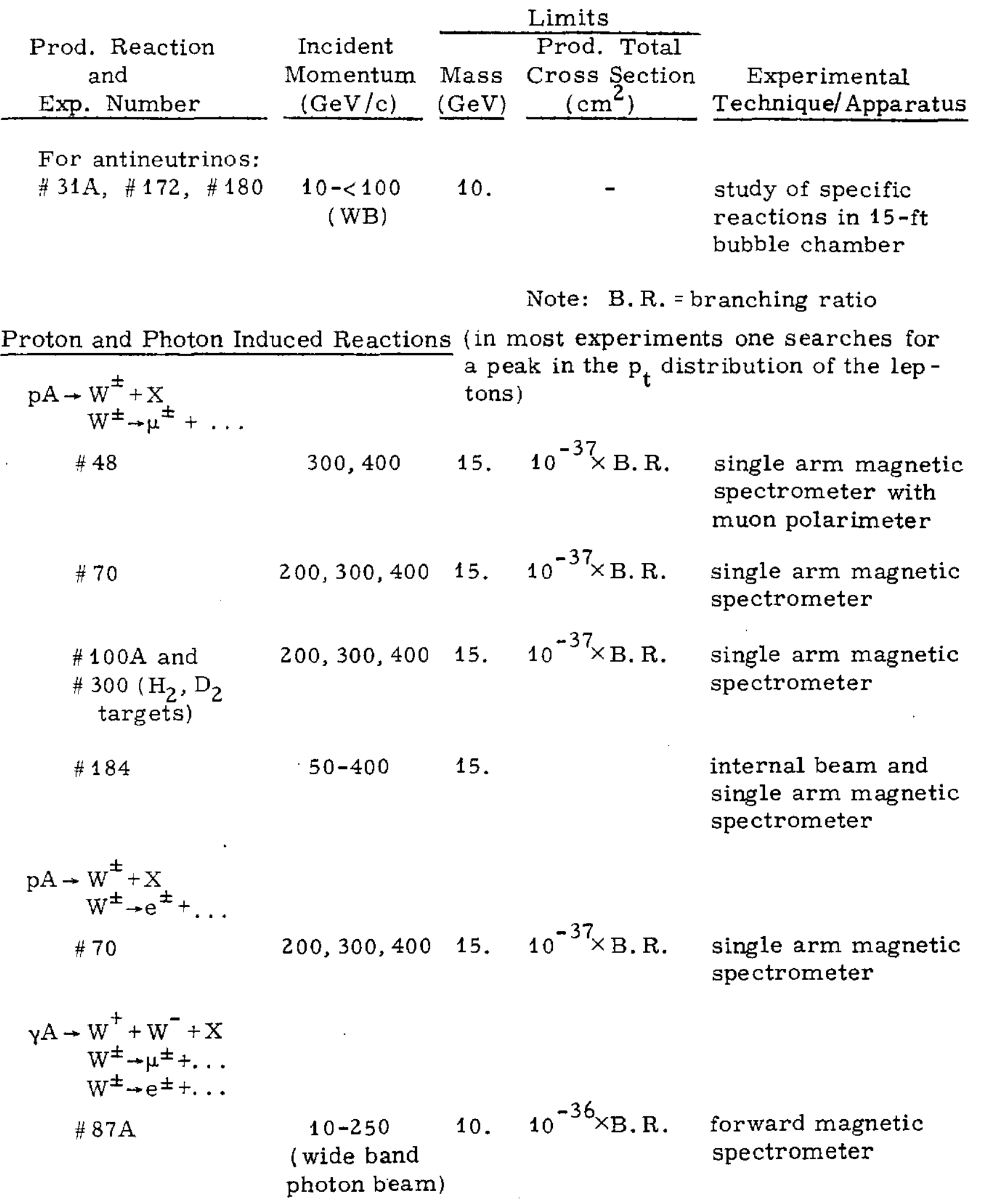


Table 13.3. (continued)

\begin{tabular}{|c|c|c|c|c|}
\hline $\begin{array}{c}\text { Prod. Reaction } \\
\text { and } \\
\text { Exp. Number }\end{array}$ & $\begin{array}{l}\text { Incident } \\
\text { Momentum } \\
(\mathrm{GeV} / \mathrm{c}) \\
\end{array}$ & $\begin{array}{l}\text { Mass } \\
(\mathrm{GeV}) \\
\end{array}$ & $\begin{array}{l}\text { Limits } \\
\text { Prod. Total } \\
\text { Cross Section } \\
\left(\mathrm{cm}^{2}\right) \\
\end{array}$ & $\begin{array}{c}\text { Experimental } \\
\text { Technique/Apparatus } \\
\end{array}$ \\
\hline $\begin{aligned} \mathrm{pA} \rightarrow & \mathrm{W}^{ \pm}+\mathrm{W}^{-}+\mathrm{X} \\
& \mathrm{W}^{ \pm} \rightarrow \mu^{ \pm}+\ldots \\
& \mathrm{W}^{ \pm} \rightarrow \mathrm{e}^{ \pm}+\ldots \\
& \# 288\end{aligned}$ & $200,300,400$ & 15. & $10^{-36} \times \mathrm{B} . \mathrm{R}$ & $\begin{array}{l}\text { two arm magnetic } \\
\text { spectrometer }\end{array}$ \\
\hline
\end{tabular}


Table 13.4. Summary of Heavy Lepton Searches.

Prod. Reaction and Mass Limit

Exp. Number $(\mathrm{GeV})$ Experimental Technique

Note: $\mathrm{A}=$ nuclear target

$$
\nu_{\mu} A \rightarrow \lambda^{+}+X(\lambda \text { indicates a heavy lepton })
$$

Neutrino exp. with electronic detectors and 15-ft bubble chamber (see Tables 12.1 and 12.2)

$$
\begin{aligned}
& \# 247 \\
& v_{\lambda} A \rightarrow \lambda^{ \pm}+\mathrm{X} \\
& \text { \#28A } \\
& \mathrm{pA} \rightarrow \frac{\lambda^{ \pm}+\mathrm{X}}{\lambda^{ \pm} \rightarrow \mu^{ \pm} \nu \bar{\nu}} \\
& \text { \# } 48 \\
& \text { \# } 70 \\
& \text { \#100A and } \\
& \text { \#300 }\left(\mathrm{H}_{2}, \mathrm{D}_{2}\right. \\
& \text { targets) } \\
& \text { \#354 } \\
& \begin{aligned}
\mathrm{pA} & \rightarrow \lambda^{ \pm} \lambda^{-}+\mathrm{X} \\
& \rightarrow \mu^{ \pm} \mathrm{e}^{ \pm}+\ldots \\
& \rightarrow \mu^{ \pm} \mu^{ \pm}+\ldots \\
& \rightarrow \mathrm{e}^{ \pm} \mathrm{e}^{ \pm}+\ldots
\end{aligned} \\
& \text { \#288 }
\end{aligned}
$$
10. look for wrong-sign muons in $v_{\mu}$
interactions

production followed by decay of par ticles with $T=10^{-12}-10^{-15} \mathrm{sec}$; emulsion experiment

use of special targeting to obtain $v_{\lambda}$ and observation of interactions in 15-ft bubble chamber

10. search for production of direct muons having helicity opposite to muons from pion decay

10. study $p_{t}$ distribution of single lepton production

10. search for muon-like heavy particles with long lifetimes

search for muon-like heavy particles with long lifetimes 
Table 13.4. (continued)

Prod. Reaction and Mass Limit

Exp. Number (GeV) Experimental Technique

$$
\begin{aligned}
\gamma A & \rightarrow \lambda^{+} \lambda^{-}+x \\
& \rightarrow \mu^{ \pm} \mathrm{e}^{ \pm}+\ldots \\
& \rightarrow \mu^{ \pm} \mu^{ \pm}+\ldots \\
& \rightarrow \mathrm{e}^{ \pm} \mathrm{e}^{ \pm}+\ldots \\
& \# 87 \mathrm{~A}
\end{aligned}
$$
study $p_{t}$ distribution of dilepton events 
Table 13.5. Summary of Experiments Planning to Yield Information on the Existence of Charm

\begin{tabular}{|c|c|c|}
\hline $\begin{array}{l}\text { Incident Particle } \\
\text { and } \\
\text { Exp. Number } \\
\end{array}$ & $\begin{array}{l}\text { Observed } \\
\text { Final } \\
\text { State } \\
\end{array}$ & Experimental Apparatus \\
\hline \multicolumn{3}{|l|}{ Protons } \\
\hline$\# 8$ & $\Lambda_{\mu}, \bar{\Lambda}_{\mu}$ & $\begin{array}{l}\text { neutral hyperon spectrometer with } \\
\text { added muon counters }\end{array}$ \\
\hline$\# 95 \mathrm{~A}$ & $2 \gamma, 3 \gamma$ & photon shower detectors \\
\hline$\# 288$ & $\mathrm{ee}, \mu \mu, \mathrm{e} \mu$ & $\begin{array}{l}\text { two arm magnetic spectrometer with } \\
\text { muon and shower detectors }\end{array}$ \\
\hline \#325 & $\mu \mu, \mu \pi, \mu \mathrm{K}, \mu \mathrm{p}$ & $\begin{array}{l}\text { single arm magnetic spectrometer } \\
\text { with Cerenkov counters and separate } \\
\text { muon arm }\end{array}$ \\
\hline$\# 357$ & $\pi \mathrm{K}, \pi \pi, \mathrm{KK}, \overline{\mathrm{p} p}$ & $\begin{array}{l}\text { two arm magnetic spectrometer with } \\
\text { Cerenkov counters }\end{array}$ \\
\hline \#363 & $\mathrm{K} / \pi$ ratio & $\begin{array}{l}\text { single arm magnetic spectrometer } \\
\text { with Cerenkov counters to look for } \\
\text { thresholds in } \mathrm{K} / \pi \text { production }\end{array}$ \\
\hline \multicolumn{3}{|l|}{ Neutrons } \\
\hline \#305 & $\mu \mu, \pi K, K K, K p$ & $\begin{array}{l}\text { multiparticle spectrometer with muon } \\
\text { and shower detectors; employing } \\
\text { trigger on wide-angle pairs }\end{array}$ \\
\hline \# 358 & $\mu \mu$, ee, hadrons & $\begin{array}{l}\text { multiparticle spectrometer with muon } \\
\text { and shower detectors and hadron } \\
\text { calorimeter }\end{array}$ \\
\hline \#366 & $\mu \mu, \mathrm{KK}, \overline{\mathrm{p} p}$ & $\begin{array}{l}\text { two particle mass focusing spectrom- } \\
\text { eter with Cerenkov counter and muon } \\
\text { detectors }\end{array}$ \\
\hline
\end{tabular}

Pions

\# 86A

$\mathrm{K}_{\mathrm{S}}^{\circ} \mu, \Lambda \mu$

\# 192

$\mu \mu$, ee, multi- $\gamma$

streamer chamber for detection of V's with two-muon trigger

large aperture magnet with $\mathrm{NaI}$ photon identifiers and muon detectors

\#234

$\mathrm{K}_{\mathrm{S}}^{\mathrm{o}}+\pi$ 's, $\Lambda+\pi^{\prime} \mathrm{s}$,

15-ft bubble chamber exposure decay of longlifetime particles

\# 331

$\mu \mu$

large multiparticle spectrometer with muon detectors 
Table 13.5. (continued)

Incident Particle Observed

and

Exp. Number

Pions (cont.)

\#365

$\mathrm{p}+$ Missing

Mass $(\mu)$,

$\mathrm{p}+$ Missing

Mass $(2 \mu), \mu \mu$

Photons

\#25A

\# 87A

Neutrinos

Electronic

Experiments

(see Table 12.1)

15-ft Bubble

Chamber Exp.

(see Table 12.2)

\# 247

(tests)
$2 \gamma, 3 \gamma$, ee

$\mu \mu$, ee, hadrons

dimuon events

${ }_{\mathrm{K}_{\mathrm{S}}^{\mathrm{o}}}^{\Lambda_{\mathrm{e}}}, \Lambda \mathrm{e}, \mathrm{K}_{\mathrm{S}}{ }^{\mathrm{o}}{ }^{\mu}$

decay of par -

ticles with $\tau$

$=10^{-12}-10^{-15}$

$\mathrm{sec}$
Final

State

Experimental Apparatus

missing mass determination using recoil proton spectrometer with

forward muon spectrometer primarily relies on use of shower detectors

multiparticle spectrometer with muon and shower detectors and hadron calorimeter

hadron calorimeter with associated muon spectrometer

bubble-chamber exposures with hydrogen and with hydrogen and neon fillings

hybrid emulsion - spark chamber apparatus 
Table 13.6. Summary of Searches for Long-Lived Particles.

\begin{tabular}{|c|c|c|c|c|}
\hline \multirow[b]{2}{*}{$\begin{array}{l}\text { Exp. } \\
\text { Number }\end{array}$} & \multirow{2}{*}{$\begin{array}{l}\text { Incident } \\
\text { Proton } \\
\text { Momentum } \\
(\mathrm{GeV} / \mathrm{c}) \\
\end{array}$} & \multicolumn{2}{|c|}{ Limits } & \multirow[b]{2}{*}{ Experimental Technique } \\
\hline & & $\begin{array}{l}\text { Lifetime } \\
\text { (sec) }\end{array}$ & $\begin{array}{l}\text { Mass } \\
(\mathrm{GeV})\end{array}$ & \\
\hline$\# 72$ & 300 & - & $3.1-11$ & $\begin{array}{l}\text { time-of-flight measurements in } \\
\text { charged beam line }\end{array}$ \\
\hline$\# 115$ & 300 & $10^{-3}-1$ & - & $\begin{array}{l}\text { particles penetrating neutrino } \\
\text { shield, stopping and decaying in } \\
\text { hadron calorimeter }\end{array}$ \\
\hline$\# 187$ & 300 & $>10^{-7}$ & $1.4-14$ & $\begin{array}{l}\text { time-of-flight measurements in } \\
\text { charged beam line }\end{array}$ \\
\hline$\# 199$ & 300,400 & $10^{3}-10^{7}$ & - & $\begin{array}{l}\text { examine with } \text { Cerenkov counter } \\
\text { previously irradiated targets }\end{array}$ \\
\hline$\# 239$ & 300 & $10^{-3}-10^{3}$ & - & $\begin{array}{l}\text { use of Ć erenkov counter at } 90^{\circ} \text { to } \\
\text { primary proton target }\end{array}$ \\
\hline $\begin{array}{l}\# 330 \\
\text { (tests) }\end{array}$ & 300 & $>10^{-7}$ & 2. -14 & $\begin{array}{l}\text { search for neutral particles } \\
\text { employing time -of-flight and a } \\
\text { hadron calorimeter }\end{array}$ \\
\hline \#354 & 300,400 & $>10^{-7}$ & 1. -14 & $\begin{array}{l}\text { search for charge } 1 \mathrm{e} \text { and } 2 \mathrm{e} \\
\text { particles in charged beam line } \\
\text { using Cerenkov counters and } \\
\text { time-of-flight }\end{array}$ \\
\hline
\end{tabular}


Table 13.7. Summary of Searches for Super-Heavy Elements.

Prod. Reaction

and

Exp. Number

Experimental Technique

Note: $A=$ nuclear target

$Z^{* * k_{k}}=$ super-heavy element

$\mathrm{pA} \rightarrow \mathrm{Z}^{* *}+\mathrm{X}$

$\# 142$

exposure of a heavy target to a proton beam and subsequent use of neutron counters to look for decays of particles with excess neutrons

$\# 147$

use of plastic detectors to look for heavily ionizing particles produced in collisions of protons with heavy element foils

\#285

exposure of a nuclear (uranium) target to a proton beam and subsequent use of diffusion, centrifuge processes, and mass spectroscopy to look for high mass objects 


\section{EMULSION EXPERIMENTS}

Until about 1955 the nuclear emulsion technique played a dominant role in particle physics. The advent of the bubble chamber and of more sophis ticated counter experiments resulted in a decline of interest in emulsion experiments. There now seems to be a revival of the technique, at least judging from the number of exposures performed at Fermilab. The physics interests cover the fields of elementary particle and nuclear physics. The main physics subjects studied in the Fermilab experiments are:

(i) Study of the charged multiplicity and of the higher multiplicity moments. For all events one determines the average number of fast tracks, $\left\langle\mathrm{n}_{\mathrm{s}}>\right.$, of grey tracks, $\left\langle\mathrm{n}_{\mathrm{g}}>\right.$, and of heavy -prongs, $\left\langle\mathrm{N}_{\mathrm{h}}\right\rangle$. From these it is possible to obtain the average number of charged particles in nucleonnucleon collisions, $\left\langle\mathrm{n}_{\mathrm{ch}}>\right.$, and information on the propagation of newly formed hadronic states as well as nuclear excitations.

(ii) Pseudorapidity distributions, using the variable $\eta^{*}=-\ln \tan \theta^{*} / 2$. The main purpose is to identify groups of particles (clusters, jets) going together. These should yield information on the mechanism of particle production, in particular, on the fireball(s) produced.

(iii) Search for new short-lived particles with lifetimes in the range $10^{-15}<\tau<10^{-12} \mathrm{sec}$. The emulsion technique represents a unique tool for detecting particles in this lifetime range. The proposed charmed particles and some types of heavy leptons have given new impetus to these studies. (See Section 13).

(iv) Direct production of electron-positron pairs. 
(v) Study of diffraction dissociation and coherent events.

(vi) New measurements of the $\pi^{\circ}$ lifetime.

(vii) Angular distributions and other features as a function of the type of nuclear excitation.

Item (i) above may be considered to be a standard measurement, which every group makes. The other measurements are less standard and interest in these may vary from one experiment to another. There also seem to be variations in the techniques used in the emulsion exposures. These include, for example, use of foils of heavy elements interleaved in the emulsion stacks and heavy element wires imbedded in the emulsion material itself. Incident beam densities range from $10^{4}$ to $10^{5}$ particles per $\mathrm{cm}^{2}$.

Emulsion stacks have been exposed to a $200 \mathrm{GeV}$ proton beam for Experiments \#90, \#103, \#105, \#114, \#116, \#117A, \#156, \#171, \#183, \#189, and a similar exposure for \#271 remains to be done. Experiments $\# 181, \# 195, \# 232, \# 233, \# 237, \# 242, \# 244, \# 250$, and \#275 have completed their exposures to a $300 \mathrm{GeV}$ proton beam. Irradiation by a $400 \mathrm{GeV}$ proton beam remains to be done for Experiments \#238, \#243, \#245, \#249, $\# 251, \# 265, \# 279, \# 292, \# 329, \# 336, \# 346$, and \#364. Four experiments have been approved for exposures to $\pi^{-}$at $200 \mathrm{GeV}$; Experiments \#264 and \#328 are complete and Experiments \#339 and \#362 remain to be done. A $\mu^{+}$beam at $150 \mathrm{GeV}$ has been used in exposures for Experiments \#205A and \#255, while a high energy electron exposure for Experiment \#340 is not yet complete. Experiment \#247 involves a test of a hybrid emulsion-spark chamber apparatus exposed to a neutrino beam. 


\section{MISCELLANEOUS EXPERIMENTS}

This section describes a collection of experiments which do not easily fit into any of the previous categories. For the most part they involve the development of detectors, some for future use in particle identification at higher particle beam energies. So far there are three independent studies of transition radiation detectors with plans for use of these devices in very high energy particle beams where Čerenkov counters are not as effective.

Other detector projects include development of ionization measuring devices and thus particle identification using sampling with drift chambers or by measuring the total energy from a nuclear cascade. The external muon identifier (EMI) is used for neutrino experiments in the $15-\mathrm{ft}$ bubble chamber. The EMI relies on hadron absorber provided by the chamber magnet coils (with additional zinc) and on proportional wire chambers to identify as muons penetrating particles leaving the chamber volume. There is one primarily nuclear chemistry experiment at the Laboratory and there have been a number of measurements of the effects of radiation resulting from high energy proton bombardments. All of these experiments are listed in Table 15.1 with a brief notation as to the primary emphasis of the measurements. 
Table 15.1. Summary of Miscellaneous Experiments.

Type of Study and

Exp. Number

Major Physics Emphasis

Transition Radiation Detectors

$\# 206$

test of transition radiation techniques using interleaved radiators and proportional chambers

\# 229

test of transition radiation techniques using styrofoam radiators and $\mathrm{NaI}$ and proportional chamber detectors

\#261

test of transition radiation techniques using radiation foils and $\mathrm{NaI}$ detector

Other Detectors

$$
\text { \# } 32
$$

test and calibration of a total nuclear cascade detector using a $\mathrm{NaI}(\mathrm{T} \ell)$ detector

\#34

ionization spectrometer development

\#155

development of external muon identifier (EMI) for use in 15-ft bubble chamber neutrino experiments

\#327

test of particle identification by ionization sampling using multiwire drift chambers (ISIS)

Nuclear Chemistry

\# $81 \mathrm{~A}$

survey of nuclear reactions from high energy proton collisions with heavy nuclei

General Radiation Studies

studies of radiation effects from high energy proton bombardments

$\# 211$

studies of radiation effects from high energy proton bombardments 


\section{ACKNOWLEDGMENTS}

We wish to express our appreciation to many staff members at Fermilab. This report grew largely from discussions we have had with colleagues and visiting physicists having theoretical and experimental interests in the program. We are appreciative of the support by the Fermilab Director's Office, and in particular for the assistance of Shirley Burton, Anne Burwell, and Jean Plese. Our thanks go to Rene Donaldson and Doris Pinneo of the Fermilab Publications Office for their editing and typing assistance. The critical reading of the manuscript . by R. Diebold, E. L. Goldwasser, B. W. Lee, C. Quigg, and T. Yamanouchi is also gratefully acknowledged. One of us (GG) appreciates the hospitality of the Fermilab staff during a visiting appointment. 


\section{LIST OF EXPERIMENTS}

This section is included as a cross reference for this survey. Throughout the report, due to the limited space in the text and tables, we have referred to experiments only by their number. Here we show the numbers for the approved experiments, a short title indicative of the type of physics being done, and a list of institutions participating in the work. Adjacent to each entry is given the section numbers in this report where the experiment is referred to. The total number of approved experiments shown here is 184 . For a more complete list of all proposals to Fermilab, one should refer to the "Fermilab Research Program Reference Book for 1974-1975", and updated versions of it. Copies of this book are available at the libraries of the U.S. high energy physics laboratories and at CERN. Information on the progress of the approved experiments can be obtained from the Experimental Program Situation Report, usually published quarterly in "NALREP," the monthly report of the Laboratory. 


\begin{tabular}{|c|c|}
\hline $\begin{array}{l}\text { Experiment } \\
\text { Number }\end{array}$ & $\begin{array}{l}\text { Short Title - } \\
\text { Section Number }\end{array}$ \\
\hline $1 \mathrm{~A}$ & Neutrino-2, $5,12,13$ \\
\hline $2 \mathrm{~B}$ & $30-$ In. Hybrid-9 \\
\hline 3 & Monopole-13 \\
\hline 4 & Neutron Cross Section-2, 5 \\
\hline 7 & Elastic Scattering-3 \\
\hline 8 & Neutral Hyperon-3, 8, 13 \\
\hline 12 & Neutron Backward Scattering -3, 4 \\
\hline $14 \mathrm{~A}$ & Proton-Proton Inelastic -5 \\
\hline $21 \mathrm{~A}$ & Neutrino-2, $5,12,13$ \\
\hline 22 & Multigamma-7, 13 \\
\hline $25 \mathrm{~A}$ & $\begin{array}{c}\text { Photon Total Cross Section- } \\
2,5,10,13\end{array}$ \\
\hline 26 & Muon-11 \\
\hline $27 \mathrm{~A}$ & Neutron Dissociation-2, 5, 6 \\
\hline $28 \mathrm{~A}$ & 15-Ft Neutrino $/ \mathrm{H}_{2} \& \mathrm{Ne}-2,12,13$ \\
\hline $31 \mathrm{~A}$ & 15-Ft Antineutrino $/ \mathrm{H}_{2}-2,12,13$ \\
\hline 32 & Detector Development-15 \\
\hline 34 & Detector Development-15 \\
\hline $36 \mathrm{~A}$ & Proton-Proton Scattering-2, 3, 5 \\
\hline $37 \mathrm{~A}$ & 30-In.p-p@300-9 \\
\hline $45 \mathrm{~A}$ & 15-Ft Neutrino/ $\mathrm{H}_{2}-2,12,13$ \\
\hline 48 & Muon Search-13 \\
\hline $51 \mathrm{~A}$ & Missing Masg-5 \\
\hline $53 \mathrm{~A}$ & $15-\mathrm{Ft}$ Neutrino $/ \mathrm{H}_{2}$ or $\mathrm{Ne}-2,12,13$ \\
\hline 61 & Polarized Scattering-3 \\
\hline $63 \mathrm{~A}$ & Photon Search-5 \\
\hline $67 \mathrm{~A}$ & Proton-Proton Missing Mass-5 \\
\hline $69 \mathrm{~A}$ & Elastic Scattering $-2,3$ \\
\hline 70 & Lepton-5, 13 \\
\hline 72 & Quark-13 \\
\hline 75 & Quark-13 \\
\hline 76 & Monopole-13 \\
\hline $81 \mathrm{~A}$ & Nuclear Chemistry-15 \\
\hline
\end{tabular}

Participating Institutions

Fermilab, Harvard, Pennsylvania, Wisconsin

ANL, Duke, Fermilab, Iowa State, Maryland, Michigan State, Notre Dame, Purdue, Toronto Wisconsin

LBL

LBL, Michigan

ANL, Fermilab, Indiana, Michigan

Michigan, Rutgers, Wisconsin

Carleton, Michigan State, Ohio State

Columbia, SUNY-Stony Brook

Caltech, Fermilab

BNL, VPI

UC-Santa Barbara, Fermilab, Toronto

UC-San Diego, Cornell, LBL, Michigan State

Fermilab, Massachusetts, Northwestern, Rochester

CERN, Hawaii, LBL, Wisconsin

ANL, Carnegie-Mellon

Stanford

Louisiana State, Max Planck Inst.

Fermilab, JINR-Dubna, Rochester, Rockefeller

Caltech, UC-Los Angeles, Fermilab

Fermilab, IHEP-Serpukhov, ITEP-Moscow, Michigan

BNL, Fermilab, Yale

Northeastern

BNL, Columbia

ANL, Fermilab, Harvard, LBL, SLAC, Suffolk, Wyoming, Yale

Fermilab, Hawaii, Northern fllinois

nlinois-Chicago Circle, Imperial College, Rutgers, Upsala

Fermilab, Rutherford, Yale

Columbia, Fermilab

BNL, Yale

Fermilab, NYU

Fermilab

ANL, BNL, Carnegie-Mellon, Chicago, IllinoisChicago Circle, LASL, Orsay, Purdue, Reid College 


\begin{tabular}{|c|c|c|}
\hline $\begin{array}{l}\text { Experiment } \\
\text { Number }\end{array}$ & $\begin{array}{l}\text { Short Title - } \\
\text { Section Number }\end{array}$ & Participating Institutions \\
\hline 82 & $\mathrm{~K}^{\circ}$ Regeneration $-2,4,5,8$ & UC-San Diego, Chicago, SLAC \\
\hline $83 \mathrm{~A}$ & $15-\mathrm{Ft} \pi^{-}-\mathrm{p} @ 100-9$ & Fermilab, Tohoku \\
\hline $86 \mathrm{~A}$ & Pion Dissociation-6, 13 & Orsay, Washington \\
\hline $87 \mathrm{~A}$ & Photoproduction $-5,7,10,13$ & Columbia, Fermilab, Hawaii, Illinois \\
\hline 89 & $15-\mathrm{Ft} \pi^{-}-\mathrm{p} \& \mathrm{Ne} @ 200-9$ & UC-Berkeley \\
\hline 90 & Emulsion/Protons $\propto 200-14$ & Cracow \\
\hline $95 \mathrm{~A}$ & Photon Search $-5,7,13$ & Fermilab, Johns Hopkins \\
\hline 96 & Elastic Scattering $-3,5,6$ & $\begin{array}{l}\text { ANL, Bari, Brown, CERN, Cornell, Fermilab, } \\
\text { MIT, Northeastern, Stanford }\end{array}$ \\
\hline 97 & Charged Hyperon-2, 3,8 & Fermilab, Yale \\
\hline 98 & Muon-11 & Chicago, Harvard, Illinois, Oxford \\
\hline 99 & Associated Production -4 & ANL, Fermilab, SLAC, Wisconsin \\
\hline $100 \mathrm{~A}$ & Particle Search-5, 13 & Chicago, Princeton \\
\hline 103 & Emulsion/Protons@200-14 & Tennessee \\
\hline 104 & Total Cross Section-2, 5 & $\begin{array}{l}\text { BNL, Fermilab, Max Planck Inst., Rockefeller, } \\
\text { Washington }\end{array}$ \\
\hline 105 & Emulsion/Protons @ 200-14 & Tata Inst. \\
\hline 108 & Beam Dump-15 & Fermilab \\
\hline $110 \mathrm{~A}$ & Multiparticle-7 & $\begin{array}{l}\text { Caltech, UC-Los Angeles, Fermilab, Illinois- } \\
\text { Chicago Circle, Indiana }\end{array}$ \\
\hline 111 & Pion Charge Exchange-4,5 & Caltech, LBL \\
\hline 114 & Emulsion/Protons@200-14 & SUNY - Buffalo \\
\hline 115 & Long-Lived Particles-13 & LBL \\
\hline 116 & Emulsion/Protons@200-14 & $\begin{array}{l}\text { Barcelona, Fermilab, Lyon, McGill, Montreal, } \\
\text { Ottawa, Strasbourg, Valencia }\end{array}$ \\
\hline $117 \mathrm{~A}$ & Emulsion/Protons@200-14 & $\begin{array}{l}\text { Hiroshima, Kinki, Osaka City, Science Educ. Inst. } \\
\text { of Osaka, Tokyo }\end{array}$ \\
\hline $118 \mathrm{~A}$ & Inclusive Scattering $-5,6$ & Bari, Brown, Fermilab, MrT \\
\hline 120 & Photon Search-5 & Chicago, Harvard, Wisconsin \\
\hline $121 \mathrm{~A}$ & $30-$ In. $\pi^{+}-p @ 100-9$ & UC-Davis, LBL \\
\hline 125 & $30-$ In. $\pi^{-}-p @ 100-9$ & CERN \\
\hline 137 & $30-$ In. $\pi^{-}-p @ 200-9$ & UC-Berkeley, Fermilab, LBL \\
\hline 138 & 30-In. p-p@400-9 & BNL, Michigan, Rochester \\
\hline $141 \mathrm{~A}$ & 30-In. p-p@200-9 & $\begin{array}{l}\text { ANL, Fermilab, Iowa State, Maryland, Michigan } \\
\text { State }\end{array}$ \\
\hline 142 & Super-Heavy Elements-13 & ANL, ORNL \\
\hline $143 \mathrm{~A}$ & 30-In. $\pi^{-}-p @ 300-9$ & $\mathrm{BNL}$ \\
\hline 147 & Super-Heavy Elements-13 & Ottawa, Strasbourg \\
\hline $152 \mathrm{~B}$ & Photoproduction-10 & UC-Santa Cruz \\
\hline 154 & 30-In. Hybrid-9 & $\begin{array}{l}\text { Brown, Fermilab, Illinois, IIT, Indiana, Johns } \\
\text { Hopkins, MIT, Rutgers-Stevens, Tennessee, Yale }\end{array}$ \\
\hline
\end{tabular}




\begin{tabular}{|c|c|c|}
\hline $\begin{array}{l}\text { Experiment } \\
\text { Number } \\
\end{array}$ & $\begin{array}{l}\text { Short Title - } \\
\text { Section Number }\end{array}$ & Participating Institutions \\
\hline 155 & 15-Ft EMI Test-12, 13,15 & Hawaii, LBL \\
\hline 156 & Emulsion/Protons@200-14 & Tokyo \\
\hline 161 & 30-In. p-p \& Ne@300-9 & Wisconsin \\
\hline $163 \mathrm{~A}$ & 30-In. $\pi^{-}-\mathrm{p} \& \mathrm{Ne} @ 200-9$ & Duke, Fermilab, North Carolina \\
\hline 171 & Emulsion/Protons@200-14 & Washington \\
\hline 172 & $15-\mathrm{Ft}$ Antineutrino/ $\mathrm{H}_{2} \& \mathrm{Ne}-2,12,13$ & UC-Berkeley, Hawaii, LBL, Washington \\
\hline $177 \mathrm{~A}$ & Test Proton-Proton Elastic -3 & Cornell, Lebedev Inst., McGill, Northeastern \\
\hline 178 & Multiplicities & Cornell, Fermilab, MIT \\
\hline 180 & 15-Ft Antineutrino $/ \mathrm{H}_{2} \& \mathrm{Ne}-2,12,13$ & $\begin{array}{l}\text { Fermilab, IHEP-Serpukhov, ITEP-Moscow, } \\
\text { Michigan }\end{array}$ \\
\hline 181 & Emulsion/Protons@300-14 & Harvey Mudd \\
\hline 183 & Emulsion/Protons@200-14 & Lebedev Inst. \\
\hline 184 & Particle Search-5, 13 & Chicago, Harvard, Pennsylvania, Wisconsin \\
\hline 186 & Proton-Deuteron Scattering $-2,3,5$ & Fermilab, JINR-Dubna, Rochester, Rockefeller \\
\hline 187 & Particle Search-13 & Columbia, Fermilab \\
\hline 188 & Proton-Nucleon Inclusive -5 & Imperial College, Rutgers, Upsala \\
\hline 189 & Emulsion/Protons@ 200-14 & Stanford \\
\hline 192 & Multigamma-5, 7,13 & Fermilab, Houston, Rice, Stanford \\
\hline 194 & 30-In. p-d@100-9 & $\begin{array}{l}\text { Carnegie-Mellon, Fermilab, Michigan, } \\
\text { SUNY-Stony Brook }\end{array}$ \\
\hline 195 & Emulsion/Protons@300-14 & $\begin{array}{l}\text { Air Force Cambridge, Emmanuel College, } \\
\text { Mississippi State, Singapore }\end{array}$ \\
\hline 196 & 30-In. p-d@400-9 & $\begin{array}{l}\text { Carnegie-Mellon, Fermilab, Michigan, } \\
\text { SUNY-Stony Brook. }\end{array}$ \\
\hline $198 \mathrm{~A}$ & Proton-Nucleon Scattering-3 & Imperial College, Rochester, Rutgers \\
\hline 199 & Massive Particle Search-13 & Fermilab, Pennsylvania \\
\hline 202 & Tachyon Monopole-13 & Colorado, Princeton \\
\hline $205 \mathrm{~A}$ & Emulsion/Muons@150-14 & Kinki, Osaka City, Tokyo \\
\hline 206 & Detector Development-15 & Fermilab, Hawaii, Maryland \\
\hline 207 & 30-In. p-p@500-9 & SUNY-Stony Brook \\
\hline 209 & 30-In.p-d@300-9 & Caltech, Indiana, Iowa State, Tufts, Vanderbilt \\
\hline 211 & Beam Dump-15 & CERN, Fermilab \\
\hline 215 & 30-In. $\pi^{\top}-p @$ High Energy-9 & UC-Berkeley, Fermilab, LBL \\
\hline 216 & Test Form Factor -10 & $\begin{array}{l}\text { UC-Los Angeles, Fermilab, Notre Dame, } \\
\text { Pittsburgh }\end{array}$ \\
\hline 217 & $30-$ In. $\pi^{+}-p @ 200-9$ & UC-Davis, LBL \\
\hline $218 \mathrm{~A}$ & $30-$ In. $\pi^{-}-\mathrm{d} @ 200-9$ & UC-Davis, Cracow, Warsaw, Washington \\
\hline 221 & Proton-Proton Inelastic -5 & Columbia, SUNY-Stony Brook \\
\hline 226 & $\mathrm{~K}_{\mathrm{S}}^{\circ}$-Electron Regeneration- $2,8,10$ & $\begin{array}{l}\text { UC-San Diego, Chicago, SLAC, Swiss Fed. Inst. } \\
\text { of Tech., Wisconsin }\end{array}$ \\
\hline 228 & $30-$ In. $\pi^{+} / \mathrm{p}-\mathrm{p} @ 60-9$ & Michigan, Rochester \\
\hline
\end{tabular}




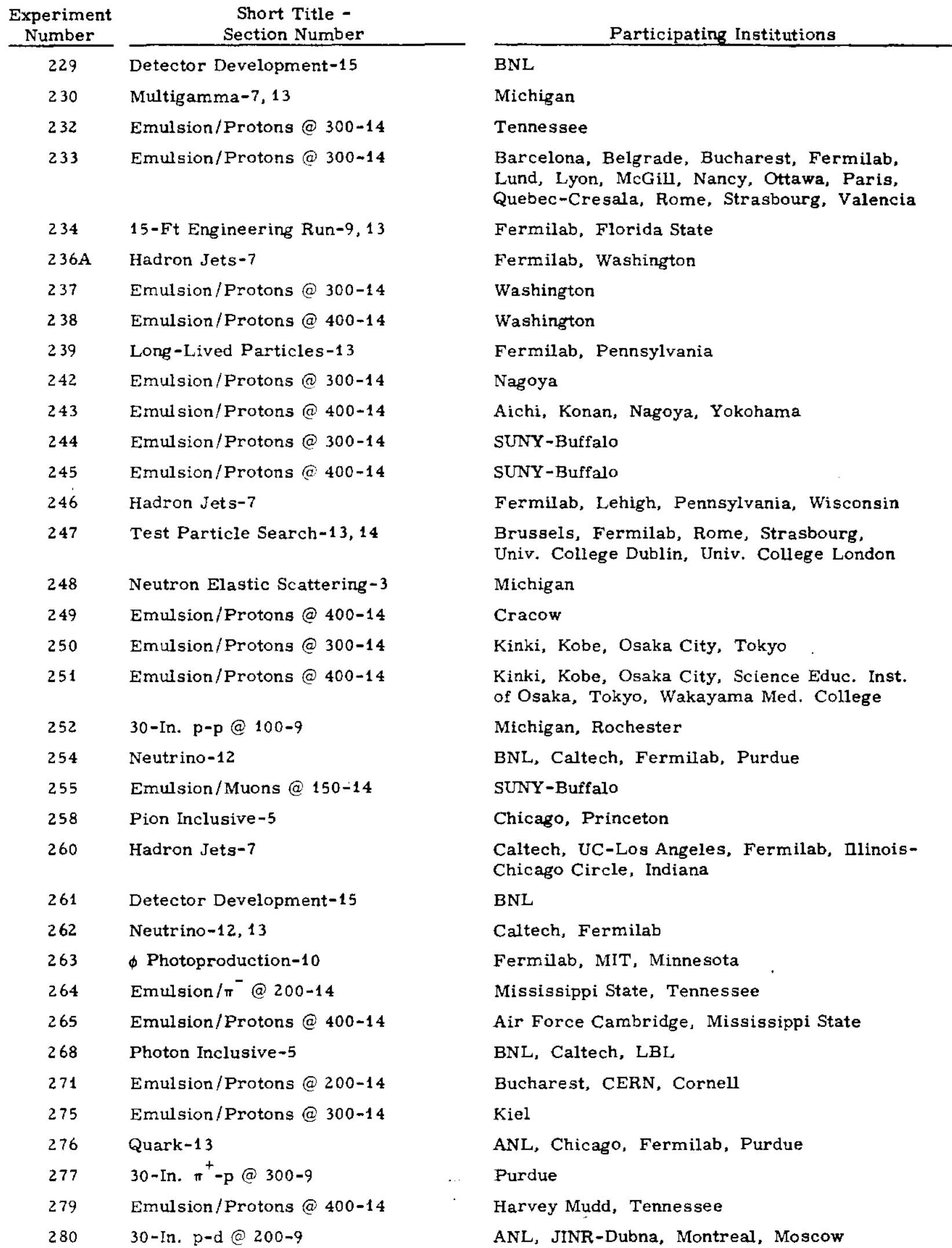




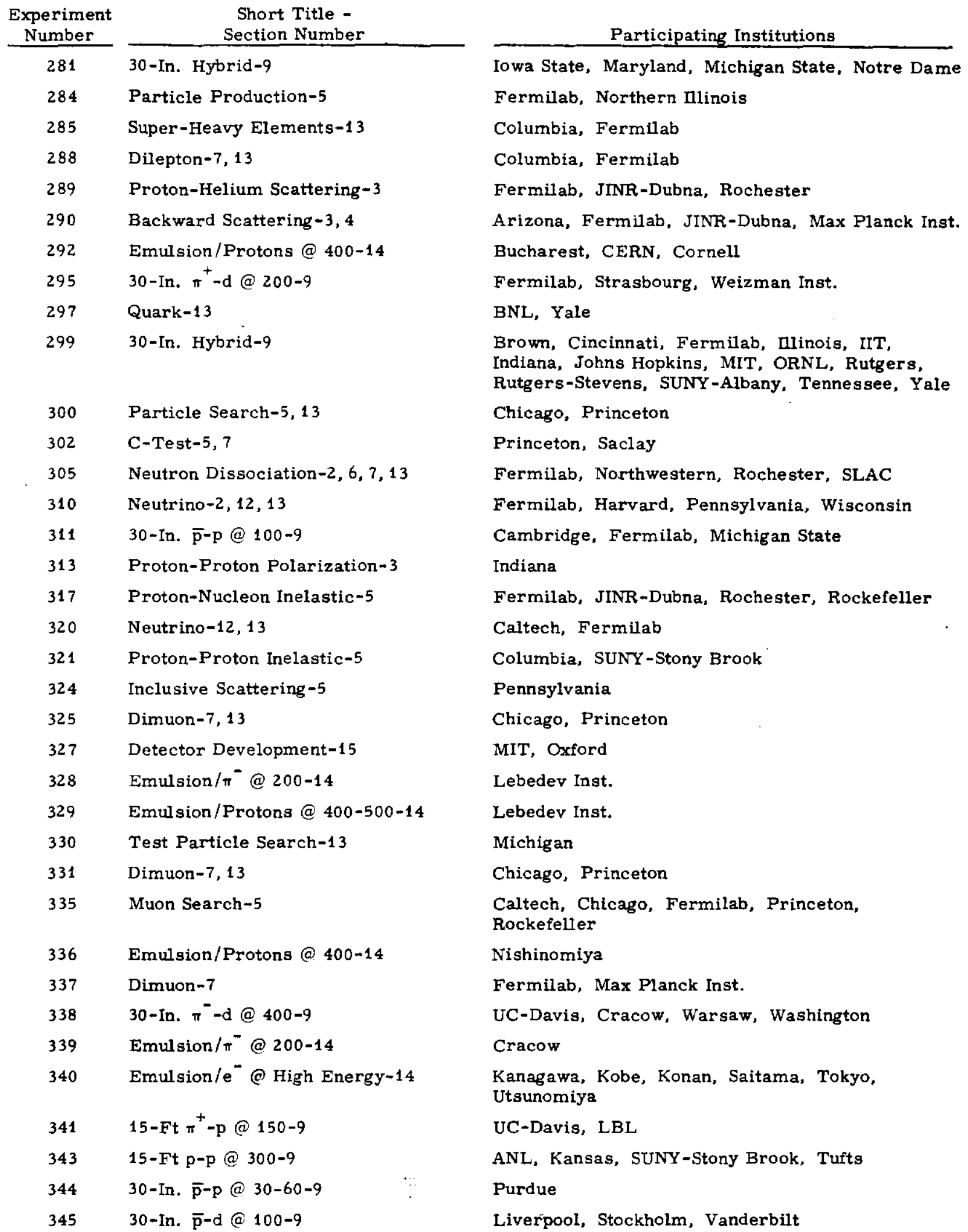




\begin{tabular}{cll}
$\begin{array}{c}\text { Experiment } \\
\text { Number }\end{array}$ & & \multicolumn{1}{c}{$\begin{array}{c}\text { Short Title - } \\
\text { Section Number }\end{array}$} \\
\cline { 1 - 1 } 346 & & Emulsion/Protons @ 400-14 \\
350 & & Neutral Meson Inclusive-5 \\
354 & & Particle Search-13 \\
356 & & Neutrino-12, 13 \\
357 & Particle Search-7, 13 \\
358 & Dimuon-7, 13 \\
362 & Emulsion/ - @ 200-14 \\
363 & Particle Search-13 \\
364 & Emulsion/Protons @ 400-14 \\
365 & Particle Search-7, 13 \\
366 & Particle Search-7, 13
\end{tabular}

Participating Institutions
Stockholm
BNL, Caltech, LBL
BNL, Fermilab, Rockefeller
Caltech, Fermilab
Fermilab, Michigan, Purdue
Columbia, Cornell, Fermilab, Hawaii, Illinois
SUNY-Buffalo
Florida State, Imperial College, Rochester,
Rutgers
Brussels, Rome, Strasbourg, Univ. College
Dublin, Univ. College London, Warsaw
Northeastern
Carleton, Michigan State, Ohio State

